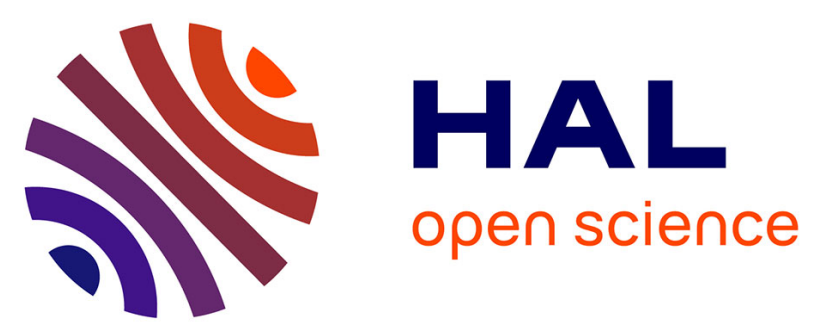

\title{
From the conventional biological wastewater treatment to hybrid processes, the evaluation of organic micropollutant removal: A review
}

Camille Grandclement, Isabelle Seyssiecq, Anne Piram, Pascal Wong-Wah-Chung, Guillaume Vanot, Nicolas Tiliacos, Nicolas Roche, Pierre Doumenq

\section{To cite this version:}

Camille Grandclement, Isabelle Seyssiecq, Anne Piram, Pascal Wong-Wah-Chung, Guillaume Vanot, et al.. From the conventional biological wastewater treatment to hybrid processes, the evaluation of organic micropollutant removal: A review. Water Research, 2017, 111, pp.297-317. 10.1016/j.watres.2017.01.005 . hal-01456484

\section{HAL Id: hal-01456484 \\ https://hal-amu.archives-ouvertes.fr/hal-01456484}

Submitted on 21 Feb 2017

HAL is a multi-disciplinary open access archive for the deposit and dissemination of scientific research documents, whether they are published or not. The documents may come from teaching and research institutions in France or abroad, or from public or private research centers.
L'archive ouverte pluridisciplinaire HAL, est destinée au dépôt et à la diffusion de documents scientifiques de niveau recherche, publiés ou non, émanant des établissements d'enseignement et de recherche français ou étrangers, des laboratoires publics ou privés. 
Review

\title{
From the conventional biological wastewater treatment to hybrid processes, the evaluation of organic micropollutant removal: A review
}

\author{
Camille Grandclément a, b, c , Isabelle Seyssiecq ${ }^{\mathrm{b}}$, Anne Piram a, \\ Pascal Wong-Wah-Chung a , Guillaume Vanot ${ }^{\text { }}$, Nicolas Tiliacos ${ }^{\text {c }}$, Nicolas Roche b, *, \\ Pierre Doumenq ${ }^{\text {a }}$ \\ a Aix-Marseille Univ, CNRS, LCE, Marseille, France \\ ${ }^{\mathrm{b}}$ Aix-Marseille Univ, CNRS, Centrale Marseille, M2P2, Marseille, France \\ c Société Seakalia SAS, Groupe Ovalee, Technopôle de Château-Gombert, Héliopolis, 13013, Marseille, France
}

\section{A R T I C L E I N F O}

\section{Article history:}

Received 17 May 2016

Received in revised form

15 December 2016

Accepted 2 January 2017

Available online 6 January 2017

\section{Keywords:}

Trace organic contaminants removal

Process parameters

Membrane bioreactor

Advanced treatment

Enzymatic treatment

\begin{abstract}
A B S T R A C T
Because of the recalcitrance of some micropollutants to conventional wastewater treatment systems, the occurrence of organic micropollutants in water has become a worldwide issue, and an increasing environmental concern. Their biodegradation during wastewater treatments could be an interesting and low cost alternative to conventional physical and chemical processes. This paper provides a review of the organic micropollutants removal efficiency from wastewaters. It analyses different biological processes, from conventional ones, to new hybrid ones. Micropollutant removals appear to be compound- and process- dependent, for all investigated processes. The influence of the main physico-chemical parameters is discussed, as well as the removal efficiency of different microorganisms such as bacteria or white rot fungi, and the role of their specific enzymes. Even though some hybrid processes show promising micropollutant removals, further studies are needed to optimize these water treatment processes, in particular in terms of technical and economical competitiveness.
\end{abstract}

(c) 2017 Elsevier Ltd. All rights reserved.

\section{Contents}

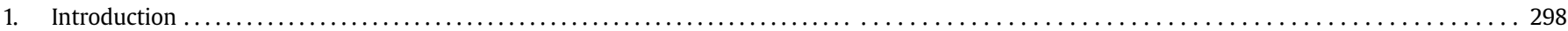

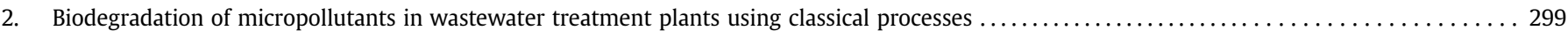

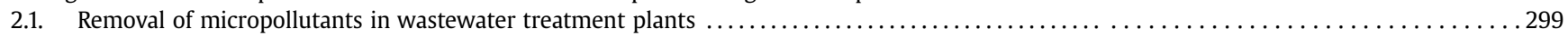

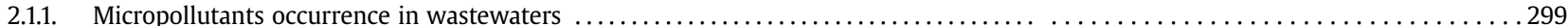

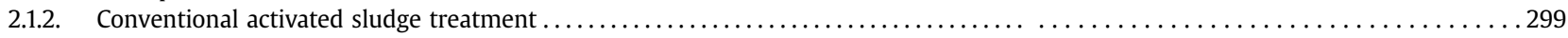

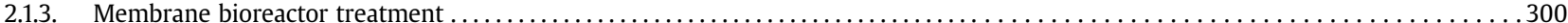

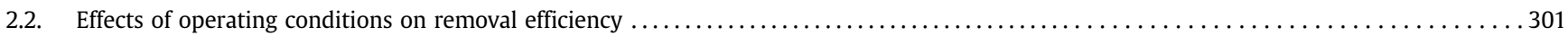

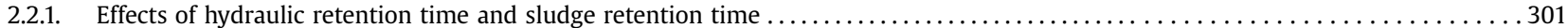

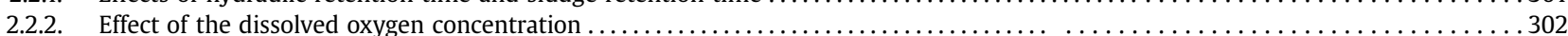

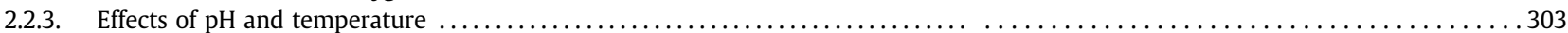

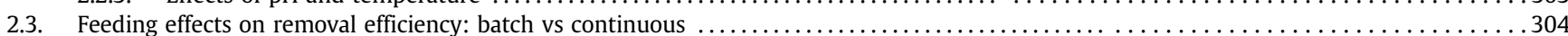

2.4. Effects of microorganism communities or enzymes extracted from microorganisms on removal efficiency ................. $\ldots 305$

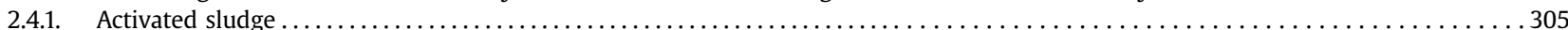

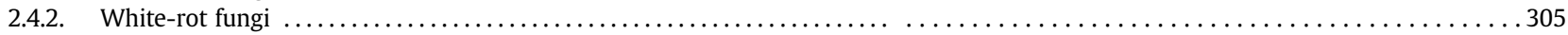

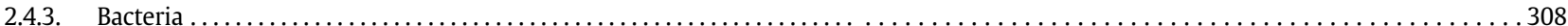

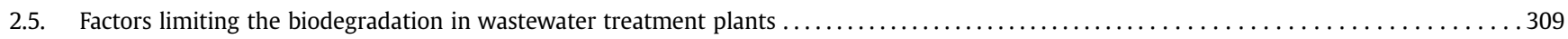

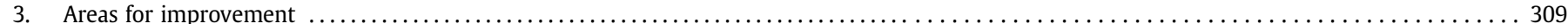

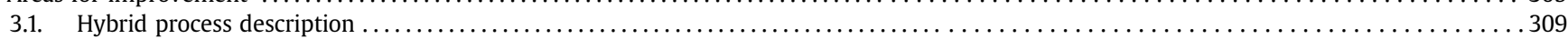

\footnotetext{
* Corresponding author.

E-mail address: nicolas.roche@univ-amu.fr (N. Roche).
} 


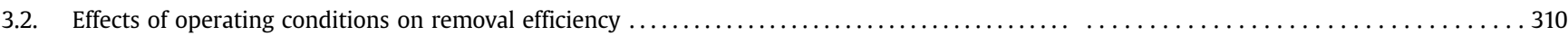

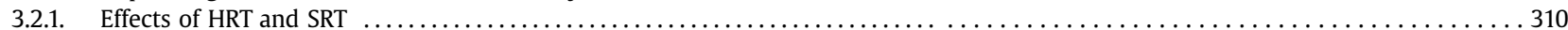

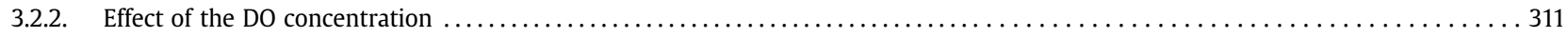

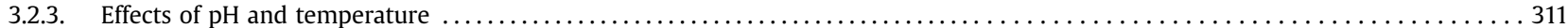

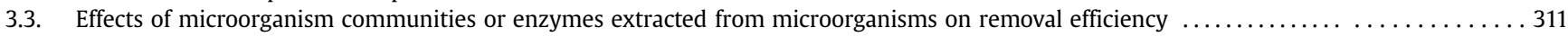

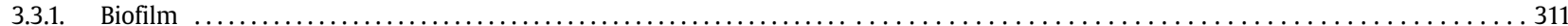

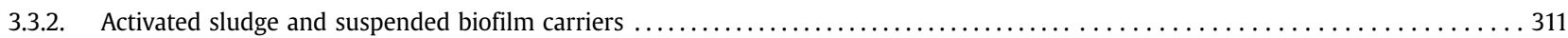

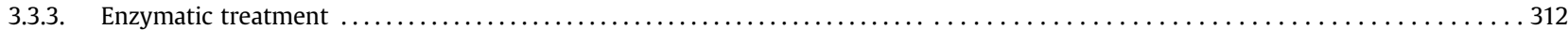

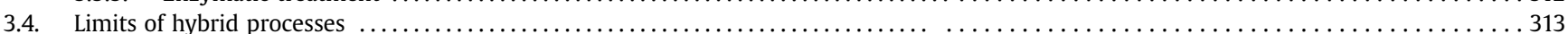

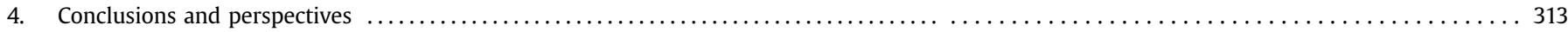

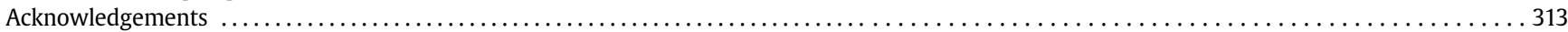

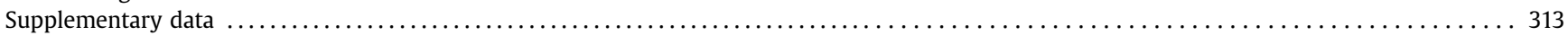

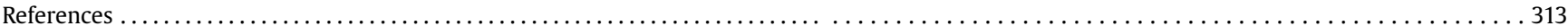

\section{Introduction}

Agriculture, industry and domestic practices around the world are releasing multiple compounds in wastewater, inducing an increasing environmental concern about pollutants occurrence in aquatic environments (Kim et al., 2007; Deblonde et al., 2011). Emerging pollutants, also called trace organic contaminants (TrOCs), are compounds present in the environment at trace concentrations and whose effects on the environment and human health are currently unknown. These contaminants include pharmaceuticals, personal care products, industrial chemicals, pesticides, polycyclic aromatic hydrocarbons (PAH), as well as metallic trace elements. To date, discharge guidelines and standards do not exist for most of these compounds. However, the EU water framework directive 2000/06/CE announces in Annex X a list of 45 priority substances or groups of substances. This list which includes metals, pesticides, phthalates, PAHs, and endocrine disruptors as well, imposes the removal of these compounds within an objective of quality and preservation of the good ecological status of water by 2015 , not only in receiving waters but in order to remove ecotoxicity of these compounds. Indeed, because of their persistence, some organic micropollutants could be toxic and bioaccumulate with potential significant impacts on human health and the environment. This bioaccumulation is typically associated with the high lipid solubility property of a compound and its ability to accumulate in the fatty tissues of living organisms for a long time period. These persistent compound move up the food chain, and they increase in concentration as they are processed and metabolized in certain tissues of organisms, increasing their toxicity in the environment (Burkhardt-Holm, 2011). Furthermore, a watch list of substances for European Union-wide monitoring was, recently, reported in the Decision 2015/495/EU of 20 March 2015, including two pharmaceuticals (diclofenac (DCF) and the synthetic hormone $17-\alpha$-ethinylestradiol (EE2)) and a natural hormone (17- $\beta$-estradiol (E2)), three macrolide antibiotics (azithromycin (AZI), clarithromycin (CLA) and erythromycin (ERY)), other natural hormone (estrone (E1)), some pesticides (methiocarb, oxadiazon, imidacloprid, thiacloprid, thiamethoxam, clothianidin, acetamiprid and triallate), a UV filter (2-ethylhexyl-4-methoxycinnamate) and, an antioxidant (2,6-di-tert-butyl-4-methylphenol) commonly used as food additive (Barbosa et al., 2016).

The increasing concern about the potential accumulation of micropollutants in the aquatic environment triggered many investigations about their biological degradation in wastewater treatment systems (Stackelberg et al., 2007). Some mechanisms such as adsorption on activated sludge flocs or photolysis have been studied for the removal of micropollutants during water treatment processes (Radjenović et al., 2009). However, current wastewater treatment plants (WWTPs) using conventional biological processes are not specifically designed to eliminate recalcitrant TrOCs. Thus, due to their persistence, many of these molecules are able to pass through wastewater biological treatment processes. This recalcitrance has often been linked to their molecular properties, which define their biodegradation abilities by a given strain of microorganism under given operating conditions (Tahri et al., 2013). For instance, Kimura et al. (2005) suggested that the presence of chlorine in the molecular structure, and a relatively complex aromatic structure are the reasons for the low degradation rates observed in the case of clofibric acid (CFA), dichloprop, and DCF. Moreover, Tadkaew et al. (2011) examined the relationship between chemical structures and the removal of TrOCs using membrane bioreactors (MBRs). Some physico-chemical properties such as hydrophobicity and the presence of electron withdrawing (EWGs), or electron donating functional groups (EDGs) appear to be important factors governing TrOCs biodegradation. This study shows high removal efficiency for hydrophobic compounds with a $\log \mathrm{K}_{\mathrm{ow}}>3.2$ (at $\mathrm{pH}=8.0$ ) and hydrophilic compounds (log $\mathrm{K}_{\mathrm{ow}}<$ 3.2) which possess only EDGs such as hydroxyl groups or primary amine groups. In contrast, the removal of hydrophilic compounds bearing only EWGs is very low (below 20\%). For hydrophilic compounds which have both EDGs and EWGs, their removal rate is variable depending on their functional groups. Beside biodegradation, adsorption can also govern the removal of TrOCs from the aqueous phase during MBR or conventional activated sludge (CAS) treatments. According to Fan et al. (2014), removal efficiencies of five pharmaceuticals by sludge adsorption were positively correlated with their $\mathrm{K}_{\mathrm{ow}}$ (namely octanol-water partition coefficients). The removal of pharmaceuticals by sludge adsorption is mainly affected by the electrostatic interactions between the molecule and sludge surface, and the hydrophobic/hydrophilic character of the molecule.

Many review papers have been published regarding the occurrence and fate of micropollutants in the aquatic environment (Miège et al., 2009; Oulton et al., 2010; Deblonde et al., 2011; Lapworth et al., 2012; Wijekoon et al., 2013; Luo et al., 2014b,...). Most of these studies focused on the removal of micropollutants through CAS processes or MBR treatments (Clara et al., 2005b; Clouzot et al., 2008), but only a few of them have treated the removal of micropollutants using recently developed advanced processes, such as adsorption processes, advanced oxidation processes, or membrane processes (Oulton et al., 2010; Luo et al., 2014b; Ahmed et al., 2016). Besides, no attempt has been made to provide a comprehensive review of the removal of contaminants using hybrid processes, combining different technologies, such as fixed and free biomasses for instance, or a comparison between processes using different microorganism's strains. In this context, 
the aim of this work is to review the performance of different processes regarding the removal of emerging contaminants. Several processes from classical ones (CAS treatment, MBR treatment), to more original approaches such as fixed-bed bioreactors or hybrid processes will be studied among different scales from laboratory pilot plants to real WWTP. The type of microorganisms used to efficiently degrade these micropollutants is also reviewed, as well as the effects of operating conditions on removal efficiencies.

\section{Biodegradation of micropollutants in wastewater treatment plants using classical processes}

\subsection{Removal of micropollutants in wastewater treatment plants}

\subsubsection{Micropollutants occurrence in wastewaters}

Several review papers report the occurrence of micropollutants in different water bodies such as influent and effluent from WWTPs (Miège et al., 2009; Deblonde et al., 2011; Verlicchi et al., 2012; Benner et al., 2013; Luo et al., 2014b; Evgenidou et al., 2015, ...), but also groundwaters (Lapworth et al., 2012; Luo et al., 2014b; Sui et al., 2015), surface waters (Luo et al., 2014b), or seawater (ArpinPont et al., 2014). The occurrence and repartition of TrOCs, especially pharmaceuticals, in sewage water and sludge flocs along with conventional activated sludge, or MBR wastewater treatment processes, have been studied and these compounds are generally found in concentrations ranging from low ng. $\mathrm{L}^{-1}$ to a few $\mu \mathrm{g} . \mathrm{L}^{-1}$ in the liquid phase, as well as in solid phase: from a few ng. ${ }^{-1}$ to a

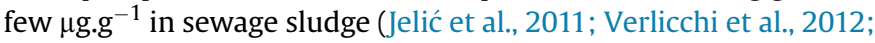
Jiang et al., 2013). For instance, the study of 78 peer-reviewed papers has showed that analgesics and non-steroidal anti-inflammatory drugs (NSAID) concentrations are ranging from 1.60 ng.. $\mathrm{L}^{-1}$ to $373 \mu \mathrm{g} . \mathrm{L}^{-1}$ in the raw influent of municipal WWTPs.

The most commonly investigated compounds were ibuprofen (IBP), DCF, naproxen (NPX), ketoprofen (KPF) and acetaminophen (ACE). Regarding antibiotics, variability of their concentrations was found between $1.0 \mathrm{ng} . \mathrm{L}^{-1}$ and $32 \mu \mathrm{g} . \mathrm{L}^{-1}$ in the raw influent to municipal WWTPs, and the most commonly investigated compounds were trimethoprim (TMP), sulfamethoxazole (SMX), ERY, and ciprofloxacin (CIP) (Verlicchi et al., 2012). In addition, other review papers, such as Bolong et al. (2009), focused on physical, biological, or chemical treatment methods for endocrine disrupting compounds and other pharmaceuticals.

The major part of micropollutants comes from several sources like domestic or industrial wastewater, hospital effluents, or agricultural run-off (Luo et al., 2014b). Even though the discharge from WWTPs is only one of the pathways for the introduction of micropollutants to surface water, WWTPs act as primary barriers against their spread. Indeed, non-negligible removal rates (from 13 to $100 \%$ for some compounds such as atrazine (ATZ), DCF, triclosan (TCS), estriol (E3)...) have been observed in WWTP's effluents of 14 different countries where they are commonly present in wastewaters at trace concentrations, ranging from a few ng. $\mathrm{L}^{-1}$ to several $\mu \mathrm{g} . \mathrm{L}^{-1}$ (Luo et al., 2014b).

TrOCs removal is generally dependent on compound physicochemical properties, process-specific factors such as sludge retention time (SRT), or hydraulic retention time (HRT) as well as seasonal parameters such as temperature, precipitation rate, and solar radiation (Vieno et al., 2005). According to Luo et al. (2014b), a firm conclusion about the persistency of each compound cannot be easily drawn, as many compounds showed significantly different removal rates in different conventional WWTPs. Nevertheless, the authors presented a simple classification for the removal rates of these compounds in conventional WWTPs. For instance, ATZ, diazinon (DZN), DCF, carbamazepine (CBZ), metoprolol (METOP), as well as mefenamic acid (MFA) are, on the average, removed with poor rates (<40\%), while bisphenol A (BPA), caffeine (CFN), IBP, E2, E1, NPX, nonylphenol (NP), TCS are generally removed with high rates $(>70 \%)$

Some reliable complementary processes can help improving micropollutant removal. For example, ozonation process can highly remove molecules such as DCF, CBZ, TCS, E1 (>90\%) (Sui et al., 2010). Nevertheless, this process implies important operating costs due to high energy requirements. Some by-products, such as bromate, can also be produced by this treatment from the oxidation of bromide, through a combination of ozone and $\mathrm{OH}$ radical reactions (Von Gunten, 2003). Coagulation and flocculation processes have also been tested, but most of the time they did not show any significant removal efficiencies of the tested micropollutants, whereas activated carbon adsorption can allow important removal efficiencies especially for hydrophobic compounds with a $\log \mathrm{K}_{\mathrm{ow}}>$ 4. On the contrary, according to Rogers (1996) compounds with log $\mathrm{K}_{\mathrm{ow}}<2.5$ have a low sorption potential on activated carbon. Using this process, DCF and CBZ can be removed with efficiencies higher than 90\% (Grover et al., 2011; Kovalova et al., 2013). Besides, organic micropollutants in aqueous solution will partially be in their ionic form at a given $\mathrm{pH}$ (depending on their $\mathrm{pKa}$ ), and as $\log \mathrm{D}$ is $\mathrm{pH}-$ dependent, $\log \mathrm{D}$ values are important factors to take into account in the removal by sorption of such micropollutants Tadkaew et al. (2010).

However, the maintenance cost of adsorption processes is not negligible. Indeed, granulated activated carbon-based removal technology will become less efficient over time as the adsorption bed ages and adsorption sites become less and less regenerated. Furthermore, micropollutants can be released back into the solution when the influent concentration of a contaminant drops, in order to restore equilibrium or in case of competition between organic compounds and other adsorbed species. Bourneuf et al. (2015) studied the desorption phenomenon of micropollutants onto activated carbon in water phase. The results showed that several cycles of adsorption and desorption of methyldiethanolamine and 2,4-dimethylphenol could be successively run on a column of fixed-bed adsorbent, and that attenuation is largely dependent on the contaminant (chemical structure of the pollutant, and notably the occurrence of aromatic moieties, or their hydrophobicity).

\subsubsection{Conventional activated sludge treatment}

The activated sludge treatment is commonly used in municipal WWTPs. It involves the addition of pretreated wastewater and microorganisms to remove nutrients, and to oxidize carbonaceous biological matter and nitrogenous matter, mainly ammonium and nitrogen. The process begins by mixing the polluted influent from industrial or sewage wastewater with an aerobic bacterial culture in an aerated reactor (Eckenfelder and Cleary, 2014). The aeration tank retention time is then adjusted to ensure that the effluent is sufficiently treated before undergoing a solid/liquid separation in a gravimetric clarifier (Tchobanoglous et al., 2003). The collected settled activated sludge is then mainly recycled back to the aeration tank in order to maintain a fixed concentration of depolluting microorganisms (Eckenfelder and Cleary, 2014).

Three main pathways of degradation exist during activated sludge treatment: microbial processes (biodegradation, either metabolic, or co-metabolic), sorption onto sludge flocs, and volatilization (mainly during aeration). However, volatilization can be considered negligible for the majority of pharmaceuticals and personal care products (PPCPs), because of the Henry's constant value of such molecules (Joss et al., 2006). Adsorption onto activated sludge flocs could be a significant pathway for some compounds such as musk fragrances in CAS, or estrogens in MBR due to the hydrophobicity of such compounds (Carballa et al., 2005; 
Clouzot et al., 2010; Maeng et al., 2013). Besides, organic micropollutants in aqueous solution will partially be in their ionic form at a given $\mathrm{pH}$ (depending on their $\mathrm{pKa}$ ), and as $\log \mathrm{D}$ is $\mathrm{pH}$-dependent, $\log \mathrm{D}$ values are important factors to take into account in the removal by sorption of such micropollutants. As said previously, Tadkaew et al. (2010), as well as Wells (2006), showed that log D is $\mathrm{pH}$-dependent and suggested that the sorption of a TrOC onto activated sludge flocs could be assessed by considering the $\log \mathrm{D}$ value of the compound at a given $\mathrm{pH}$.

Regarding biodegradation, according to some authors, cometabolic biodegradations could play a major role on the removal mechanism of micropollutants during activated sludge treatment of municipal wastewater, since the concentrations in micropollutants could be too low to serve as a direct growth substrate (Quintana et al., 2005; Xue et al., 2010; Fischer and Majewsky, 2014). In this aerated tank occurs the nitrification which leads to the conversion of ammonia to nitrates thanks to nitrifying microorganisms. These organisms, such as ammonia-oxidizing bacteria could possibly co-metabolically oxidize micropollutants thanks to the presence of an ammonia monooxygenase, and thus improve the removal of organic micropollutants (Margot et al., 2016).

For PPCPs, the removal of these molecules occurs thanks to a combination of biodegradation and sorption pathways. Hence, conventional activated sludge systems give rise to a wide range of removal efficiencies regarding PPCPs (Verlicchi et al., 2012). Among the PPCPs and some of their human metabolites, ACE, CFN, digoxigenin, E1, IBP, NPX, and paraxanthine are for instance rather well removed (>90\%); whereas CBZ, EDTA, MFA, gemfibrozil (GFZ), CIP, E3, ofloxacin (OFX), penicillin V, SMX, TMP are poorly removed from influent (Bernhard et al., 2006; Radjenović et al., 2009; Blair et al., 2015). It is worth noting that the degradation of some PPCPs like CFN, ACE, and metformin that are highly degradable, slowed or stopped at trace, but notable, concentrations within an activated sludge system. A degradation plateau has been observed with these molecules: 40 ng.L $\mathrm{L}^{-1}$ for CFN, 90 ng.L ${ }^{-1}$ for ACE, and 1000 ng. $\mathrm{L}^{-1}$ for metformin (Blair et al., 2015). This phenomenon may explain, according to the authors, the continuous low levels of degradable PPCPs in the effluents of WWTPs. Furthermore, this study revealed negative mass balances for some PPCPs, such as CBZ or OFX, whose both soluble and sorbed concentrations increased over time during aerobic batch experiments (Blair et al., 2015). It has been hypothesized that some PPCPs can be enclosed in fecal particles and then, released to the liquid phase when the feces are broken down by microorganisms (Gobel et al., 2007). Another potential theory is that the undetected PPCPs metabolites are further transformed back into the parent compounds through microbial activity (Verlicchi et al., 2012). The deconjugation of conjugates by hydrolysis during treatment, yielding the parent compound, could lead to an additional source of contaminant load (Suárez et al., 2008; Kovalova et al., 2013). According to Blair et al. (2015), the negative mass balances are due to a combination of all of these processes, with the driving factor being compound specific. DCF removal efficiencies ranging from $0 \%$ to $70 \%$ have been reported according to the biological composition of the sludge used (Clara et al., 2005b; Bernhard et al., 2006; De Wever et al., 2007; Kimura et al., 2007; Radjenović et al., 2009). Between 50 and 65\% removal of KPF and NPX have been found in previous studies (Carballa et al., 2004; Quintana et al., 2005; Radjenović et al., 2009). A complete removal of NPX was even reported in one study during a process of wastewater treatments involving disinfection (Metcalfe et al., 2003). Quintana et al. (2005) used a sludge which was withdrawn from a reactor treating real municipal wastewater in which all five selected pharmaceuticals such as KPF, DCF, bezafibrate (BZF), NPX, and IBP were found (Quintana and Reemtsma, 2004). The results of this study showed that KPF could serve as sole substrate for the microbial growth, which could explain its high biodegradability, whereas a cometabolic transformation appeared to be, generally, the important biodegradation pathway in the case of acidic pharmaceuticals. TMP was removed with around $40 \%$ efficiency. This compound is generally considered recalcitrant, but Pérez et al. (2005) observed its degradation using slow-growing nitrifying bacteria. Some antibiotics such as AZI, ERY, OFX, or TMP are expected to sorb onto negatively charged surface of sludge flocs through ionic interactions (Radjenović et al., 2009).

More generally, the observed important differences between removal efficiencies for a given molecule from one work to another are probably due to the differences in operating parameters of the compared CAS systems, such as the SRT, the HRT, or the solid phase concentration, but also to the biological composition of sludge flocs and the chemical composition of wastewaters.

\subsubsection{Membrane bioreactor treatment}

MBR is another type of common technology for biological wastewater treatment in which activated sludge treatment is directly combined to a membrane separation process. It presents several advantages such as low space requirement and high effluent quality. Membranes allow a complete retention of particulate matter, but also work at higher solid concentrations without limitation due to the subsequent solid/liquid separation (Wisniewski, 2007).

Several observations have been reported on the removal of micropollutants by MBR treatment. In the case of compounds with an intermediate removal in CAS treatments (between 15 and 80\%), MBR treatments can generally further reduce micropollutant concentrations by $20-50 \%$. However, in the case of compounds which are already highly degraded by CAS processes or in the case of recalcitrant compounds, the results using MBRs did not show any significant improvements (Hai et al., 2010). Some authors also concluded that removal rates in MBRs and CAS processes are comparable for selected pharmaceuticals, fragrances, endocrine disrupting compounds, naphthalene sulfonates, and benzothiazole-2-sulfonate (Clara et al., 2005b; Joss et al., 2005). On the contrary, Bernhard et al. (2006) showed significantly better removal rates of studied persistent polar pollutants such as DCF, mecoprop, and sulfophenyl carboxylates with MBRs compared to CAS systems, whereas recalcitrant micropollutants such as EDTA and CBZ were not eliminated at all during wastewater treatments by these processes. A better removal efficiency for NP and nonylphenol ethoxylates (NPEO) using a MBR compared to a CAS system has been noticed by González et al. (2006). Similarly, the two MBRs used by Kimura et al. (2007) exhibited better elimination rates for the six selected acidic pharmaceuticals than the reference activated sludge process. Kim et al. (2007) also observed that a MBR system seems to be efficient for hormones (e.g. E3, testosterone, androstene-dione) and some pharmaceuticals (e.g. ACE, IBP, and CFN) with approximately $99 \%$ removal, but that this process did not decrease the exit concentration for molecules such as ERY, TMP, NPX, DCF, and CBZ. Concerning the adsorption phenomenon, Radjenović et al. (2009) found higher concentrations in MBR sludge flocs than in CAS sludge flocs for hydrochlorothiazide, AZI, CBZ, and KPF which could either be explained by a modified intrinsic hydrophobicity (e.g. aliphatic and aromatic groups), an increase of surface area, or increased electrostatic interactions (e.g. amino groups) with MBR sludge flocs (Kim et al., 2007). MBR could also improve the degradation of TrOCs because it allows reaching different values for process parameters such as HRT or SRT, compared to CAS system. Because MBRs generally operate at higher SRTs (at least 15 days) than CAS systems (at most 15 days), higher removal efficiencies can be achieved as reported by Clara et al (2005a), Radjenović et al. (2009), and Weiss and Reemtsma 
(2008). However, the relationship between some process parameters is still unclear. A comparison between CAS systems and a MBR operating at comparable SRT showed no significant differences in the treatment efficiency (Clara et al., 2005a).

According to Cirja et al. (2008), the solid phase properties also varies in MBRs compared to CAS systems, both as a function of wastewater composition and operating conditions, in particular hydrodynamics, through an increase of the average shear rate. Indeed, hydrodynamic stress in MBRs reduces floc size which is also dependent upon mixed liquor suspended solids or exopolymeric substances concentrations (Zhang et al., 1997). Smaller flocs (10-100 $\mu \mathrm{m}$ in MBRs against $100-500 \mu \mathrm{m}$ in CAS systems) and the presence of some free-living bacteria in MBRs could improve masstransfer kinetics, and thus elimination efficiencies with this process. Indeed, MBRs typically run at lower food/microorganisms (F) $\mathrm{M}$ ) ratio than CAS process in order to mitigate membrane fouling and maintain high oxygen transfer efficiency. The $\mathrm{F} / \mathrm{M}$ ratio, which is a balance between substrate consumption and biomass generation, determines the degree of decomposition of organic matter, and the removal of micropollutants. However, it is hard to demonstrate that only a low $\mathrm{F} / \mathrm{M}$ ratio encourages micropollutant biotransformation, other parameters such as HRT may come into play (Petrie et al., 2014). Thanks to the presence of smaller flocs and free-living bacteria, the biomass in a MBR also seems to have a more viable fraction compared to that of a CAS system (Cicek et al., 1999). Finally, specific floc surface per unit of reactor volume was ten times higher in MBRs than in CAS systems. As a consequence, the contact between microorganisms and pollutants could be favored with MBRs, which could stimulate enzymatic activities. Indeed, part of the enzymatic activity seems to increase proportionally with the specific surface area of contact between suspended biosolids and polluted waters (Cirja et al., 2008).

Finally, MBR is able to deliver lower and more stable effluent concentrations in comparison to CAS systems, generally under lower HRT, as far as compounds with moderate removals in CAS systems are concerned (including NPX, DCF, phenazone, CFA). However, this effect is not important enough to serve as a financial argument for developing the use of MBRs in municipal WWTPs, according to Weiss and Reemtsma (2008).

\subsection{Effects of operating conditions on removal efficiency}

Table 1 (Appendix A: supplementary data) reports examples of selected micropollutant removal using classical bioreactors (batch experiments or MBR systems) from an analysis of literature data. The operating conditions such as temperature, HRT, or SRT of each study are also compiled in this table. Removal efficiencies given in Table 1 are grouped according to their references, and represent the total removal of the species from the liquid phase, so they include the contributions of biodegradation (both metabolic and cometabolic) and/or adsorption onto activated sludge flocs.

\subsubsection{Effects of hydraulic retention time and sludge retention time}

The sludge retention time, also known as solid retention time or sludge age, indicates the mean residence time of microorganisms in the reactor and is related to the growth rate of microorganisms. It is calculated through the ratio of the tank volume compared to the sludge volumetric removal flow rate. High SRTs allow an enrichment of the biomass in slowly growing autotrophic bacteria such as nitrifiers which can also excrete enzymes that can possibly break down some low degradable molecules with aromatic rings (Rosenberger et al., 2002; Cirja et al., 2008). Monod-type kinetics deal with the relationship between the growth rate of a microbial species and the concentration of a critical substance sustaining its growth. Compounds must be sufficiently easy to degrade, and it also must be available in sufficient amounts to result in significant energy and/or biomass recovery. The degradation of a certain amount of pollutants enables a proportional enhancement in microbial biomass. On the assumption that the biodegradation of a given micropollutant is described by a Monod kinetic, a specific SRT can be associated to this substance even at low concentration, or in the case of a co-metabolism. Indeed, in a process using biomass recirculation, the installed SRT corresponds approximately to the reciprocal of the growth rate (Clara et al., 2005a). Considering this relationship, according to Clara et al. (2005a), the effluent concentration of some organic micropollutants is dependent on the selected/operated SRT and independent of influent concentrations. This is why SRT is a fundamental parameter to design a WWT process. For example, a minimum value of 10-15 days for the SRT was proposed by Clara et al. (2005a). Micropollutants can be only degraded from a critical SRT value, which are determined for different compounds. If a WWTP operates with SRTs below this critical value, effluent concentrations of micropollutants are expected to be in the range of influent concentrations. This concept is useful to allow an estimation of outlet concentrations, and for the design of WWTP to enhance the removal of organic micropollutants such as pharmaceutical active compounds (PhACs) and the nitrification process along biological wastewater treatment systems (Kreuzinger et al., 2004). For instance, it has sometimes been reported that an increase in SRT could enhance the elimination of some pharmaceuticals (Jelić et al., 2012b). Indeed, in a MBR, higher biomass concentration and the presence of slower growing species, both resulting from higher SRTs, have led to higher removal efficiencies of some PPCPs, as revealed by Table 1 (FernandezFontaina et al., 2012). According to Xia et al. (2012), higher SRTs (above 30 days) correspond to the suitable operational condition for sufficient antibiotics removal (up to 80\%). For Tambosi et al. (2010), a MBR with a SRT of 30 days presented higher removal efficiencies than a MBR with a SRT of 15 days for all tested pharmaceutical compounds. The same observation has been made by Kimura et al. (2007). In their study, the MBR with the higher SRT exhibited the best performances for the removal of pharmaceuticals such as CFA, DCF, KPF, and NPX, as it is collected in Table 1. For instance, for a SRT of 65 days, the removal efficiencies of KPF and CFA achieved $99 \%$ and $82 \%$ respectively, whereas for a SRT of 15 days the degradation was about $83 \%$ and $50 \%$ respectively. Moreover, low effluent concentrations can be achieved in WWTPs operated at SRTs higher than 10 days, in particular for the biodegradation of hormones, BZF, and IBP (Clara et al., 2005a). Besides, even if its influence on the removal of PPCPs has scarcely been reported, acclimation of biomass is known to be beneficial for degradation of xenobiotics (Suárez et al., 2012).

However, the correlation between the removal rate and the SRT was not straightforward. Some authors such as Joss et al. (2005) and Vieno et al. (2007) reported that the effect of an increase in SRT is not clear and may vary significantly depending on the tested compounds. Falås et al. (2016) supports this idea, observing no strong and systematic correlation between the SRT and the rate constants of more than 20 micropollutants with SRTs ranging from 25 to 80 days. The removal of some pharmaceuticals such as CBZ, DCF, or ACE during biological treatments did not show any significant dependency on SRT. Regarding CBZ, Bernhard et al. (2006) and Maeng et al. (2013) have observed that this molecule still remain recalcitrant regardless of the change of SRT using a MBR reactor. Concerning DCF, even if most of the studies reported higher elimination at higher SRTs using MBRs, Clara et al. (2005b) and Suárez et al. (2012) noted no correlation. Besides, Bernhard et al. (2006) have observed that an enhanced DCF elimination (reaching a plateau) was obtained at higher SRTs using a MBR reactor. DCF removal rate was $8-38 \%$ when SRT was $20-48$ days, $59 \%$ at a SRT of 
62 days, and 53\% at a SRT of 322 days. Additionally, hydrophilicneutral pharmaceuticals (based on $\log \mathrm{K}_{\mathrm{ow}}$ and $\mathrm{pK}_{\mathrm{a}}$ values) such as CFN, phenacetine, or ACE, and hydrophilic-ionic pharmaceuticals as IBP and estrogens (E1, E2, EE2) can be removed by a MBR operated at a SRT as small as 8 days (up to 90\%). Conversely, other compounds such as KPF, CFA, and EE2 need a higher SRT from 20 to 80 days to be correctly were removed (removal efficiencies achieved $65-90 \%, 6-34 \%$ and $71-78 \%$ respectively, as collected in Table 1) (Maeng et al., 2013). Finally, some studies have found the SRT to be a determining factor as far as biodegradation kinetics of micropollutants are concerned. Majewsky et al. (2011) compared biodegradation kinetics of some pharmaceuticals such as CFN, DCF, CBZ, ACE, as well as SMX, using activated sludge from two WWTPs notably differing by their SRT. The results, collected in Table 1 , showed that PhAC removal was more important under high concentration of heterotrophic microorganisms at a low SRT. Besides, according to Sipma et al. (2010), the biodegradation of some micropollutants is mostly due to co-metabolism processes since their low concentrations are not likely to sustain microorganisms growth. Since SRT is the relevant parameter to achieve an efficient biodegradation of the primary substrate, this could explain the fact that an increase in SRT beyond 30 days does not seem to give any improvement in terms of removal efficiencies of different compounds (Sipma et al., 2010). For example, an increase in SRT appears to be a relevant parameter for an efficient biodegradation in the case of very low concentrated compounds such as pharmaceuticals (concentration range from ng. $\mathrm{L}^{-1}$ to a few $\mu \mathrm{g} . \mathrm{L}^{-1}$ ) (Sipma et al., 2010). Gobel et al. (2007) demonstrated that the combination of a high SRT with reduced F/M ratios may induce an increased biodiversity, and thus enhance elimination of compounds such as TMP, and CLA by co-metabolism processes.

The hydraulic retention time (HRT) corresponds to the mean residence time of the liquid phase in the reactor. This parameter has an impact on the reaction volume and on the $\mathrm{F} / \mathrm{M}$ ratio, but not on the $K_{b i o l}$ coefficient of the compound. However, even with a lack of information about temperature and sludge age, the influence of this parameter on the biodegradation efficiencies of different micropollutants was largely investigated. Bernhard et al. (2006) found no significant correlation between the removal of micropollutants such as pharmaceuticals and the HRT in a MBR, but noticed that the tested MBR showed better removal efficiencies (even if its HRT was lower) than a 22 h HRT reference WWTP. Vieno et al. (2007) also noticed that the relationship between HRT and removal efficiency was not straightforward for all selected compounds, sampled in different WWTPs in Finland, having a SRT between 2 and 20 days. They observed that a decrease of the HRT reduces the elimination for some beta-blockers such as METOP, and atenolol, but the effect was not so evident for sotalol. On the contrary, no significant effects were found by Weiss and Reemtsma (2008), who studied the variation of HRT in the range of $7 \mathrm{~h}-14 \mathrm{~h}$ on different TrOCs removal rates, using a MBR. Weiss and Reemtsma (2008) assumed that a combination of a high SRT and a reduced $\mathrm{F} / \mathrm{M}$ ratio at low HRT, which may force microorganisms to utilize poorly degradable polar compounds as substrates, induces an increased biodiversity in MBRs. Indeed, a lower $\mathrm{F} / \mathrm{M}$ ratio results in stronger substrate limitation. This could explain why removal efficiencies of some persistent PhACs are higher in MBRs operated under such feeding conditions than in CAS systems, and why this can be obtained even under low HRT (Weiss and Reemtsma, 2008).

Gros et al. (2010) calculated PhACs removal efficiencies in Spanish WWTPs (SRT data are unknown) and the corresponding PhAC half-life times $t_{1 / 2}$, assuming that compound degradation followed a pseudo-first order kinetic. Indeed, they assumed that the decrease of the concentration through time is proportional to the concentration remaining in the matrix used. On the one hand, Gros et al. (2010) concluded that degradation kinetics of compounds with high pseudo-first order biological degradation rate constants $\left(\mathrm{K}_{\text {biol }}\right)$ (or low $\mathrm{t}_{1 / 2}$ ) and low $\log \mathrm{K}_{\mathrm{ow}}$ (low sorption abilities) are more influenced by HRT, while degradations kinetics of compounds with low $\mathrm{K}_{\mathrm{biol}}$ and high $\log \mathrm{K}_{\mathrm{ow}}$ are more influenced by SRT. On the other hand, there are some exceptions such as IBP which is a high $\mathrm{K}_{\text {biol }}$ and low $\log \mathrm{K}_{\mathrm{ow}}$ molecule that remains well removed whatever the HRT and SRT values are (Gros et al., 2010). Besides, the HRT value does not influence removal efficiencies for compounds with high $\mathrm{t}_{1 /}$ 2 like CBZ always showing poor or no elimination, whereas for compounds with medium $\mathrm{t}_{1 / 2}$ (between 10 and $20 \mathrm{~h}$ ), the HRT value seems to play a role on the achieved percentage of degradation (Gros et al., 2010). Joss et al. (2006) also observed a pseudo firstorder degradation kinetics for many organic micropollutants down to ng. $\mathrm{L}^{-1}$ concentrations, indicating that their biodegradation is directly influenced by micropollutant concentration. As a consequence of this pseudo first-order kinetic, micropollutant concentration decreases exponentially with time with a constant directly related to $\mathrm{K}_{\mathrm{biol}}$ so that the effects of operating conditions are less obvious for low degradable compounds $\left(\mathrm{K}_{\mathrm{biol}}<0.1 \mathrm{~L} . \mathrm{g}_{\mathrm{SS}}^{-1} \cdot \mathrm{d}^{-1}\right)$ as well as highly degradable compounds $\left(K_{\text {biol }}>10 \mathrm{~L}_{\mathrm{SS}}^{-1} \cdot \mathrm{d}^{-1}\right)$. They concluded by proposing three groups of micropollutants:

- $\mathrm{K}_{\mathrm{biol}}<0.1 \mathrm{~L}_{\mathrm{SS}}^{-1} \cdot \mathrm{d}^{-1}$ : no substantial removal by degradation $(<20 \%)$, but for strongly sorbing compounds with $K_{d}>1 L^{2} g_{S S}^{-1}$ the removal may be higher due to transfer to sludge.

- $0.1<\mathrm{K}_{\mathrm{biol}}<10 \mathrm{~L} . \mathrm{g}_{\mathrm{SS}}^{-1} \cdot \mathrm{d}^{-1}$ : partial removal (20-90\%)

- Kbiol > 10 L.g KS $_{S}^{-1} \cdot \mathrm{d}^{-1}$ : more than $90 \%$ removal by biological degradation; specific degradation efficiency strongly dependent on reactor configuration.

If $\mathrm{K}_{\mathrm{biol}}$ for a micropollutant is known, the HRT could be adjusted to ensure efficient removal of this compound. However, this makes sense in very specific contexts where one or a few pollutants are of particular concern, such as in industrial wastewaters. Indeed, HRT cannot be increased to the extent to remove some of the very recalcitrant compounds in municipal WWTP.

\subsubsection{Effect of the dissolved oxygen concentration}

Biodegradation experiments described in the literature were mostly carried out under aerobic conditions. It is indeed known that some ammonia-oxidizing microorganisms such as nitrifying microorganisms, whose growth is favored under high dissolved oxygen (DO) environments, have the potential to degrade some TrOCs (Ren et al., 2007).

Since conventional WWTPs combine the existence of aerobic and anoxic conditions, and since different metabolites could be formed under these conditions, it is interesting to investigate the potential removal mechanism of various pollutants under different redox conditions. For instance, for compounds with amide groups, the first transformation step of primary and secondary amides is usually a hydrolysis of the amide group, while the primary transformation step of tertiary amides is an oxidation. Hydrolysis of primary and secondary amides can occur under both oxic and anoxic conditions, whereas oxidation of tertiary amides specifically requires the presence of molecular oxygen (Helbling et al., 2010). In this context, Suárez et al. (2010) studied the removal of some PPCPs under both nitrifying and denitrifying conditions. Under nitrifying conditions, aerobic bacteria using inorganic chemicals as an energy source were found, whereas anaerobic or heterotrophic facultative anaerobic bacteria formed a denitrifying biomass under anoxic or anaerobic conditions. They observed an increase of DCF removal from $0 \%$ to $74 \%$ in an aerobic reactor due to the development of the nitrifying biomass, while an efficient aerobic (95\%) and anoxic 
transformation of IBP (75\%) was observed after an acclimatization period. Oxygen may also directly participate in biochemical reactions, or play a role by regulating the enzymatic activity. Xue et al. (2010) reported that the first-order biodegradation rate constants were positively related to the DO level for most of the studied compounds. The DO concentration level may, as a consequence, be crucial in promoting the overall degradation.

Lahti and Oikari (2011) also compared removal efficiencies of micropollutants under both aerobic and anaerobic conditions. Biotransformation of NPX and, to a lesser degree, bisoprolol (BSP) was observed under both aerobic and anaerobic environmental conditions. The biotransformation using inocula from activated sludge processes achieved about $40 \%$ in aerobic and $97.3 \%$ in anaerobic conditions for NPX after 75 and 161 days respectively, and about $35 \%$ in aerobic and $14 \%$ in anaerobic conditions for BSP after 75 and 161 days respectively. Suárez et al. (2010) indicated that fluoxetine, natural estrogens (E1, E2, EE2), and musk fragrances, galaxolide (HHCB), tonalide (AHTN), and celestolide (ADBI), were transformed to a large extent under both dissolved oxygen conditions (aerobic $(>75 \%$ ) and anoxic ( $>65 \%$ ) conditions). However, NPX, EE2, roxithromycin (ROX), and ERY were only significantly transformed in the aerobic reactor ( $>80 \%)$. The transformation rate of BSP, especially anaerobically, was slow, but rose immediately under aerobic conditions. DCF was recalcitrant under both aerobic and anaerobic conditions (Lahti and Oikari, 2011). Some other compounds, such as CBZ, diazepam (DZP), SMX, and TMP, also showed high resistance to biological transformation (Suárez et al., 2010), whatever the DO concentration.

Moreover, Falås et al. (2016) noticed that many micropollutants such as atenolol, and BZF are almost ubiquitously degraded under aerobic treatment systems, whereas TMP, DCF, and DIU seem to be degraded under specific aerobic treatment processes. On the contrary, demethylation and deiodination of some micropollutants with high aerobic persistence, such as venlafaxine, or diatrizoate, can be achieved under anaerobic conditions. Thus, a combination of different aerobic and anaerobic treatment conditions could expand the spectrum of organic micropollutants susceptible to biological degradation at WWTPs.

Regarding pesticides, Stasinakis et al. (2009) investigated the impacts of aerobic and anaerobic conditions on diuron (DIU) degradation, using activated sludge reactors. The results showed that, under aerobic conditions, DIU could be biodegraded by activated sludge (Table 1 ) and that the role of sorption onto biomass was not significant, while under anoxic conditions DIU seems to act as a source of carbon and energy for the microorganisms used in this study. Besides, the degradation of DIU was enhanced by acclimatization of the biomass under anoxic conditions. Almost $50 \%$ of DIU was degraded after a $140 \mathrm{~h}$ batch experiment.

\subsubsection{Effects of $\mathrm{pH}$ and temperature}

The $\mathrm{pH}$ of an aqueous body can influence both the solubility of micropollutants present in this environment and the activity of microorganisms, in particular the microbial enzymatic activities. Alterations in $\mathrm{pH}$ can inactivate some microbial enzymes that are essential to complex molecules biodegradation. It can also denature proteins within the cells, thus preventing microbial activity from occurring (Sylvia, 2005). Consequently, the fate of micropollutants during bioreactor treatments can be affected by $\mathrm{pH}$ variations. Chemical, physical, or biological processes involving such micropollutant molecules can show some changes, notably in terms of their kinetics, depending on the pH value (Cirja et al., 2008). Indeed, depending on their pKa values, PPCPs can exist in various protonation states as a consequence of $\mathrm{pH}$ variations. At pH 6.0-7.0, some micropollutants are deprotonated and adsorption sludge becomes an important removal mechanism. Besides $\mathrm{pH}$ values varied from neutral to acidic in MBR as nitrification became significant, which improve the degradation of some pharmaceuticals such as KPF or IBP (Cirja et al., 2008). Urase et al. (2005) reported a considerable enhancement in removal efficiency of some TrOCs when MBRs were operated under acidic ( $\mathrm{pH}=4.3-5.0$ ) rather than basic conditions ( $\mathrm{pH}=7.5-8.0$ ) (see Table 1 ). Higher removal of acidic pharmaceuticals was achieved under low $\mathrm{pH}$ conditions due to an increase of their adsorption onto sludge particles. According to Tadkaew et al. (2010), who studied the effects of pH variations between 5.0 and 9.0 on the removal of different TrOCs, removal efficiencies of acidic pharmaceuticals such as DCF, KPF, or IBP by submerged MBR are strongly $\mathrm{pH}$-dependent. The $\mathrm{pK}_{\mathrm{a}}$ values of these three compounds are ranging from 4.2 to 4.4. That is why at $\mathrm{pH}=5.0$ these molecules are predominantly present as deprotonated species. Consequently, they can readily adsorb onto the activated sludge flocs improving the MBRs removal efficiencies of these compounds by adsorption. However, the removal mechanisms are quite different for ionizable and non-ionizable compounds. Indeed, the removal efficiencies of BPA and CBZ remained relatively constant and independent of the mixed liquor. High removal efficiency of BPA could be attributed to both high biodegradability and adsorption, while CBZ does not readily adsorb onto sludge flocs pH (Tadkaew et al., 2010). Moreover, Gulde et al. (2014) investigated the influence of $\mathrm{pH}$ on the biotransformation of 15 micropollutants with cationic-neutral speciation in batch experiment using activated sludge. One control micropollutant with neutral-anionic speciation, and two neutral micropollutants at pHs 6.0, 7.0, and 8.0 were also performed in same operating conditions. The authors noticed that biotransformation was $\mathrm{pH}$-dependent and correlated qualitatively with the neutral fraction of the ionizable micropollutants. At the same time, they observed that the sorption coefficients derived from control experiments were small and showed no notable pH-dependence. They concluded that, $\mathrm{pH}-$ dependent removal of polar, ionizable organic micropollutants in activated sludge systems is less likely an effect of $\mathrm{pH}$-dependent sorption but rather of $\mathrm{pH}$-dependent biotransformation (Gulde et al., 2014). Furthermore, in the case of MBR using white rot fungi such as Trametes versicolor, the $\mathrm{pH}$ of the medium was found to be the most important factor, followed by the initial substrate concentration (Tavares et al., 2006). The optimal pH for T. versicolor activity was shown to be acidic ( $\mathrm{pH}=4.5$ ). However, it should be taken into account for a good $\mathrm{pH}$ regulation that the addition of carbon and nitrogen sources, aiming at boosting the enzymatic activity (production of laccase), also results in $\mathrm{pH}$ variations. Zhang and Geißen (2012) showed a relationship between a pH decrease and an increase in the activity of acidogenic bacteria present in a non-sterile wastewater. Other authors observed a $\mathrm{pH}$ decrease during the growth under carbon consumption of $T$. versicolor.

Another parameter that can influence the degradation of micropollutants is the temperature. However, only a few studies have investigated the effects of temperature variations on the performances of wastewater treatment processes in the case of micropollutants. Temperature fluctuations can arise from hot industrial effluents mixed with municipal wastewaters, or diurnal and seasonal variations, and affect treatment performances. Temperature fluctuations can play a role on microbial activity, solubility, other physicochemical properties of micropollutant molecules, and on the reaction rate which can be expressed by the Arrhenius equation. On the one hand, an increase of temperature of the effluent can decrease DO concentration, and encourage the development of specific microorganisms. Temperature upshifts (from $35^{\circ} \mathrm{C}$ to $45^{\circ} \mathrm{C}$ ) are known to cause an increase in suspended solid levels in the effluents, caused by sludge defloculation and a decrease (up to 20\%) of chemical oxygen demand. On the other hand, temperature upshifts (from $35^{\circ} \mathrm{C}$ to $45^{\circ} \mathrm{C}$ ) and periodic 
temperature oscillations (from $31.5{ }^{\circ} \mathrm{C}$ to $40{ }^{\circ} \mathrm{C}, 6$ day period, for 30 days) caused the decrease in bioflocs ability to settle, due to filamentous bacteria proliferation (Morgan-Sagastume and Allen, 2003). Moreover, temperature modifications can also impact other phenomenon such as membrane fouling (Zhang et al., 2006; Hai et al., 2011) but the link between temperature variations and membrane fouling is not very clear. Vieno et al. (2005) observed the effects of seasonal variations on the remaining concentration of different pharmaceuticals in effluent waters: the total concentration of all studied pharmaceuticals was 3-5 times higher in wintertime than during other seasons. Even though the inlet PhAC concentrations are higher during wintertime than during summertime because of an important consumption of antibiotics for instance, a slowdown of microbial activity was also observed during wintertime. However, because of the absence of controlled experimental conditions, the overall effects of temperature variations are still unclear. Other factors such as photodegradation or precipitation rate can also play a part in the observed seasonal variations on the overall degradation of micropollutants. According to Hai et al. (2011), a temperature increase (from 10 to $45^{\circ} \mathrm{C}$ ) caused an increase in total organic carbon (TOC) and total nitrogen (TN) levels in the bioreactor supernatant, as well as higher concentrations of soluble microbial products released in the mixed liquor. Besides, results of experiments measuring the removal of micropollutants at different temperatures in a batch mode demonstrated the existence of a temperature dependent correlation between hydrophobicity, molecular properties, and micropollutant removal. Experiments conducted at $45{ }^{\circ} \mathrm{C}$ allowed a good removal of some less hydrophobic $\left(\log \mathrm{K}_{\mathrm{ow}}<3.2\right)$ micropollutants possessing strong EWGs. On the contrary, the removal of most of the hydrophobic compounds ( $\log \mathrm{K}_{\mathrm{ow}}>3.2$ ) was stable around $80-100 \%$ for experiments conducted in a temperature range of $10-35^{\circ} \mathrm{C}$, but became very low for temperature above $45{ }^{\circ} \mathrm{C}$ ( $<40 \%$ for E1, BPA, EE2 for instance). Moreover, Suárez et al. (2012) concluded that the influence of temperature is inversely proportional to the biological degradation rate constants of PPCPs, and that temperature is a relevant factor for the elimination of PPCPs with moderate to low $\mathrm{K}_{\text {biol. }}$. Finally, Kruglova et al. (2014) studied the removal of three pharmaceuticals using a nitrifying activated sludge at a $12{ }^{\circ} \mathrm{C}$ operated at full-scale in a WWTP and in a laboratory-scale sequencing batch reactor. Under this temperature, CBZ showed no biodegradation, IBP was almost completely removed (up to 99\%), and DCF showed high concentration fluctuations, as revealed by Table 1 . This latter phenomenon could be caused by time variations in nitrite concentration during the development of the nitrifying biomass (Barbieri et al., 2012). Since, each biomass such as carbon oxidizing heterotrophs, nitrifiers, or denitrifiers, have their own temperature correction factor, and the effect of temperature on the reaction rate of a biological process can be expressed by the Arrhenius equation, nitrification is the most temperature sensitive process in biological system. The conversion of ammonia into nitrate due to the presence of autotrophic biomass may have slowed down due to a temperature decrease. The temperature correction factor of 1.072 is widely recently accepted for designing wastewater treatment plants (Melcer and Water Environment Federation, 2003; Hwang and Oleszkiewicz, 2007). Hwang and Oleszkiewicz (2007) investigated the effect of temperature decrease on nitrification. A sudden temperature decrease from $20^{\circ} \mathrm{C}$ to $10^{\circ} \mathrm{C}$ had an important effect on nitrification, more intense than predicted by the commonly used temperature correction factor. With this abrupt $10{ }^{\circ} \mathrm{C}$ temperature decrease, a $20 \%$ decrease of the nitrification rate was observed. On the contrary, a gradual temperature change of minus $2{ }^{\circ} \mathrm{C}$ per day induced a nitrification rate decrease similar to the prediction with the temperature correction factor of 1.072 (Hwang and Oleszkiewicz, 2007). Thus, consequence on nitrification biomass may have an impact on micropollutant removal.

To conclude on this point, even though these two parameters have an influence on the removal of organic micropollutants, the modification or regulation of $\mathrm{pH}$ and temperature requires a large amount of energy, and acid and base products, which is hardly economically feasible for municipal WWTPs. However, these parameters could be monitored and regulated for concentrated industrial wastewaters, which have a low hydraulic flow.

\subsection{Feeding effects on removal efficiency: batch vs continuous}

A bioreactor may be classified as batch, fed batch, or continuous. A typical batch reactor consists in an agitated tank, equipped with a temperature regulating system, in which a bioreaction is carried on without any addition until the reaction is considered to be complete. A fed-batch reactor is a process during which one or more substrates are added to the bioreactor during the cultivation, while the products remain in the bioreactor until the end of the experiment. Finally, a continuous reactor is one in which substrates are continuously fed into the reactor, and from which a continuous stream of products is drawn (Nanda and Pharm, 2008). These feeding modes can largely influence the removal efficiencies of different micropollutant families. A few authors have performed experiments with bioreactors operated according to different feeding modes and noticed significant differences on the biodegradation percentages obtained. Jelić et al. (2012a) studied the degradation of CBZ and its metabolites using an air pulsed fluidized bed bioreactor (FBR) inoculated with $T$. versicolor and operated in fed-batch and continuous mode. A unique metabolite was found, and CBZ was well removed (about 96\%) after 2 days of FBR operated in fed-batch mode. This percentage of degradation is higher than the percentage obtained using Erlenmeyer flasks (94\% after 6 days of incubation), because glucose was continuously added, $\mathrm{pH}$ was controlled, and the air pulses supplied allowed the fungus used in the fed-batch reactor to thrive. However, using a continuous mode operation with a hydraulic retention time of 3 days, only $54 \%$ of the inlet concentration was degraded after the reactor reached a steady state (25 days). This corresponds to a CBZ degradation rate of $11.9 \mu \mathrm{g} \mathrm{CBZ} \mathrm{g}^{-1}$.dry weight pellets. $\mathrm{d}^{-1}$. A sufficient supply of nutrients was also considered as a crucial parameter for an effective removal of CBZ by Zhang and Geißen (2012), who used a bioreactor inoculated with Phanerochaete chrysosporium in both batch and continuous modes. Under continuous operation, and thus input of nutrients, a high elimination of CBZ (60-80\%) was achieved, and the elimination rate was stabilized around 100 days. Regarding batch experiments, a high elimination was achieved after $4 \mathrm{~h}$ (around 80\%), mostly due to an adsorption onto the foam. The proportion of biotransformation in CBZ elimination during the batch experiment varied between 21 and 68\%. In addition, the elimination of some pharmaceutical compounds was also studied by Rodarte-Morales et al. (2012), using a fed-batch reactor and a continuous stirred tank reactor. A continuous feeding in the stirred tank reactor operated with free pellets of $P$. Chrysosporium allowed a complete degradation of three NSAID: DCF, IBP, and NPX; a partial elimination of CBZ, but no degradation of DZP. Using fixed-bed reactors under either continuous air flow or oxygen pulses, DCF, IBP, and NPX were well removed under both aeration conditions, while CBZ and DZP were only partially (60-90\%) degraded throughout these experiments.

Nevertheless, feeding effects, such as sequencing batch reactor versus continuous flow, have hardly an impact on the removal of micropollutants, which are predominated by the influence of SRT, temperature, and batch or plug flow reactor. Besides, because of the low concentration of organic micropollutants in wastewaters and 
their first order reaction, batch or plug flow reactors seem to be more efficient than completely mixed reactors, especially regarding the toxicity of influents.

\subsection{Effects of microorganism communities or enzymes extracted from microorganisms on removal efficiency}

Table 2 (Appendix A: supplementary data) presents the removal of selected micropollutants using classical bioreactors (batch experiments or MBR systems), depending on microorganism communities or enzyme extracted from microorganisms.

\subsubsection{Activated sludge}

Most studies dealing with the problem of micropollutant degradation have thus used batch or membrane bioreactors inoculated with activated sludge from classical wastewater treatment, in order to investigate removal efficiencies of these molecules. Luo et al. (2015) notably investigated the performance of a conventional $\mathrm{MBR}$, and membrane fouling during the treatment of different micropollutants. The results showed moderate or low removal of $\mathrm{KPF}, \mathrm{CBZ}$, primidone (PRM), BPA (50\%, 10\%, 58\%, 50\% respectively) and a significant membrane fouling as compared to the hybrid moving bed biofilm reactor-MBR. Wijekoon et al. (2013) investigated the relationship between molecular properties and the fate of 29 micropollutants such as UV-filter, pesticides, phytoestrogens, or pharmaceuticals using a MBR inoculated with municipal activated sludge. Adsorption is the dominant removal mechanism from the aqueous phase for hydrophobic ( $\log \mathrm{K}_{\mathrm{ow}}>3.2$ ) compounds (up to $50 \%$ ), while biodegradation is the most important removal mechanism from the aqueous phase for hydrophilic compounds (up to 70\%) (see Table 2). Compounds with a moderate hydrophobicity that remains recalcitrant to biodegradation, such as CBZ, accumulated significantly onto the solid phase while highly hydrophobic, but readily biodegradable compounds (up to 75\%), such as E1 and E2, did not accumulate onto activated sludge solids $(<20 \%)$ (Wijekoon et al., 2013). Fan et al. (2014) investigated the removal efficiencies of five pharmaceuticals from synthetic domestic wastewater using a submerged MBR. They studied separately the contributions of sludge adsorption and biodegradation, as provided in Table 2. The results of batch adsorption experiments at different reaction times of $0-6 \mathrm{~h}$, using sterilized sludge, showed that the removal efficiencies of ACE, E2, NPX, DCF, and CBZ by sludge adsorption were $28,68,60,40$, and $72 \%$ respectively. Besides, these adsorption percentages were positively correlated to the molecules $\mathrm{K}_{\mathrm{ow}}$. The results of batch experiments using activated sludge showed that $83 \%$ of ACE, $98 \%$ of E2, and $47 \%$ of NPX were removed due to a combination of sludge adsorption and biodegradation, while adsorption of these molecules onto the sludge solid phase was only $1.8,1.3$, and $7.0 \%$ respectively. Regarding the continuous process, the average removal efficiencies observed in the submerged MBR for ACE, E2, NPX, and DCF was about 92, 90, 55, 39\% respectively and low removal efficiency of $\mathrm{CBZ}(<5 \%)$ was also observed. Biodegradation thus seems to be the main way of degradation for ACE, E2, and NPX. On the other hand, the removal of DCF was mainly achieved by sludge adsorption. Indeed, the total removal efficiency of DCF was $19.7 \%$ and the contributions of sludge adsorption and biodegradation were 14.9 and $4.8 \%$ respectively. Regarding CBZ, this compound still remains recalcitrant and its removal efficiency only achieved $8.9 \%$ (see Table 2). This implies that, in the operating conditions studied by the authors, neither sludge adsorption nor biodegradation was very effective for the removal of $\mathrm{CBZ}$.

However, a few studies have evaluated the influence of different micropollutants on the bacterial community. The experiments were based on evaluating the influence of some compounds on the endogenous and exogenous respiration using a biomass initially sampled from a CAS process. For instance, Aubenneau et al. (2010) evaluated the potential effect of CBZ on the heterotrophic microorganisms taken from CAS and a pilot-scale MBR. During batch tests, they noticed some effects on both the respiratory activity of the bacterial community and on the floc size. Moreover, no inhibition, and no significant difference on chemical oxygen demand (COD) removal, sludge production, or oxygen requirement were observed with or without $1 \mu \mathrm{g} . \mathrm{L}^{-1}$ of CBZ, during a MBR wastewater treatment experiment. The authors have chosen this concentration, which was higher than WWTP influents, in order to induce a strong biomass reaction. On the one hand, under endogenous conditions, the observed increase of oxygen uptake rate (OUR) suggests an increase in maintenance requirements, essentially to manage the chemical stress induced by the CBZ's presence. On the other hand, under exogenous conditions, an OUR decrease was noticed. This observation could suggest a change in the metabolic pathways of the substrate or in the active bacterial species (Aubenneau et al., 2010). However, further studies would be useful to predict the influence of micropollutants on WWTP bacterial communities, but the concentration of $\mathrm{CBZ}$ found in municipal wastewaters should have no effect on biomass that treats wastewaters with several hundred mg.L $\mathrm{L}^{-1}$ of COD.

\subsubsection{White-rot fungi}

A biological alternative to activated sludge and a promising process may be based on the use of white rot fungi (WRF) cultures. These microorganisms were reported to degrade a wide range of xenobiotics due to the action of fungal oxidative enzymes, such as manganese peroxidase $(\mathrm{MnP})$, lignin peroxidase (LiP), versatile peroxidase (VP), or laccase. MnP (Mn(II): hydrogen-peroxide oxydoreductase, EC 1.11.1.13) is a heme glycoprotein enzyme which catalyzes the oxidation of organic compounds in the presence of $\mathrm{H}_{2} \mathrm{O}_{2}$ (Wong, 2009). LiP (diarylpropane: oxygen, hydrogenperoxide oxidoreductase (C-C-bond-cleaving), EC 1.11.1.14) catalyzes the $\mathrm{H}_{2} \mathrm{O}_{2}$-dependent oxidative depolymerization of lignin. LiP has been shown to eliminate several recalcitrant aromatic compounds such as PAH and phenolic compounds (Christian et al., 2005). VP (EC 1.11.1.16) is a hemoprotein which combines the substrate-specificity characteristics of the two other ligninolytic peroxidases, MnP and LiP. It is able to involve multiple binding sites for substrates in order to oxidize phenolic and non-phenolic substrates, hydroquinones, and both low- and high-redox-potential dyes (Camarero et al., 1999). Finally, laccase (benzenediol: oxygen oxidoreductase, EC 1.10.3.2) belongs to a family of multicopper enzymes of low-specificity. The enzyme catalyzes the oxidation of hydrogen-donating substrates such as lignin, phenol, or acrylamines via the four-electron reduction of $\mathrm{O}_{2}$ to $\mathrm{H}_{2} \mathrm{O}$. Laccase oxidizes phenolic compounds in the presence of $\mathrm{O}_{2}$ (Wong, 2009; Yang et al., 2013b). All fungal species cannot secrete all four extracellular enzymes which have been reported to oxidize persistent TrOCs. Apart from theses enzymes, intracellular enzyme systems, such as cytochrome $\mathrm{P} 450$, have also been reported to play important roles in the removal of some TrOCs (Golan-Rozen et al., 2011).

In previous studies, the removals of TrOCs by different species of WRF have been reported. Bouchiat et al. (2016) investigated the removal of four emergent pollutants (di(2-ethylhexyl)phthalate (DEHP), fluoranthene (Fl), aminomethylphosphonic acid (AMPA), and E1) by filamentous fungi (Fusarium oxysporum, Geotrichum galactomyces, Trichoderma harzianum, and Fusarium solani) in mineral medium for 10 days. Except for E1 which was not degraded by any fungi, AMPA was degraded at $69 \%$ by T. harzianum, and DEHP was completely degraded by $F$. oxysporum and $F$. solani after 10 days of incubation. Fl was not significantly degraded by G. galatomyces and $T$. harzianum, whereas the degradation by F. oxysporum and 
F. solani was moderate, as revealed Table 2 (42 and $12 \%$ respectively).

However, previous works showed that the results varied depending on the tested enzyme systems. Trametes versicolor, which seems to have a good potential for the degradation of micropollutants (Cruz-Morató et al., 2013; Nguyen et al., 2014b), secretes all four types of extracellular enzyme systems (laccase may be the predominant one in some strains). The cytochrome P450 system may be also involved in the first step of the degradation of some pharmaceuticals (Marco-Urrea et al., 2009). It allowed for high removal rates, especially with some of the most recalcitrant compounds such as CBZ, CFA, DCF, DIU in batch experiments (Bending et al., 2002; Marco-Urrea et al., 2009; Tran et al., 2010; Jelić et al., 2012a; Margot et al., 2013b). At least two different mechanisms using cytochrome P450 or laccase were described by Marco-Urrea et al. (2009) for the almost complete ( $\geq 94 \%$ ) removal of DCF during the first hour of incubation, using $T$. versicolor mycelia pellets in Erlenmeyer flasks. The cytochrome P450 system may also be involved in the first step of CFA and CBZ oxidation by T. versicolor (which reached $91 \%$ and $57 \%$ respectively after 7 days of incubation). On the contrary, extracellular fungal enzyme systems did not appear to play a significant role during the first step of degradation (Marco-Urrea et al., 2009). Intracellular enzymes may be involved in the biodegradation of KPF, propyphenazone (PPZ), fenoprofen (FEP), and GFZ, while laccase preferentially removed DCF, NPX, and indomethacin (IDM) among the targeted PhACs degraded by the whole fungal culture. Tran et al. (2010) noticed a complete removal of DCF, NPX, IDM, IBP, and FEP and partial degradation of other selected PhACs after $48 \mathrm{~h}$ of incubation with the 7-day-old liquid fungal culture, both in the presence and absence of a laccase mediator ABTS (2,2'-azino-bis-(3-ethylbenzothiazoline)-6sulfonate) (see Table 2). T. versicolor also seems to be able to degrade pesticides. Important degradations of DIU, ATZ, and terbuthylazine were achieved after 42 days of batch experiments (99\%, $>86 \%$, and $63 \%$ respectively), whereas for metalaxyl less than $44 \%$ was reached (Bending et al., 2002). At last, T. versicolor also showed a good ability to remove endocrine-disrupting compounds such as BPA, NP, or EE2 (Cajthaml et al., 2009) even recalcitrant anticancer drugs such as azathioprine, etoposide (more than $97 \%$ after 8 days in batch experiment) (Ferrando-Climent et al., 2015). Polychlorinated biphenyls (PCBs) can also be degraded by T. versicolor. Ruiz-Aguilar (2002) studied the degradation of a mixture of PCBs at high initial concentrations from 600 to $3000 \mathrm{mg} \cdot \mathrm{L}^{-1}$, in the presence of a non-ionic surfactant (Tween 80 ). PCB degradation ranged from 29 to $70 \%$ using $T$. versicolor in 10-day incubation tests.

Nevertheless, only a few studies related to fungi have focused on the degradation of PhACs from real urban wastewater under nonsterile conditions, in the presence of mixtures of contaminants at low concentrations (ng.L $\mathrm{L}^{-1}$ to $\mathrm{mg} . \mathrm{L}^{-1}$ ) as well as other active microorganisms. Cruz-Morató et al. (2013) used a batch fluidized bed bioreactor to evaluate the effects of non-sterile urban wastewater substrate on a T. versicolor culture. They concluded that T. versicolor can remain active when fed with real wastewater where bacteria and contaminants are present, if a source of nutrients such as glucose and nitrogen is also added to maintain a significant biological fungus activity. Using this batch FBR, around half of the detected PhACs (at environmentally relevant concentrations) achieved a complete removal, while $25 \%$ were partially removed (average removal of 35\% after 8 days). Regarding the other compounds, no degradation or very low degradation $(<20 \%)$ was observed. For instance, CBZ showed no removal from the real wastewater used. Furthermore, its concentration increased to 37\% after 8 days due to deconjugation of CBZ intermediates (Kovalova et al., 2012). Yang et al. (2013a) studied the removal of DCF and BPA using a MBR inoculated with $T$. versicolor and operated during three months under non-sterile conditions. They confirmed that biodegradation is the main mechanism for the removal of both compounds. Relatively stable removals of BPA (80-90\%) and DCF $(\sim 55 \%)$ were achieved by applying a HRT of two days. Besides, T. versicolor also seems to be able to degrade $\mathrm{CBZ}$ in aqueous medium using an air pulsed fluidized bed bioreactor operated in batch or continuous mode. Using the batch reactor, the $\mathrm{CBZ}$ removal achieved $96 \%$ within 2 days, whereas CBZ concentration decreased by more than a half (54\%), using the air pulsed fluidized bed bioreactor operated at steady state in continuous mode with a HRT of 3 days. However, according to Erlenmeyer flask batch experiments, CBZ (at 9 mg. $\mathrm{L}^{-1}$ ) was almost completely eliminated (94\%) after 6 days, while close to environmentally relevant concentrations (50 mg. $\mathrm{L}^{-1}$ ), $61 \%$ of the contaminant was degraded after 7 days (Jelić et al., 2012a). Studies on the relative contribution of biosorption compared to various modes of biodegradation (e.g., extracellular enzyme dependent or independent) during fungal removal of TrOC remain scarce. Nguyen et al. (2014b) confirmed that biodegradation was, over all studied compounds, the main mechanism of removal. However, hydrophilic compounds generally remained poorly removed which may indicate the importance of biosorption in subsequent degradation by whole-cell cultures. In addition, inhibiting the intracellular cytochrome P450 during the degradation of some TrOCs by whole-cell cultures resulted in a reduction in biodegradation efficiencies which may point out the importance of extracellular enzyme-independent catalytic pathways. The degradation profile of the tested TrOCs using a WRF fungal culture is quite different from that obtained using activated sludge processes.

The capacity of $P$. chrysosporium to remove TrOCs has also been evaluated by some authors despite the lack of laccase and VP in their enzymatic system (Hatakka, 1994). P. chrysosporium has been reported to achieve high removals in the case of some pharmaceuticals. The elimination of NPX and DCF was 100\% after 4 days of incubation in batch (Rodarte-Morales et al., 2011). In a subsequent study, Rodarte-Morales et al. (2012) used a stirred-tank reactor inoculated with free pellets of $P$. chrysosporium to remove PhACs. High removal efficiencies, collected in Table 2, were achieved for DCF, NPX, and IBU (94, 94, and 100\% respectively); CBZ removal varied from 24 to $63 \%$ between 20 and 50 days of operation. Using P. chrysosporium immobilized on polyurethane foam in a stirredtank reactor, removal efficiencies were $93 \%$ for DCF and IBP, up to $90 \%$ for NPX during the first 3 days then decreased between 65 and $77 \%$. Since some metabolites of these compounds have been identified in the reactors, their back transformation into parent compounds could explain the observed decrease in removal efficiency after day 3. A chemical balance between precursors and metabolites could also disadvantage the biodegradation of the active product. For antiepilectic and tranquilizers, the removal percentages were up to 50\% (Rodarte-Morales et al., 2012). The same FBR was operated 100 days with immobilized $P$. chrysosporium, DCF, IBP, and NPX were completely removed regardless of the continuous air flow (1 L.min ${ }^{-1}$ ) or pulsation of oxygen, and high removal efficiencies were observed for CBZ and diazepam (60-90\%) (RodarteMorales et al., 2012). Li et al. (2015) also reported an almost complete removal of NPX and a $60-80 \%$ removal of CBZ after two weeks, using a fixed-bed bioreactor packed with a mixture of WRF pellets and wood chips (see Table 2). However, after the 14th day, the removal efficiencies for both compounds suddenly dropped due to a possible contamination by other microorganisms. According to the studies, CBZ biodegradation experiments using WRF bioreactors presented high variations. $\mathrm{CBZ}$ either showed no removal at all after 7 days of incubation in batch experiment inoculated with a blended mycelial suspension of $P$. chrysosporium (Marco-Urrea et al., 2009); limited degradation $(<10 \%)$ during in vitro batch 
experiments, using LiP from $P$. chrysosporium (Zhang and Geißen, 2010), but high elimination was achieved with a novel plate bioreactor, using $P$. chrysosporium grown on polyether foam under non-sterile conditions (Zhang and Geißen, 2012). Endocrine disrupting compounds have also been degraded using P. chrysosporium cultures. For example, almost complete removal of NP (up to 90\%) has been reported using a 3 day-batch experiment (Cajthaml et al., 2009; Subramanian and Yadav, 2009), while only $30-50 \%$ of removal has been reported by Soares et al. (2005) after 25 days of incubation in aerobic batch experiments. Regarding pesticides, poor removal of CFA has been observed after 7 days of incubation with P. chrysosporium (Marco-Urrea et al., 2009). Besides, almost complete removal of DIU has been reported after 10 days in Erlenmeyer flasks and the results showed that the presence of this herbicide did not cause any drop in the biomass production (Coelho-Moreira et al., 2013). Although P. chrysosporium has been intensively studied as a model for the white-rot group of basidiomycete, there is an increasing evidence in the literature that $T$. versicolor can degrade xenobiotics more efficiently than P. chrysosporium or other species of WRF like Bjerkandura adusta, or Pleurotus ostreatus (Soares et al., 2005; Cajthaml et al., 2009; Marco-Urrea et al., 2009).

Enzymatic treatments seem very attractive as far as the removal of TrOCs from wastewaters is concerned. They consume less chemicals, water and energy and produce less wastes than other chemically catalyzed bioprocesses. Recent studies have investigated the capacity of laccase solutions to degrade a wide range of TrOCs that are persistent, using other biological processes. On the one hand, Margot et al. (2013a) investigated the ability of four strains of the bacterial genus Streptomyces (S. cyaneus, S. ipomoea, S. griseus and S. psammoticus) and the white-rot fungus T. versicolor to produce active extracellular laccase in biologically treated wastewater with different carbon sources. They concluded that T. versicolor was the most promising strain. Indeed, this fungus produced more than 20-times more laccase activity than S. cyaneus, the best candidate of the Streptomyces strains evaluated (especially in treated wastewater with forestry waste as the sole substrate). Besides, laccase from $T$. versicolor was more active than that from S. cyaneus near neutral $\mathrm{pH}$ and between 10 and $25{ }^{\circ} \mathrm{C}$ (conditions usually found in municipal wastewater) and presented faster degradation kinetics of DCF, BPA, and MFA (Margot et al., 2013a). On the other hand, purified or commercial laccase solutions showed high removal of DCF, NPX, TCS, NP, E1, EE2, and BPA, as collected in Table 2 (Kim and Nicell, 2006; Lloret et al., 2010; Tran et al., 2010), but the removal of CBZ, IBP, and CFA still remains low $(<40 \%)$ (Tran et al., 2010). Besides, a complete degradation of DCF was observed using LiP from P. chrysosporium at pH 3.0-4.5 with 3-24 ppm $\mathrm{H}_{2} \mathrm{O}_{2}$ (Zhang and Geißen, 2010). However, CBZ degradation was limited (mostly below 10\%) using LiP from P. chrysosporium (Zhang and Geißen, 2010) whereas it seems to be well oxidized (98\%) by MnP and VP produced by $P$. ostreatus after 32 days of incubation in Erlenmeyer flasks (Golan-Rozen et al., 2011). MnP solutions can also degrade efficiently methoxychlor (69\% after $24 \mathrm{~h}$ ) (Hirai et al., 2004), BPA (100\% after $12 \mathrm{~h}$ ) (Tsutsumi et al., 2001), and hormones such as EE2, E1 (>80\% after 8 h) (Suzuki et al., 2003). An innovative strategy based on the induction of hydroxyl radicals in T. versicolor using the quinone redox cycling have been studied by (Marco-Urrea et al., 2010). The results of this study showed a high percentage of CBZ removal (80\%) after 6 h of batch experiment.

Redox mediators act as electron shuttles between the oxidizing enzyme and target compounds to enhance fungal enzyme-catalysis depending on both TrOC and mediator molecular structures (Kim and Nicell, 2006). In the case of laccase, two oxidative steps are involved. First, laccase oxidizes the mediator which finally transfers the electron to the substance of interest. The most commonly used redox mediators are 1-hydroxybenzotriazole (HBT), ABTS or violuric acid (VA) (Fabbrini et al., 2002). The influence of different mediators (synthetic and natural) and of their concentration on the laccase-based oxidation system were evaluated by Lloret et al. (2010). Among the different selected natural or synthetic mediators, syringaldehyde (SA) or HBT as well, greatly enhanced the action of the laccase enzyme, in the case of the biodegradation of estrogens and DCF (100\% after $15 \mathrm{~min}$ and $1 \mathrm{~h}$ of incubation respectively). The other natural mediators (vanillin, p-coumaric acid, or ferulic acid) presented significantly high efficiencies, allowing to achieve percentages of removal ranging from $80 \%$ to $100 \%$ after 24 h of enzymatic reaction on DCF, NPX, EE2, E3, and E1. HBT addition also improved the removal of pentachlorophenol (31-91\%), DCF (70-95\%), and NPX (20-98\%) (Nguyen et al., 2013b). Tetracycline antibiotics were completely eliminated after $1 \mathrm{~h}$ using a treatment with a laccase-HBT system (Suda et al., 2012). Furthermore, Hata et al. (2010) suggested that repeated addition of laccase and HBT is effective in CBZ removal. They observed a decrease of $22 \%$ of CBZ concentration after $24 \mathrm{~h}$ using a single treatment, and a drop of $60 \%$ after $48 \mathrm{~h}$ using a repeated treatment. Even though the use of redox mediators seems to be relevant to improve micropollutant removal in an enzymatic system, these substances are somewhat toxic and further studies are needed to evaluate their chronic toxicity and the effluent toxicity.

Previous studies have confirmed significant removal of TrOCs by WRF under sterile batch test conditions. Only a few studies have been conducted using a continuous flow fungal reactor in a nonsterile environment or a combination of white-rot fungi and activated sludge. Yang et al. (2013a) focused their study on the removal of DCF and BPA using a fungal MBR in non-sterile conditions. In these conditions and with a HRT of 2 days, relatively stable removal rates for BPA (80-90\%) and DCF (about 55\%) were observed. The degradation of 30 TrOCs using a WRF-augmented MBR was investigated by Nguyen et al. (2013b) and collected in Table 2. The obtained results suggest that activated sludge and WRF would be complementary. Indeed, TrOCs resistant to bacterial degradation such as DCF, TCS, NPX, and ATZ could be degraded by laccase and further enhanced using HBT as a redox mediator (from 22 to 93\%). Nevertheless, a low removal was observed for some compounds that are well removed by simple CAS treatment such as IBP, GBZ, and amitriptyline. CAS and TrOCs degradation ability of the fungalenzyme was also studied during batch tests using crude enzyme extracts (laccase). Over the 30 tested molecules, 13 significant enzymatic degradations were observed. Some other molecules showed low or negligible degradation. The variation of enzymatic degradation efficiencies is attributed to the differences in chemical structure of the selected TrOCs.

As in the case of CAS or MBR treatments, TrOC removal by enzymatic systems is dependent upon a range of operating factors such as $\mathrm{pH}$, temperature, molecular structure, and so on. For example, because laccase promotes the single electron oxidation of phenols (Yang et al., 2013b), TrOC molecules with a hydroxyl group attached to a benzene ring are highly degraded (70-90\%) by laccase extracts. The optimal temperature for laccase production is $25-30{ }^{\circ} \mathrm{C}$ and the optimal temperature for peroxidases production is $37-40^{\circ} \mathrm{C}$ (Cabana et al., 2007). PH is another controlling factor that can influence the development of fungal cultures, and thus the removal efficiencies of TrOCs using such cultures. Margot et al. (2013b) investigated the optimal conditions for the transformation of two pharmaceuticals, DCF and MFA, one biocide, TCS, and one plastic additive (BPA) by laccase from T. versicolor. Batch experiments were conducted in spiked solutions at $\mathrm{pH}$ varying

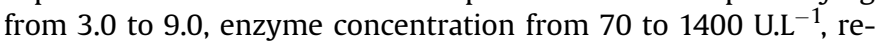
action times $\left(0-26 \mathrm{~h}\right.$ ) and temperature $\left(10,25\right.$ and $\left.40^{\circ} \mathrm{C}\right)$. They concluded that all four factors had a significant effect on the 
micropollutant removal, but that the greatest effect was obtained with $\mathrm{pH}$. Even though, optimal conditions were compounddependent, they were found to be between $\mathrm{pH}=4.5$ to 6.5 and between $25{ }^{\circ} \mathrm{C}$ to more than $40{ }^{\circ} \mathrm{C}$ (Margot et al., 2013b). Other studies evaluated the efficiency of some enzymes depending on $\mathrm{pH}$ values. For instance, DCF was completely degraded by LiP in the $\mathrm{pH}$ range of $3.0-4.5$ whereas only $10 \%$ was degraded at $\mathrm{pH}=6.0$ due to the inactivation of LiP at higher $\mathrm{pH}$ (Zhang and Geißen, 2010). However, $\mathrm{pH}=6.0$ was reported as the optimum $\mathrm{pH}$ for laccasecatalyzed treatment of estrogens (Auriol et al., 2007) and BPA by purified laccase from Trametes villosa (Fukuda et al., 2001). The optimum $\mathrm{pH}$ for the degradation of TCS by laccase from $T$. versicolor was observed at $\mathrm{pH}=5.0$ (Kim and Nicell, 2006), while the optimal $\mathrm{pH}$ for laccase to degrade chlorophenols was around 5.5 (Zhang et al., 2008).

A few studies have investigated the degradation of TrOCs under continuous operation using an enzymatic membrane reactor (EMR). Lloret et al. (2012a,b) first used a fed-batch reactor to evaluate the effect of process parameters such as gas composition (air or oxygen), pH, enzyme concentration; then the continuous degradation of E1 and E3 was investigated by an EMR, composed of a stirred tank reactor coupled with an ultrafiltration membrane. The highest removal rates under steady state operation reached up to $95 \%$ for E1 and nearly complete degradation for E3. Nguyen et al. (2014a) studied the effect of a redox mediator addition to a continuous EMR on the removal of different TrOCs. Under these conditions, high removals of BPA and DCF were achieved ( $>85 \%$ and $>60 \%$, respectively). They were improved to $>95 \%$ and $>80 \%$, respectively, by adding a natural redox-mediator compound, SA ( $5 \mu \mathrm{M})$, to the culture medium. In addition, the use of EMR can facilitate the separation of enzymes from products and substrates due to the semi-permeable membrane, and thus decrease the losses in enzymes that are often washed out with the treated effluent when using conventional bioreactors (Lloret et al., 2012a,b).

Even though, the use of WRF or immobilized enzyme showed interesting efficiencies regarding the removal of organic micropollutants, their implementation in a biological treatment seems hardly effective because of the overgrowth by the normal biomass. Moreover, this biological treatment could present a significant cost for municipal WWTPs, but may be an interesting alternative for industrial wastewaters.

\subsubsection{Bacteria}

The use of specific bacteria has often been investigated to remove PCBs or PAHs (Haritash and Kaushik, 2009; Murínová et al., 2014; Isaac et al., 2015; Kuppusamy et al., 2016). However, only a few authors, whose results are gathered in Table 2, have tried to use specific bacteria isolated from activated sludge to remove PhACs. Li et al. (2013) studied the degradation of CBZ by a bacterium which can use CBZ as its sole source of carbon and energy. This strain was identified as Pseudomonas sp. by the 16S rRNA gene sequence. Pseudomonas sp. CBZ-4 can effectively degrade CBZ under optimal conditions ( $\mathrm{pH} 7.0,10{ }^{\circ} \mathrm{C}$, mechanical stirring). After $144 \mathrm{~h}$ of incubation, the average removal rate of CBZ reached $46.6 \%$ (Li et al., 2013). Another strain of Pseudomonas sp., Pseudomonas putida, can be used for the oxidation of some micropollutants. As an example, DCF is rapidly degraded during ongoing manganese oxidation by P. putida MnB6 (Meerburg et al., 2012). A co-metabolic removal of DCF has been proved to be the main degradation path during active $\mathrm{Mn}^{2+}$ oxidation by P. putida. Regarding P. putida, Kuddus et al. (2013) showed the production of laccase enzyme from P. putida MTCC 7525 was achieved at $30^{\circ} \mathrm{C}$ at $\mathrm{pH}=8.0$ after $108 \mathrm{~h}$ of incubation. Besides, the optimal activity of the purified enzyme was observed at $\mathrm{pH}=8.0$ and $40^{\circ} \mathrm{C}$. This bacterium, isolated from soil samples containing sawdust and dairy effluents, was used in order to treat synthetic dyes and industrial effluents. The results respectively showed $74-93 \%$ and $58-68 \%$ of decolorization within $24 \mathrm{~h}$ of incubation (Kuddus et al., 2013). Furthermore, YanzeKontchou and Gschwind (1994) observed up to 50\% of mineralization for ATZ using Pseudomonas DSM93-99 in batch experiments.

Streptomyces sp. is also of some interest for the degradation of micropollutants. Streptomyces MIUG 4.89 was studied by Popa Ungureanu et al. (2014) for its ability in CBZ biodegradation during cultivation in a submerged system under aerobic conditions at an initial CBZ concentration of $0.2 \mathrm{mg} \cdot \mathrm{L}^{-1}$. A $30 \%$ of CBZ biotransformation was yielded under optimal conditions: liquid medium containing 6.5 g.L $\mathrm{L}^{-1}$ glucose and 2 g.L $\mathrm{L}^{-1}$ yeast extract, inoculated at $7 \%(\mathrm{v} / \mathrm{v})$ and cultivated at $\mathrm{pH} 6.0$, during 7 days of incubation at $25{ }^{\circ} \mathrm{C}$ and $150 \mathrm{rpm}$. Besides, Castillo et al. (2006) observed the degradation of DIU by 17 Streptomyces strains isolated from agricultural and non-agricultural soils. Twelve strains degraded the herbicide by up to $50 \%$ and four of them by up to $70 \%$. Strain A7-9, belonging to the $S$. albidoflavus cluster, was the most efficient organism ( $95 \%$ of degradation after 5 days of incubation and complete degradation after 10 days).

DIU can also be degraded by Sphingomonas sp., even at low pollutant concentrations ( $\left.\mu \mathrm{g} . \mathrm{L}^{-1}\right)$. Sphingomonas sp. SRS2 is capable of DIU mineralization with an initial degradation pathway consisting of two successive $N$-demethylations, followed by a cleavage of the urea group that gives 3,4-dichloroaniline (3,4-DCA). $86 \%$ of ${ }^{14} \mathrm{C}$-carbonyl-diuron was mineralized to ${ }^{14} \mathrm{CO}_{2}$ within 72 days. Moreover, the mineralization activity can be enhanced by combining SRS2 with the 3,4-DCA-mineralizing Variovorax sp. SRS16 (Sorensen et al., 2003). In other studies, Sphingomonas sp. has been used to remove some PAHs. Rentz et al. (2008) showed that concentrations around $1.2 \mu \mathrm{g} . \mathrm{L}^{-1}$ of benzo[a]pyrene (BaP) were completely removed within $20 \mathrm{~h}$ of batch experiments when Sphingomonas yanoikuyae JAR02 was grown on salicylate. S. yanoikuyae JAR02 uses salicylate as an inducer, as well as a carbon and energy source. Indeed, aerobic bioremediation of high molecular weight PAH uses a co-metabolic degradation that requires a carbon/energy source, an inducer of catabolic enzymes, and oxygen (Rentz et al., 2008). Guo et al. (2010) also studied the degradation of a mixture of PAHs comprising phenanthrene (Phe), $\mathrm{Fl}$, and pyrene (Pyr) by Sphingomonas strains isolated from mangrove sediments (see Table 2). Phe was degraded by more than $50 \%$ and $\mathrm{Fl}$ was degraded between 30 and 60\%, but Pyr degradation was less than $30 \%$ after 7 days of batch experiments. A co-culture of Sphingomonas and Mycobacterium strains enhanced the degradation of all three PAHs (complete removal after 7 days) (Guo et al., 2010). Regarding pharmaceuticals, Murdoch and Hay (2005) studied the degradation of IBP using Sphingomonas sp. strain Ibu-2 isolated from a WWTP, based on its ability to use IBP as a sole carbon and energy source. They observed a complete removal after $80 \mathrm{~h}$ of batch experiments.

Widehem et al. (2002) isolated and characterized Arthrobacter sp. N2 from soil treated over several years with DIU. This strain was able to aerobically transform DIU into 3,4-DCA in pure culture, either alone, or in the presence of alternatives carbon sources. Besides, Arthrobacter globiformis D47 was shown to degrade a range of substituted phenylurea herbicides in soils because of two plasmids of approximately $47 \mathrm{~kb}$ and $34 \mathrm{~kb}$. This strain was tested by Turnbull et al. (2001) for its ability to degrade DIU, which demonstrated that the degradative genes were located on the $47-\mathrm{kb}$ plasmid. When A. globiformis D47 was added to soil samples, the strain was able to degrade other urea pesticides ( $>90 \%$ after 10 days), such as chlortoluron, isoproturon, linuron, monolinuron, and monuron, initially introduced at $20 \mu \mathrm{g} . \mathrm{L}^{-1}$. 


\subsection{Factors limiting the biodegradation in wastewater treatment plants}

Several methods have been tested in WWTPs in order to remove micropollutants from effluents, but these physical, chemical, or biological treatments did not show significant results. The advanced oxidation processes using $\mathrm{O}_{3}$, UV, Fenton showed high removals, but generated some byproducts whose toxic effects and risks on health are still unknown (Benner et al., 2013). Regarding treatments using filtration, membrane fouling is the main limit because of the high organic matter content characteristic of wastewaters. Besides, these processes involve high energy requirements and important maintenance costs (Ordóñez et al., 2014). Submerged membrane systems need frequent air scouring to reduce cake deposit on them and to generate localized cross-flow conditions along the membrane surface. Some studies investigating membrane fouling in MBR processes have reported the significance of colloidal particles as an important factor contributing to fouling development. Colloids are responsible for $25-50 \%$ of the total measured fouling (Defrance et al., 2000; Bouhabila, 2001).

Furthermore, as stated above, the removal of compounds, and specially xenobiotics, using CAS is often not mainly due to biodegradation, but also to adsorption on activated sludge flocs, and to a less extent to air stripping. Many micropollutants must be considered stable in biological processes for municipal wastewater treatment (Falås et al., 2016), and due to adsorption they are just transferred to another phase, and thus still released in the environment. They are not degraded into less toxic species and they might cause health problem again (Dionisi, 2014). Biodegradation can only occur when the substrate is dissolved in the liquid phase. Because of the competition between air stripping and adsorption on microorganisms, the concentration in the liquid, and thus the substrate concentration available for biodegradation is reduced (Byrns, 2001).

Regarding enzymatic membrane processes, membrane fouling, enzyme retention, and enzyme activity decay are responsible for strong limitations on the performance of EMRs. This seems to be in tight connection with several phenomena such as catalyst leakage, but also enzyme denaturation due to various factors including physical ones ( $\mathrm{pH}$, temperature, shear stress), or chemical and biological inhibitors. Regarding shear stress, the effect of this factor has been a subject of discussion for Rios et al. (2004) since shear stress seems more difficult to characterize than enzyme leakage. Other authors, such as Jaspe and Hagen (2006), found no evidence of relationship between shear rates and the destabilization of the studied folded protein (horse cytochrome c, 104 amino acids). Moreover, Mendoza et al. (2011) observed that denaturation enzymes may be further exacerbated when a wastewater containing the target pollutant is continuously introduced into the reactor. Lloret et al. (2012b) observed no enzyme denaturation within a short $8 \mathrm{~h}$-period during the evaluation of continuous $\mathrm{TrOC}$ removal by an EMR, but beyond $24 \mathrm{~h}$ of continuous operation, a gradual drop in enzymatic activity was recorded. The observed decrease was due to enzyme denaturation rather than to the permeation of enzyme through the membrane, because no enzyme was detectable in the permeate.

To ensure the technical and economical viability of such EMR processes at industrial scale, more studies need to be conducted. Because of the huge volume of wastewaters, and thus the important quantities of enzymes that are needed, reactors with free enzymes may not be an economically viable solution for wastewater treatment. Besides, a complementary treatment may be needed at the end of such processes to remove the enzymes from the effluent. Nevertheless, for industrial-scale requests, using immobilized enzymes could be an interesting solution to decrease the cost, by reusing the biocatalyst. In addition, enzyme immobilization generally results in an enhancement of the biocatalyst stability even if enzymatic decay is still observed with time. This also increases the contact surface between enzymes and substrates, and maintains a good catalytic efficiency over many reaction cycles (de Cazes et al., 2014). As a consequence, processes with enzymes supported on a solid phase, or using cross-linking enzymes aggregates, represent interesting options to remove micropollutants.

\section{Areas for improvement}

\subsection{Hybrid process description}

As it has been previously explained in this paper, conventional processes based on activated sludge are often not sufficient to ensure high removals for most organic micropollutants. As a consequence, different alternative technologies, such as hybrid processes which are a combination of two or more treatment processes, have been studied that may appear to be effective to remove micropollutants. Indeed, the removal of some recalcitrant compounds can be improved with the combination of two processes due to synergistic effects. For instance, the addition of activated carbon can enhance the elimination of poorly biodegradable organic compounds by adsorption (Alvarino et al., 2016a). The combination of biofilm with suspended biomass can also improve the potential biodegradation of organic micropollutants due to an enhancement of the biodiversity into the systems.

The use of a biofilter system containing a fixed biofilm has been studied with a main focus on porous media biofilm processes such as sand filters (Escolà Casas and Bester, 2015). As SRT is an important factor with respect to TrOCs' removal in classical systems based on suspended biomass cultures, interesting results can be expected using low loaded biofilm processes that will tend to promote a more diverse bacterial population. Joss et al. (2004) evaluated the removal of estrogens obtained with a full-scale submerged biofilm reactor using a Biostyr ${ }^{\mathrm{TM}}$ system as a support and a reference for activated sludge process. They showed only slightly lower removal in the biofilm reactor, despite a much longer HRT in the activated sludge process. These results suggested that the shorter reaction time in the biofilm reactor can be compensated by a higher biomass concentration and/or a higher pharmaceutical removal capacity per unit of biomass, probably associated to the development of slow growing bacteria in the biofilm. Attached-growth processes thus offer a number of advantages mostly linked to an enlargement of the range of possible active strains, due to the development of slowgrowing microorganisms on the carrier media. The acidic pharmaceuticals such as IBP, DCF KPF, or NPX removals during batch experiments using activated sludge on the one hand, and suspended biofilm carriers on the other hand (AnoxKaldnes ${ }^{\mathrm{TM}}$ type $\mathrm{K} 1$ media) were compared by Falås et al. (2012). In their subsequent study, during batch experiments, Falås et al. (2013) evaluated the efficiency of a hybrid suspended \& attached growth process obtained by combination of biofilm carriers with a free activated sludge. Results were used to extrapolate the micropollutant removal at full-scale. The model estimations indicated that, in hybrid biofilm activated sludge processes, the attached biomass can significantly contribute to the removal of some micropollutants, such as DCF. In this process, two different communities of bacteria have been observed such as a slow growing community in the carrier biomass, and ammonia and nitrite oxidizing bacteria in the free biomass (Falås et al., 2013). Along with such biofilm technologies, moving bed biofilm reactors (MBBR) also seem to be a promising solution to remove micropollutants. In this context, Casas et al. (2015) proposed to remove pharmaceuticals from hospital wastewaters using a MBBR. In this system, the biofilm 
grew on small (1-4 cm diameter) plastic carriers which are suspended in a reactor. In this case, the process can be as robust as activated sludge treatment (because of the enhancement of nitrification), and has the advantage of a biofilm reactor regarding the presence of slow-growing bacteria. In a subsequent study Escolà Casas et al. (2015) evaluated the ability of a combination of suspended activated sludge and biofilm (polyethylene carriers for biofilm growth are suspended within activated sludge) on the removal of different micropollutants. The hybrid process Hybas ${ }^{\mathrm{TM}}$ (VeoliaWater Technology), based on the integrated fixed-film activated sludge technology, contains two separate biomasses. This process combines a fast growing biomass with low sludge age in free activated sludge flocs, and a slow-growing biomass with high sludge age on MBBR-carriers. For this study, a pilot plant consisting in a series of one activated sludge reactor, two hybrid processes and one MBBR have been established and successfully processed during 10 months under continuous operation (Escolà Casas et al., 2015).

Apart from plastic biofilm carriers, other materials can be used for attached-growth microorganisms, such a polyurethane sponge. The efficiency of sponge-based MBBRs in removing organic matter, among dissolved organic carbon, nitrogen and phosphorus have been investigated by some authors such as Ngo et al. (2008). Luo et al. (2014a) evaluated the short-term removal rates of five micropollutants during 24 h-batch experiments using nonacclimatized and acclimatized sponge supported biomasses (acclimatization to the synthetic wastewater without addition of micropollutants for 20 days until TOC, TN, and $\mathrm{PO}_{4}-\mathrm{P}$ removal became stable). Then, a continuous bench-scale MBBR was set for a long-term assessment (100 days' period) of selected micropollutant removal. In their subsequent study, Luo et al. (2015) compared the removal of micropollutants using a conventional MBR and a hybrid MBBR-MBR system. Results notably showed that the hybrid MBBR-MBR system could effectively remove most of the studied micropollutants thanks to biodegradation pathways, while the conventional MBR was less effective for compounds such as KPF, CBZ, PRM, BPA, and E3. Besides, membrane fouling was minimized with the hybrid system because of the alteration of the soluble microbial products and extracellular polymeric substances. Furthermore, an enhancement of the organic micropollutant removal was achieved with an innovative plant configuration based on an upflow anaerobic sludge blanket (UASB) reactor coupled to a hybrid aerobic MBR at ambient temperature and low HRT. This process demonstrated to be a sustainable and robust system which achieved high COD removal performances and better micropollutant removal efficiencies than conventional technologies (Alvarino et al., 2016b). The use of biofilm surfaces in a hybrid process seems interesting for the enhancement of the removal of organic micropollutants in small WWTPs, especially if they have to be extended in order to improve nutrient removal. Besides, the cost of such process should be moderated compared to an additional treatment as activated carbon adsorption.

Finally, due to the increasing interest in using enzymes to degrade micropollutants from wastewater, some novel processes of enzymatic treatment have been suggested, combining filtration and enzyme reactors. Ba et al. (2014) proposed a hybrid bioreactor (HBR) containing cross-linked enzymes aggregates of laccase combined with polysulfone hollow suspended fibers operated continuously to remove three pharmaceuticals (ACE, CBZ, and MFA). Synergistic action of the microfiltration and cross-linked enzymes aggregates of laccase (CLEA-Laccase) achieved significant eliminations from aqueous solution. The HBR demonstrated elimination rates up to $93 \%$ after $72 \mathrm{~h}$ for CBZ and near complete elimination was achieved within $24 \mathrm{~h}$ of treatment for ACE and MFA. Furthermore, Nguyen et al. (2015) evaluated the laccase- catalyzed degradation of 30 TrOCs using an EMR equipped with an ultrafiltration membrane. Using this process, phenolic compounds were more effectively eliminated than the non-phenolic ones due to the formation of a dynamic layer of laccase over the membrane surface which facilitated their subsequent enzyme degradation.

\subsection{Effects of operating conditions on removal efficiency}

Table 3 (Appendix A: supplementary data) presents the efficiency of some hybrid process on the removal of organic micropollutants found in selected studies.

\subsubsection{Effects of HRT and SRT}

Contrary to conventional treatments, the influence of process parameters such as HRT and SRT was not often evaluated in the case of newly developed processes. Although for hybrid systems including biofilm, the evaluation of the SRT is harder than in CAS, the biofilm biomass typically has a higher age than the suspended biomass, and the biodiversity in the biofilm is enhanced. The COD load per surface of biofilm should be an important parameter to monitor for the evaluation of a biofilm system.

Only a few studies used hybrid processes with different HRTs or SRTs, but studying the variation of these parameters did not appear as the aim of the study. For instance, Falås et al. (2012) evaluated the removal of DCF, KPF, GFZ, NPX, IBP, MFA, and CFA, whose results are collected in Table 3, using suspended biofilm carriers in order to compare the removal rates of theses micropollutants per unit of biomass to the removal rates obtained with a nitrifying activated sludge sampled from different WWTPs. Four of the seven selected WWTPs are using MBBR treatment operated at different HRTs (from $6-7 \mathrm{~h}$ to $35 \mathrm{~h}$ ) to remove micropollutants. Usually typical aerobic HRTs for nitrifying activated sludge processes are around 5-10 h and around 2-4 h for MBBR processes. Results showed in the case of several pharmaceuticals that considerably higher removal rates can be expected with MBBR processes compared to nitrifying activated sludge processes. All the selected compounds were removed faster from wastewater using low HRT in MBBR treatment (complete removal was achieved after $5 \mathrm{~h}$ for KPF, GFZ, NPX, IBP and more than $60 \%$ was achieved after $10 \mathrm{~h}$ for DCF, MFA, and CFA). Falås et al. (2012) suggested that high sludge ages and microbial adaptation to the substrate gradients in biofilms could favor degradation of some pharmaceuticals.

Furthermore, Di Trapani et al. (2013) studied organic matter removal and nitrification using a hybrid MBBR fed with municipal wastewater previously subjected to primary clarification. This process was operated at different values of the mixed liquor SRT and temperature in order to highlight the influence of these parameters. The authors hypothesized that nitrification could be maintained at far lower SRT's than in conventional activated sludge systems and under the application of high organic loading rates. The pilot plant showed very high nitrification activity and was capable of removing the organic matter at loading rates up to $3 \mathrm{~kg}$.TCOD. $\mathrm{m}^{-3} \cdot \mathrm{day}^{-1}$. Thanks to ammonia uptake rate batch tests, an increase of biofilm nitrification activity was observed when the mixed liquor SRT decreased. Results suggested that the hybrid reactor should be run under low mixed liquor SRT values in order to enhance ammonium removal efficiency, thus confirming that nitrification could be maintained at far lower SRT's than in CAS systems.

The influence of process parameters such as SRT and HRT has been scarcely studied for hybrid processes and further researches seem necessary in order to confirm and complete the results suggested by conventional processes' investigations. However, the biomass retention time in biofilm systems is not easily controlled 
even if low loaded biofilm processes tend to favor slow-growing bacteria, which seems promising for the pharmaceutical removal. A shorter reaction time in the biofilm reactor is nonetheless compensated by a higher biomass concentration and/or a higher micropollutant removal capacity per unit of biomass.

\subsubsection{Effect of the DO concentration}

Biofilm reactors produce an effluent with different particulate characteristics compared to activated sludge, in terms of floc structure, particle size distribution, and so on. Some studies have shown that a too strong aeration can have an influence on biofilm breakage and can promote the formation of colloidal particles which could enhance membrane fouling (Leiknes and Ødegaard, 2007). However, redox conditions within the biofilm may also have an influence on the removal of different micropollutants using attached-growth processes. Indeed, if controlled properly, attached-growth processes can lead to different redox conditions at different thicknesses within the biofilm. The coexistence of oxic and anoxic conditions in the overall biofilm volume can facilitate nutrient removal, and enhance the elimination of a wider spectrum of micropollutants. For instance, oxic conditions prevailing at the surface of the biofilm and among free biomass, improve the removal of molecules such as NPX, EE2, ROX, and ERY. On the contrary, anoxic conditions prevailing in the depth of the biofilm, favor the degradation of molecules such as CBZ, CFA, DCF, and iodinated X-ray contrast media such as tri-iodinated benzene derivatives (Drewes et al., 2001; Zwiener and Frimmel, 2003; Suárez et al., 2010). Falås et al. (2013) noticed that the anoxic and oxic conditions successively applied during nitrogen removal cycle affected the micropollutant removal capacity. Some compounds such as BZF, atenolol, CLA could be removed under both oxic and anoxic conditions whereas other compounds were only removed under oxic conditions (KPF, METOP, MFA, or valsartan). KPF, MFA, and valsartan were degraded faster by the attached biomass than the suspended biomass, but it was the opposite for METOP and 4-/ 5-methylbenzotriazole (see Table 3). The rate constants obtained for these selected micropollutants indicate that the presence of available molecular oxygen is critical for the degradation of several micropollutants.

Furthermore, an integrated process comprising of an anaerobic pre-treatment before an aerobic process may be an alternative to enhance micropollutant removal. Alvarino et al. (2016b) investigated the fate of 16 TrOCs in an integrated anaerobic/aerobic process. During 6 months of operation an UASB reactor coupled to a hybrid aerobic MBR showed promising results compared to a conventional process (see Table 3 ). CBZ, DZP, DCF, EE2, and fluoxetine were poorly removed $(<40 \%)$, E1 was recalcitrant under anaerobic operation $(<20 \%)$, but well removed during aerobic step (>65\%), while some molecules such as AHTN and ADBI were significantly removed by the UASB reactor (about 50\%). Regarding degradation pathways, biotransformation seemed to be the main removal mechanism except for musk fragrances.

In sum, in addition to being substance specific and dependent on the composition of the biomass, micropollutant degradation is also dependent on the redox conditions. The degradation capacity can differ significantly between the suspended and attached biomass in hybrid biofilm/activated sludge processes.

\subsubsection{Effects of $p H$ and temperature}

Di Trapani et al. (2013) investigated the removal of organic matter and nitrification through a MBBR process using different SRT values and different temperatures (between 10 and $14{ }^{\circ} \mathrm{C}$ ). Their results showed that the use of this process under low mixed liquor SRT values and low temperatures can achieve a high ammonium removal efficiency, since a large part of nitrification activity will take place in the slow growing biofilm. Temperature plays a key role on the nitrification activity, even if under low temperatures, the increased oxygen solubility could likely hinder the drop in nitrifiers biological activity.

To date, the influence of $\mathrm{pH}$ and temperature on the micropollutant biodegradation using hybrid processes has been very scarcely examined. Further investigations have to be undertaken to support the conclusions found using conventional processes, or to complete and expand the current knowledge.

\subsection{Effects of microorganism communities or enzymes extracted from microorganisms on removal efficiency}

As for the bioreactor configuration, a few studies tend to assess what are the best types of microorganisms to remove some given organic micropollutants. Some of them used activated sludge to form a suspended biofilm, while others tried to use enzymes produced by WRF and combined with activated sludge.

Table 4 (Appendix A: supplementary data) presents the removal of selected micropollutants using hybrid bioreactors, depending on microorganism communities or enzyme extracted from microorganisms.

\subsubsection{Biofilm}

Today's knowledge on micropollutant and specially PhAC removal using biofilm systems is rather limited. However, Zwiener and Frimmel (2003) investigated the biodegradation of three active pharmaceuticals using a biofilm reactor formed from activated sludge biomass during a $48 \mathrm{~h}$-period. The biodegradation obtained for CFA, IBP, and DCF using an oxic biofilm reactor was close to the one obtained using a reference pilot activated sludge plant. With the reference pilot plant, CFA and DCF were not eliminated (about $5 \%$, whereas the concentration of IBP was decreased to approximately $35 \%$. On the contrary, using the anoxic BFR, all three substances, showed elimination resulting in a decrease of their concentration to values between 60 and $80 \%$ of their initial concentration (see Table 4).

Moreover, Paje et al. (2002) evaluated the degradation of DCF by a river biofilm. Degradation was possible after acclimatization. Adapted biofilms showed that a removal of $10-25 \%$ of the initial concentration could be achieved within 4 days. Besides, the results showed that DCF can inhibit many microorganisms such as Staphylococcus epidermidis (Perilli et al., 2000) that would usually compromise a lotic biofilm. Indeed, DCF disrupted normal biofilm development in lotic systems, while some microorganisms such as Cytophaga-Flavobacterium were able to survive and even to degrade this compound.

Still little is known about the biomass capacity to remove pharmaceuticals in biofilm systems and whether this capacity differs from that of activated sludge.

\subsubsection{Activated sludge and suspended biofilm carriers}

The acidic pharmaceutical removal during batch experiments using activated sludge and suspended biofilm carriers (AnoxKaldnes $^{\mathrm{TM}}$ type K1 media) were compared by Falås et al. (2012). Similar removal rate constants for IBP (around 2-5 L.g ${ }^{-1}$ of bio-

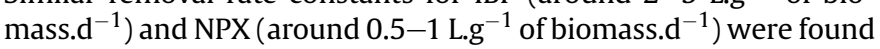
in both biofilm carriers and activated sludge biomasses, whereas significant higher rate constants for DCF, KPF, GFZ, CFA, and MFA were found with the carriers biomass $(0.06-0.38,0.9-3.6,0.6-2.1$, $0.05-0.17$ and $0.08-0.48{\mathrm{~L} . \mathrm{g}^{-1}}^{-1}$ of biomass.d $\mathrm{d}^{-1}$, respectively), as compared to the activated sludge biomass $(0-0.02,0.01-0.32$, $0.01-0.27,0-0.04$ and $0-0.06 \mathrm{L.g}^{-1}$ of biomass. $\mathrm{d}^{-1}$, respectively). In their subsequent study, Falås et al. (2013) evaluated the efficiency of a hybrid suspended/attached growth process obtained by 
combination of biofilm carriers and activated sludge. In most cases, considerably higher micropollutant removal rates were observed for the biofilm compared to the free biomass. This study confirmed that a reactor with a fixed biomass achieved rapid removals for DCF (1.3-1.7 L.g $^{-1}$ of biomass.d $\left.{ }^{-1}\right)$ and TMP (1.0-3.3 L.g $^{-1}$ of biomass. $\left.d^{-1}\right)$, while the elimination of both compounds in the suspended-free biomass reactor was insignificant $\left(\leq 0.1{\mathrm{~L} . g^{-1}}^{-1}\right.$ biomass.d ${ }^{-1}$ ) (Falås et al., 2013). Results of this study demonstrated that the degradation rate of organic micropollutants in biological wastewater treatment is substance specific and dependent on the composition of the biomass.

Casas et al. (2015) also evaluated the ability of a combination of suspended activated sludge and biofilm on the removal of different micropollutants from hospital wastewater using three MBBR in series. The authors noticed that the degradation of these micropollutants occurred in parallel with the removal of COD and nitrogen which suggest a co-metabolism pathway. Besides, the efficiency of each MBBR reactor was also evaluated. While the amount of biomass was decreasing from the first to the last reactor, the specific activities ( $\mathrm{K}_{\mathrm{bio}}$ ) of the biomass, which are the removal rate constants corrected by the amount of biomass per reactor volume, were increasing along the reactors succession. In a subsequent study, Escolà Casas et al. (2015) evaluated the efficiency of a pilot plant consisting in a series of one activated sludge reactor, two hybrid processes, and one MBBR during 10 months under continuous operation. Results, showed that removal of organic matter and nitrification mainly occurred in the first reactor which is well designed for COD or nitrogen removal and other compounds that are easily degraded by activated sludge biomass. Pharmaceuticals were globally removed efficiently, as revealed in Table 4. Batch experiments showed highest removal rate constants of the pharmaceuticals in the activated sludge reactor. However, during the continuous flow experiments, a concentration increase of compounds such as CBZ, venlafaxine, METOP, or SMX was observed in the first reactor with activated sludge. This phenomenon can occur due to a de-conjugation by bacterial enzymes of the compounds formed by sulfation, glucuronidation and acetylation during phase II of human metabolites, and eliminated via urine or feces. Another possibility may be the transformation of metabolites from other parent compounds (Kovalova et al., 2012). Besides, a better removal (close to 20\%) was noticed for these compounds in the other reactors containing activated sludge and biofilm carriers, which improved the amount of biomass per reactor volume.

The micropollutant removal rates obtained by Luo et al. (2014a) using a continuous bench-scale MBBR was of the same order of magnitude than the ones obtained with classical processes (activated sludge and MBR). IBP, salicylic acid (SLA), PRM, and NPX were efficiently eliminated using this particular process (93.7\%, 91.1\%, $83.5 \%$, and $81.1 \%$ respectively). The high removal efficiency could be ascribed to the presence of strong electron donating (readily biodegradable) functional groups (e.g., $-\mathrm{OH}$ ) on these compounds. KPF, ACE, metronidazole, and GFZ were well removed (50.0-75.0\%) by the MBBR, while DCF and CBZ were resistant to the MBBR treatment. The average removal of DCF by the MBBR was only $45.7 \%$ and CBZ showed an even lower removal of $25.9 \%$. A subsequent study Luo et al. (2015) showed that the MBBR-MBR coupled system had lower fouling tendency than a conventional MBR, and the compound-specific removal efficiencies varied significantly ranging from 25.5 to $99.5 \%$ with a HRT of $24 \mathrm{~h}$ (see Table 4 ). Previous batch experiments using non-acclimatized and acclimatized (for attached microbial growth) sponge biomasses showed that several micropollutants can be adsorbed on non-acclimatized sponge cubes, and that acclimatized sponge can improve the removal of some of the less hydrophobic $\left(\log \mathrm{K}_{\mathrm{ow}}<2.5\right.$ ) compounds like CBZ (Luo et al., 2014a). Besides, the removal efficiency achieved by the MBBR depends on physicochemical properties of the tested compounds, but the obtained degradation is comparable with other conventional processes. BPA, E1, E2, EE2, 4-n-NP, 4-tert-octylphenol, and TCS were considerably eliminated (>80.0\%) during the first two hours in the experiments with either non-acclimatized sponge or acclimatized sponge. Thus, sorption played a significant role in the removal of these compounds. ACE, DCF, GBZ, IBP, KPF, NPX, and SLA were hardly removed (mostly $<20 \%$ ) with non-acclimatized sponge, but showed markedly improved reduction when acclimatized sponge was used.

\subsubsection{Enzymatic treatment}

Only a handful of studies have investigated $\mathrm{TrOC}$ removal in EMRs operating in continuous flow. Ba et al. (2014) evaluated the removal, collected in Table 4, of three pharmaceuticals ACT, CBZ, and MFA using microfiltration alone and a combination with CLEALac. The MF alone showed significant removals of the three compounds in the filtrate varying approximately from 50 to $90 \%$ after a time-period of $8 \mathrm{~h}$. Synergistic action of the MF and CLEA-Lac during operation achieved eliminations from aqueous solution up to $85 \%$ for ACT, MFA, and CBZ, of around 99\% for ACT and nearly $100 \%$ for MFA. Under continuous operation, the HBR demonstrated elimination rates of the drugs from filtered wastewater up to $93 \%$ after $72 \mathrm{~h}$ for CBZ and near complete elimination of ACT and MFA was achieved within $24 \mathrm{~h}$ of treatment. Besides, the TrOCs removal efficiencies of EMRs depend on some factors such as the chemical structure of the targeted compounds. Nguyen et al. (2015) investigated the removal of 30 TrOCs using an EMR equipped with a nanofiltration membrane. They noticed that phenolic compounds were more effectively removed than the non-phenolic ones due to the formation of a dynamic layer of laccase over the membrane surface. Thus, TrOCs were retained and their degradation was facilitated. The addition of a redox-mediator (SA or HBT) to the EMR significantly improved the TrOC degradation. In a subsequent study, Nguyen et al. (2016b) investigated the removal of 14 phenolic and 17 non-phenolic compounds using an EMR with different TrOCs concentration values under SA loadings. The evaluation of the toxicity of laccase, SA, TrOCs, and treated effluent was also investigated by the authors. Results showed that $10 \mu \mathrm{M}$ of SA addition could improve TrOCs removal. However, a high concentration of SA ( 50 or $100 \mu \mathrm{M}$ ) did not show significant improvements regarding TrOCs removal, but increased effluent toxicity, due to the presence of unconsumed SA and radicals generated from SAoxidation by laccase. In parallel, Nguyen et al. (2016a) studied the degradation of four micropollutants in a packed-bed enzyme reactor using laccase immobilized on granular activated carbon. Results of this investigation showed high removals for all studied compounds, as described Table 4 (up to $90 \%$ after 24 h). Besides, since enzyme immobilization seems to be a good option for longterm operational stability, Ji et al. (2016) used a membrane hybrid reactor with $T$. versicolor laccase immobilized on suspended biocatalytic $\mathrm{TiO}_{2}$ nanoparticles to investigate $\mathrm{CBZ}$ removal. Even if the highest ratio of $71 \%$ within $96 \mathrm{~h}$ was observed using optimized operating conditions, and that the toxicity of CBZ was also removed, more improvements on this hybrid process and studies on the CBZ degradation at environmentally relevant concentration are still required.

It is clear that further investigations are needed to advance in the design of EMRs, in particular to demonstrate the viability of such process at full-scale in WWTPs. Abejón et al. (2015) focused their study on the evaluation of the economic aspects of EMR based on laccase immobilized over ceramic membranes and applied to the degradation of antibiotics. Results from a mathematical cost estimation model showed that the process is still far from economic competitiveness because of membrane conditioning costs. To 
achieve competitive economical results, some improvements on enzymatic activity, on the effective lifetime of the enzymatic reactors, and on membrane conditioning or regeneration costs have to be made.

\subsection{Limits of hybrid processes}

Studies about the efficiencies of a hybrid process to remove micropollutants are recent and further studies are needed in order to fill the gap regarding the influence of hydraulic parameters as suggested by Ba et al. (2014). On the one hand, a proper choice of the main operating parameters, such as $\mathrm{pH}$, HRT, or temperature might lead to a substantial improvement of the hybrid process performances. On the other hand, further researches should target the evaluation of the costs associated to the functioning of such processes. Indeed, the optimization in terms of technical and economical competitiveness of such water treatment processes could lead to the emergence of environmentally and economically sustainable water treatment processes, even though improvements regarding hybrid processes are still needed in order to maximize the removal of some of the more recalcitrant micropollutants. Escolà Casas et al. (2015) suggested to add a complementary advanced process to the treatment such as ozonation which could break down some bonds, and thus facilitates the subsequent removal by biodegradation. In that field, Navaratna et al. (2016) have investigated for seven months the elimination of s-triazine herbicide using a laboratory-scale MBR combined with ultraviolet disinfection and sorption onto granular activated carbon. More than $80.0 \%$ of the targeted herbicide was removed by this hybrid MBR through the biodegradation pathway, only with different HRT: from 1.5 to 7.5 days. Regarding pharmaceutical compounds, the complementary effects of adsorption and enzymatic degradation have been highlighted using granular activated carbon-bound laccase (Nguyen et al., 2016a). In a previous study, Nguyen et al. (2013a) evaluated the removal of TrOCs by an MBR-based hybrid treatment process using UV oxidation or nanofiltration/reverse osmosis membrane filtration. Results confirmed that UV oxidation is effective for the degradation of chlorinated TrOCs and TrOCs containing a phenolic group, but less effective for the removal of TrOCs containing an amide group such as CBZ. Only $30.0 \%$ of CBZ was removed by UV oxidation whereas a complete removal was achieved for pentachlorophenol and TCS. However, the hybrid process achieved $85.0 \%$ of removal efficiency for all 22 selected TrOCs. For instance, $96.0 \%$ of CBZ was eliminated with a contacting time of 7.5 min. Furthermore, as it was studied by Nguyen et al. (2013b), using a MBR, the efficiency of a hybrid process comprising of mixed culture of bacteria and WRF could be evaluated, and the addition of a redox mediator could improve the removal of some recalcitrant TrOCs.

Moreover, only few studies evaluated the toxicity of the effluent after a biodegradation process using a conventional process, but none using a hybrid process. It seems obvious that further experiments should be performed to evaluate the toxicity of by-products after a hybrid process. Jelić et al. (2012a) showed, using Vibrio fischeri luminescence reduction tests, that TrOC transformation via WRF often leads to detoxification, but $T$. versicolor can, for instance, produced 1,2-hydroxy ibuprofen, the main metabolites of IBP, which is more toxic than the parent compound (Marco-Urrea et al., 2009). Microtox ${ }^{\circledR}$ tests also showed that metabolites of DIU could also be more toxic than the parent compound (Tixier et al., 2002). The toxic effect of the DIU's metabolites was also demonstrated on two phytoplanktonic microorganisms, the green alga Dunaliella tertiolecta and the diatom Navicula forcipata (Gatidou and Thomaidis, 2007). Besides, Nguyen et al. (2016b) noticed that the use of a high dose of redox mediator such as SA can increase the effluent toxicity.

\section{Conclusions and perspectives}

During the past decade, a relevant number of studies have evaluated the efficiency of biodegradation processes to remove organic micropollutants from wastewaters. No significant difference exists between CAS and MBR treatments. The two systems are efficient to remove hydrophobic compounds and hydrophilic ones which possess only EDGs. In contrast, the removal of hydrophilic compounds bearing EWGs is still very low (below 20\%). Besides, few authors noticed that the use of WRF or a mixed culture of activated sludge and WRF could improve the performances of a MBR, but the operating conditions play a key role especially on enzymatic activity. Thus, $\mathrm{pH}$, aeration conditions, HRT, SRT have to be optimized depending on the selected micropollutants and their physico-chemical characteristics, e.g. hydrophobicity, chemical structure, $\mathrm{pK}_{\mathrm{a}}$, and so on. However, membrane fouling, recalcitrance of some hydrophilic compounds, and adsorption on activated sludge flocs are still important factors limiting the biodegradation of such pollutants using conventional processes. Recent studies suggested improvements regarding micropollutant degradation using hybrid processes. These processes containing biofilm carriers, suspended/attached growth system, or crosslinked enzymes aggregates showed better removal of micropollutants, even on recalcitrant compounds such as CBZ. Further studies need to be performed in order to evaluate which system is actually the more cost-benefit efficient, and to investigate the influence of operating conditions and the toxicity of effluents after treatment as well. However, even if a lack of studies at full-scale has been noticed, these processes could be a sustainable prospective treatment to improve the degradation of micropollutants from wastewaters. This could be facilitated by addition of a pretreatment step such as ozonation.

\section{Acknowledgements}

The authors sincerely thank the French public investment bank (Bpifrance) for its financial support.

\section{Appendix A. Supplementary data}

Supplementary data (tables 1, 2, 3 and 4) related to this article can be found at http://dx.doi.org/10.1016/j.watres.2017.01.005.

\section{References}

Abejón, R., Belleville, M.P., Sanchez-Marcano, J., 2015. Design, economic evaluation and optimization of enzymatic membrane reactors for antibiotics degradation in wastewaters. Sep. Purif. Technol. 156, 183-199.

Ahmed, M.B., Zhou, J.L., Ngo, H.H., Guo, W., Thomaidis, N.S., Xu, J., 2016. Progress in the biological and chemical treatment technologies for emerging contaminant removal from wastewater: a critical review. J. Hazard. Mater. 323, 274-278.

Alvarino, T., Komesli, O., Suarez, S., Lema, J.M., Omil, F., 2016a. The potential of the innovative SeMPAC process for enhancing the removal of recalcitrant organic micropollutants. J. Hazard. Mater. 308, 29-36.

Alvarino, T., Suárez, S., Garrido, M., Lema, J.M., Omil, F., 2016b. A UASB reactor coupled to a hybrid aerobic MBR as innovative plant configuration to enhance the removal of organic micropollutants. Chemosphere 144, 452-458.

Arpin-Pont, L., Bueno, M.J.M., Gomez, E., Fenet, H., 2014. Occurrence of PPCPs in the marine environment: a review. Environ. Sci. Pollut. Res. 23 (6), 4978-4991.

Aubenneau, M., Tahar, A., Casellas, C., Wisniewski, C., 2010. Membrane bioreactor for pharmaceutically active compounds removal: effects of carbamazepine on mixed microbial communities implied in the treatment. Process Biochem. 45, 1826-1831.

Auriol, M., Filali-Meknassi, Y., Tyagi, R.D., Adams, C.D., 2007. Laccase-catalyzed conversion of natural and synthetic hormones from a municipal wastewater. Water Res. 41, 3281-3288.

Ba, S., Jones, J.P., Cabana, H., 2014. Hybrid bioreactor (HBR) of hollow fiber microfilter membrane and cross-linked laccase aggregates eliminate aromatic 
pharmaceuticals in wastewaters. J. Hazard. Mater. 280, 662-670.

Barbieri, M., Carrera, J., Ayora, C., Sanchez-Vila, X., Licha, T., Nödler, K., Osorio, V., Pérez, S., Köck-Schulmeyer, M., López de Alda, M., Barceló, D., 2012. Formation of diclofenac and sulfamethoxazole reversible transformation products in aquifer material under denitrifying conditions: batch experiments. Sci. Total Environ. 426, 256-263.

Barbosa, M.O., Moreira, N.F.F., Ribeiro, A.R., Pereira, M.F.R., Silva, A.M.T., 2016. Occurrence and removal of organic micropollutants: an overview of the watch list of EU decision 2015/495. Water Res. 94, 257-279.

Bending, G.D., Friloux, M., Walker, A., 2002. Degradation of contrasting pesticides by white rot fungi and its relationship with ligninolytic potential. FEMS Microbiol. Lett. 212, 59-63.

Benner, J., Helbling, D.E., Kohler, H.-P.E., Wittebol, J., Kaiser, E., Prasse, C., Ternes, T.A. Albers, C.N., Aamand, J., Horemans, B., Springael, D., Walravens, E., Boon, N., 2013. Is biological treatment a viable alternative for micropollutant removal in drinking water treatment processes? Water Res. 47, 5955-5976.

Bernhard, M., Müller, J., Knepper, T.P., 2006. Biodegradation of persistent polar pollutants in wastewater: comparison of an optimised lab-scale membrane bioreactor and activated sludge treatment. Water Res. 40, 3419-3428.

Blair, B., Nikolaus, A., Hedman, C., Klaper, R., Grundl, T., 2015. Evaluating the degradation, sorption, and negative mass balances of pharmaceuticals and personal care products during wastewater treatment. Chemosphere 134, 395-401.

Bolong, N., Ismail, A.F., Salim, M.R., Matsuura, T., 2009. A review of the effects of emerging contaminants in wastewater and options for their removal. Desalination 239, 229-246.

Bouchiat, R., Veignie, E., Grizard, D., Soebert, C., Vigier, M., Rafin, C., 2016. Ability of filamentous fungi to degrade four emergent water priority pollutants. Desalination Water Treat. 57, 6740-6746.

Bouhabila, E., 2001. Fouling characterisation in membrane bioreactors. Sep. Purif. Technol. 22-23, 123-132.

Bourneuf, S., Jacob, M., Albasi, C., Sochard, S., Richard, R., Manero, M.H., 2015. Desorption experiments and modeling of micropollutants on activated carbon in water phase: application to transient concentrations mitigation. Int. J. Environ. Sci. Technol. 13 (1), 1-10.

Burkhardt-Holm, P., 2011. Linking water quality to human health and environment: the fate of micropollutants. Inst. Water Policy Natl. Univ. Singap. 1-62.

Byrns, G., 2001. The fate of xenobiotic organic compounds in wastewater treatment plants. Water Res. 35, 2523-2533.

Cabana, H., Jones, J.P., Agathos, S.N., 2007. Elimination of endocrine disrupting chemicals using white rot fungi and their lignin modifying enzymes: a review. Eng. Life Sci. 7, 429-456.

Cajthaml, T., Křesinová, Z., Svobodová, K., Möder, M., 2009. Biodegradation of endocrine-disrupting compounds and suppression of estrogenic activity by ligninolytic fungi. Chemosphere 75, 745-750.

Camarero, S., Sarkar, S., Ruiz-Dueñas, F.J., Martínez, M.J., Martínez, Á.T., 1999. Description of a versatile peroxidase involved in the natural degradation of lignin that has both manganese peroxidase and lignin peroxidase substrate interaction sites. J. Biol. Chem. 274, 10324-10330.

Carballa, M., Omil, F., Lema, J.M., 2005. Removal of cosmetic ingredients and pharmaceuticals in sewage primary treatment. Water Res. 39, 4790-4796.

Carballa, M., Omil, F., Lema, J.M., Llompart, M., García-Jares, C., Rodríguez, I., Gómez, M., Ternes, T., 2004. Behavior of pharmaceuticals, cosmetics and hormones in a sewage treatment plant. Water Res. 38, 2918-2926.

Casas, M.E., Chhetri, R.K., Ooi, G., Hansen, K.M.S., Litty, K., Christensson, M., Kragelund, C., Andersen, H.R., Bester, K., 2015. Biodegradation of pharmaceuticals in hospital wastewater by staged moving bed biofilm reactors (MBBR). Water Res. 83, 293-302.

Castillo, M.A., Felis, N., Aragón, P., Cuesta, G., Sabater, C., 2006. Biodegradation of the herbicide diuron by streptomycetes isolated from soil. Int. Biodeterior. Biodegr. 58, 196-202.

Cicek, N., Franco, J.P., Suidan, M.T., Urbain, V., Manem, J., 1999. Characterization and comparison of a membrane bireactor and a conventional activated-sludge system in the treatment of wastewater containing high-molecular-weight compounds. Water Environ. Fed. 71, 64-70.

Cirja, M., Ivashechkin, P., Schäffer, A., Corvini, P.F.X., 2008. Factors affecting the removal of organic micropollutants from wastewater in conventional treatment plants (CTP) and membrane bioreactors (MBR). Rev. Environ. Sci. Biotechnol. 7, 61-78.

Christian, V., Shrivastava, R., Shukla, D., Modi, H.A., Vyas, B.R.M., 2005. Degradation of xenobiotic compounds by lignin-degrading white-rot fungi: enmology and mechanisms involved. Indian J. Exp. Biol. 43, 301-312.

Clara, M., Kreuzinger, N., Strenn, B., Gans, O., Kroiss, H., 2005a. The solids retention time-a suitable design parameter to evaluate the capacity of wastewater treatment plants to remove micropollutants. Water Res. 39, 97-106.

Clara, M., Strenn, B., Gans, O., Martinez, E., Kreuzinger, N., Kroiss, H., 2005b. Removal of selected pharmaceuticals, fragrances and endocrine disrupting compounds in a membrane bioreactor and conventional wastewater treatment plants. Water Res. 39, 4797-4807.

Clouzot, L., Doumenq, P., Vanloot, P., Roche, N., Marrot, B., 2010. Membrane bioreactors for $17 \alpha$-ethinylestradiol removal. J. Membr. Sci. 362, 81-85.

Clouzot, L., Marrot, B., Doumenq, P., Roche, N., 2008. 17 $\alpha$-Ethinylestradiol: an endocrine disrupter of great concern. Analytical methods and removal processes applied to water purification. A review. Environ. Prog. 27, 383-396.

Coelho-Moreira, J. da S., Bracht, A., Souza, A.C. da S. de, Oliveira, R.F., Sá-
Nakanishi, A.B. de, Souza, C.G.M. de, Peralta, R.M., 2013. Degradation of diuron by Phanerochaete chrysosporium: role of ligninolytic enzymes and cytochrome P450. Biomed. Res. Int. 2013, 1-9.

Cruz-Morató, C., Ferrando-Climent, L., Rodriguez-Mozaz, S., Barceló, D., MarcoUrrea, E., Vicent, T., Sarrà, M., 2013. Degradation of pharmaceuticals in nonsterile urban wastewater by Trametes versicolor in a fluidized bed bioreactor Water Res. 47, 5200-5210.

de Cazes, M., Abejón, R., Belleville, M.-P., Sanchez-Marcano, J., 2014. Membrane bioprocesses for pharmaceutical micropollutant removal from waters. Membranes 4, 692-729.

De Wever, H., Weiss, S., Reemtsma, T., Vereecken, J., Müller, J., Knepper, T., Rörden, O., Gonzalez, S., Barcelo, D., Dolores Hernando, M., 2007. Comparison of sulfonated and other micropollutants removal in membrane bioreactor and conventional wastewater treatment. Water Res. 41, 935-945.

Deblonde, T., Cossu-Leguille, C., Hartemann, P., 2011. Emerging pollutants in wastewater: a review of the literature. Int. J. Hyg. Environ. Health 214, 442-448.

Defrance, L., Jaffrin, M.Y., Gupta, B., Paullier, P., Geaugey, V., 2000. Contribution of various constituents of activated sludge to membrane bioreactor fouling. Bioresour. Technol. 73, 105-112.

Di Trapani, D., Christensson, M., Torregrossa, M., Viviani, G., Ødegaard, H., 2013. Performance of a hybrid activated sludge/biofilm process for wastewater treatment in a cold climate region: influence of operating conditions. Biochem. Eng. J. 77, 214-219.

Dionisi, D., 2014. Potential and limits of biodegradation processes for the removal of organic xenobiotics from wastewaters. ChemBioEng Rev. 1, 67-82.

Drewes, J.E., Fox, P., Jekel, M., 2001. Occurrence of iodinated X-ray contrats media in domestic effluents and their fate during indirect potable reuse. J. Environ. Sci. Health Part A 36, 1633-1645.

Eckenfelder, W.W., Cleary, J.G., 2014. Activated Sludge Technologies for Treating Industrial Wastewaters: Design and Troubleshooting.

Escolà Casas, M., Bester, K., 2015. Can those organic micro-pollutants that are recalcitrant in activated sludge treatment be removed from wastewater by biofilm reactors (slow sand filters)? Sci. Total Environ. 506-507, 315-322.

Escolà Casas, M., Chhetri, R.K., Ooi, G., Hansen, K.M.S., Litty, K., Christensson, M. Kragelund, C., Andersen, H.R., Bester, K., 2015. Biodegradation of pharmaceuticals in hospital wastewater by a hybrid biofilm and activated sludge system (Hybas). Sci. Total Environ. 530-531, 383-392.

Evgenidou, E.N., Konstantinou, I.K., Lambropoulou, D.A., 2015. Occurrence and removal of transformation products of PPCPs and illicit drugs in wastewaters: a review. Sci. Total Environ. 505, 905-926.

Fabbrini, M., Galli, C., Gentili, P., 2002. Comparing the catalytic efficiency of some mediators of laccase. J. Mol. Catal. B Enzym 16, 231-240.

Falås, P., Baillon-Dhumez, A., Andersen, H.R., Ledin, A., la Cour Jansen, J., 2012 Suspended biofilm carrier and activated sludge removal of acidic pharmaceuticals. Water Res. 46, 1167-1175.

Falås, P., Longrée, P., la Cour Jansen, J., Siegrist, H., Hollender, J., Joss, A., 2013. Micropollutant removal by attached and suspended growth in a hybrid biofilmactivated sludge process. Water Res. 47, 4498-4506.

Falås, P., Wick, A., Castronovo, S., Habermacher, J., Ternes, T.A., Joss, A., 2016. Tracing the limits of organic micropollutant removal in biological wastewater treatment. Water Res. 95, 240-249.

Fan, H., Li, J., Zhang, L., Feng, L., 2014. Contribution of sludge adsorption and biodegradation to the removal of five pharmaceuticals in a submerged membrane bioreactor. Biochem. Eng. J. 88, 101-107.

Fernandez-Fontaina, E., Omil, F., Lema, J.M., Carballa, M., 2012. Influence of nitrifying conditions on the biodegradation and sorption of emerging micropollutants. Water Res. 46, 5434-5444.

Ferrando-Climent, L., Cruz-Morató, C., Marco-Urrea, E., Vicent, T., Sarrà, M., Rodriguez-Mozaz, S., Barceló, D., 2015. Non conventional biological treatment based on Trametes versicolor for the elimination of recalcitrant anticancer drugs in hospital wastewater. Chemosphere 136, 9-19.

Fischer, K., Majewsky, M., 2014. Cometabolic degradation of organic wastewater micropollutants by activated sludge and sludge-inherent microorganisms. Appl. Microbiol. Biotechnol. 98, 6583-6597.

Fukuda, T., Uchida, H., Takashima, Y., Uwajima, T., Kawabata, T., Suzuki, M., 2001 Degradation of bisphenol a by purified laccase from Trametes villosa. Biochem. Biophys. Res. Commun. 284, 704-706.

Gatidou, G., Thomaidis, N.S., 2007. Evaluation of single and joint toxic effects of two antifouling biocides, their main metabolites and copper using phytoplankton bioassays. Aquat. Toxicol. 85, 184-191.

Gobel, A., Mcardell, C., Joss, A., Siegrist, H., Giger, W., 2007. Fate of sulfonamides, macrolides, and trimethoprim in different wastewater treatment technologies. Sci. Total Environ. 372, 361-371.

Golan-Rozen, N., Chefetz, B., Ben-Ari, J., Geva, J., Hadar, Y., 2011. Transformation of the recalcitrant pharmaceutical compound carbamazepine by Pleurotus ostreatus: role of cytochrome $\mathrm{P} 450$ monooxygenase and manganese peroxidase. Environ. Sci. Technol. 45, 6800-6805.

González, S., Müller, J., Petrovic, M., Barceló, D., Knepper, T.P., 2006. Biodegradation studies of selected priority acidic pesticides and diclofenac in different bioreactors. Environ. Pollut. 144, 926-932.

Gros, M., Petrović, M., Ginebreda, A., Barceló, D., 2010. Removal of pharmaceuticals during wastewater treatment and environmental risk assessment using hazard indexes. Environ. Int. 36, 15-26.

Grover, D.P., Zhou, J.L., Frickers, P.E., Readman, J.W., 2011. Improved removal of estrogenic and pharmaceutical compounds in sewage effluent by full scale 
granular activated carbon: impact on receiving river water. J. Hazard. Mater. 185, 1005-1011.

Gulde, R., Helbling, D.E., Scheidegger, A., Fenner, K., 2014. pH-dependent biotransformation of ionizable organic micropollutants in activated sludge. Environ. Sci. Technol. 48, 13760-13768.

Guo, C., Dang, Z., Wong, Y., Tam, N.F., 2010. Biodegradation ability and dioxygenase genes of PAH-degrading Sphingomonas and Mycobacterium strains isolated from mangrove sediments. Int. Biodeterior. Biodegr. 64, 419-426.

Hai, F.I., Tessmer, K., Nguyen, L.N., Kang, I., Price, W.E., Nghiem, L.D., 2011. Removal of micropollutants by membrane bioreactor under temperature variation. J. Membr. Sci. 383, 144-151.

Hai, F.I., Yamamoto, K., Nakajima, F., Fukushi, K., 2010. Recalcitrant Industrial Wastewater Treatment by Membrane Bioreactor (MBR)

Haritash, A.K., Kaushik, C.P., 2009. Biodegradation aspects of polycyclic aromatic hydrocarbons (PAHs): a review. J. Hazard. Mater. 169, 1-15.

Hata, T., Shintate, H., Kawai, S., Okamura, H., Nishida, T., 2010. Elimination of carbamazepine by repeated treatment with laccase in the presence of 1 hydroxybenzotriazole. J. Hazard. Mater. 181, 1175-1178.

Hatakka, A., 1994. Lignin-modifying enzymes from selected white-rot fungi: production and role from in lignin degradation. FEMS Microbiol. Rev. 13, 125-135.

Helbling, D.E., Hollender, J., Kohler, H.-P.E., Fenner, K., 2010. Structure-based interpretation of biotransformation pathways of amide-containing compounds in sludge-seeded bioreactors. Environ. Sci. Technol. 44, 6628-6635.

Hirai, H., Nakanishi, S., Nishida, T., 2004. Oxidative dechlorination of methoxychlor by ligninolytic enzymes from white-rot fungi. Chemosphere 55, 641-645.

Hwang, J.H., Oleszkiewicz, J.A., 2007. Effect of cold-temperature shock on nitrification. Water Environ. Res. 79, 964-968.

Isaac, P., Martínez, F.L., Bourguignon, N., Sánchez, L.A., Ferrero, M.A., 2015. Improved PAHs removal performance by a defined bacterial consortium of indigenous Pseudomonas and actinobacteria from Patagonia, Argentina. Int. Biodeterior. Biodegr. 101, 23-31.

Jaspe, J., Hagen, S.J., 2006. Do protein molecules unfold in a simple shear flow? Biophys. J. 91, 3415-3424.

Jelić, A., Cruz-Morató, C., Marco-Urrea, E., Sarrà, M., Perez, S., Vicent, T., Petrović, M. Barcelo, D., 2012a. Degradation of carbamazepine by Trametes versicolor in an air pulsed fluidized bed bioreactor and identification of intermediates. Water Res. 46, 955-964.

Jelić, A., Gros, M., Ginebreda, A., Cespedes-Sánchez, R., Ventura, F., Petrovic, M. Barcelo, D., 2011. Occurrence, partition and removal of pharmaceuticals in sewage water and sludge during wastewater treatment. Water Res. 45 1165-1176.

Jelić, A., Gros, M., Petrović, M., Ginebreda, A., Barceló, D., 2012b. Occurrence and elimination of pharmaceuticals during conventional wastewater treatment. In: Guasch, H., Ginebreda, A., Geiszinger, A. (Eds.), Emerging and Priority Pollutants in Rivers. Springer Berlin Heidelberg, Berlin, Heidelberg, pp. 1-23.

Ji, C., Hou, J., Wang, K., Zhang, Y., Chen, V., 2016. Biocatalytic degradation of carbamazepine with immobilized laccase-mediator membrane hybrid reactor. J. Membr. Sci. 502, 11-20.

Jiang, J.-Q., Zhou, Z., Sharma, V.K., 2013. Occurrence, transportation, monitoring and treatment of emerging micro-pollutants in waste water - a review from globa views. Microchem. J. 110, 292-300.

Joss, A., Andersen, H., Ternes, T., Richle, P.R., Siegrist, H., 2004. Removal of estrogens in municipal wastewater treatment under aerobic and anaerobic conditions: consequences for plant optimization. Environ. Sci. Technol. 38, 3047-3055.

Joss, A., Keller, E., Alder, A.C., Göbel, A., McArdell, C.S., Ternes, T., Siegrist, H., 2005. Removal of pharmaceuticals and fragrances in biological wastewater treatment Water Res. 39, 3139-3152.

Joss, A., Zabczynski, S., Göbel, A., Hoffmann, B., Löffler, D., McArdell, C.S., Ternes, T.A., Thomsen, A., Siegrist, H., 2006. Biological degradation of pharmaceuticals in municipal wastewater treatment: proposing a classification scheme. Water Res. 40, 1686-1696

Kim, S.D., Cho, J., Kim, I.S., Vanderford, B.J., Snyder, S.A., 2007. Occurrence and removal of pharmaceuticals and endocrine disruptors in South Korean surface, drinking, and waste waters. Water Res. 41, 1013-1021.

Kim, Y.-J., Nicell, J.A., 2006. Laccase-catalysed oxidation of aqueous triclosan. J. Chem. Technol. Biotechnol. 81, 1344-1352.

Kimura, K., Hara, H., Watanabe, Y., 2007. Elimination of selected acidic pharmaceuticals from municipal wastewater by an activated sludge system and membrane bioreactors. Environ. Sci. Technol, 41, 3708-3714.

Kimura, K., Hara, H., Watanabe, Y., 2005. Removal of pharmaceutical compounds by submerged membrane bioreactors (MBRs). Desalination 178, 135-140.

Kovalova, L., Siegrist, H., Singer, H., Wittmer, A., McArdell, C.S., 2012. Hospital wastewater treatment by membrane bioreactor: performance and efficiency for organic micropollutant elimination. Environ. Sci. Technol. 46, 1536-1545.

Kovalova, L., Siegrist, H., von Gunten, U., Eugster, J., Hagenbuch, M., Wittmer, A., Moser, R., McArdell, C.S., 2013. Elimination of micropollutants during posttreatment of hospital wastewater with powdered activated carbon, ozone, and UV. Environ. Sci. Technol. 47, 7899-7908.

Kreuzinger, N., Clara, M., Strenn, B., Kroiss, H., 2004. Relevance of the sludge retention time (SRT) as design criteria for wastewater treatment plants for the removal of endocrine disruptors and pharmaceuticals from wastewater. Water Sci. Technol. 50, 149-156.

Kruglova, A., Ahlgren, P., Korhonen, N., Rantanen, P., Mikola, A., Vahala, R., 2014. Biodegradation of ibuprofen, diclofenac and carbamazepine in nitrifying activated sludge under $12{ }^{\circ} \mathrm{C}$ temperature conditions. Sci. Total Environ. 499,
$394-401$.

Kuddus, M., Joseph, B., Wasudev Ramteke, P., 2013. Production of laccase from newly isolated Pseudomonas putida and its application in bioremediation of synthetic dyes and industrial effluents. Biocatal. Agric. Biotechnol. 2, 333-338. Kuppusamy, S., Thavamani, P., Megharaj, M., Naidu, R., 2016. Biodegradation of polycyclic aromatic hydrocarbons (PAHs) by novel bacterial consortia tolerant to diverse physical settings - assessments in liquid- and slurry-phase systems. Int. Biodeterior. Biodegr. 108, 149-157.

Lahti, M., Oikari, A., 2011. Microbial transformation of pharmaceuticals naproxen, bisoprolol, and diclofenac in aerobic and anaerobic environments. Arch. Environ. Contam. Toxicol. 61, 202-210.

Lapworth, D.J., Baran, N., Stuart, M.E., Ward, R.S., 2012. Emerging organic contaminants in groundwater: a review of sources, fate and occurrence. Environ. Pollut. $163,287-303$

Leiknes, T., Ødegaard, H., 2007. The development of a biofilm membrane bioreactor. Desalination 202, 135-143.

Li, A., Cai, R., Cui, D., Qiu, T., Pang, C., Yang, J., Ma, F., Ren, N., 2013. Characterization and biodegradation kinetics of a new cold-adapted carbamazepine-degrading bacterium, Pseudomonas sp. CBZ-4. J. Environ. Sci. 25, 2281-2290.

Li, X., Toledo, R.A. de, Wang, S., Shim, H., 2015. Removal of carbamazepine and naproxen by immobilized Phanerochaete chrysosporium under non-sterile condition. New Biotechnol.

Lloret, L., Eibes, G., Feijoo, G., Moreira, M.T., Lema, J.M., 2012a. Degradation of estrogens by laccase from Myceliophthora thermophila in fed-batch and enzymatic membrane reactors. J. Hazard. Mater. 213-214, 175-183.

Lloret, L., Eibes, G., Feijoo, G., Moreira, M.T., Lema, J.M., 2012b. Continuous biotransformation of estrogens by laccase in an enzymatic membrane reactor. Chem. Eng. Trans. 31-36.

Lloret, L., Eibes, G., Lú-Chau, T.A., Moreira, M.T., Feijoo, G., Lema, J.M., 2010. Laccasecatalyzed degradation of anti-inflammatories and estrogens. Biochem. Eng. J. 51, 124-131.

Luo, Y., Guo, W., Ngo, H.H., Nghiem, L.D., Hai, F.I., Kang, J., Xia, S., Zhang, Z., Price, W.E., 2014a. Removal and fate of micropollutants in a sponge-based moving bed bioreactor. Bioresour. Technol. 159, 311-319.

Luo, Y., Guo, W., Ngo, H.H., Nghiem, L.D., Hai, F.I., Zhang, J., Liang, S., Wang, X.C., 2014b. A review on the occurrence of micropollutants in the aquatic environment and their fate and removal during wastewater treatment. Sci. Total Environ. 473-474, 619-641.

Luo, Y., Jiang, Q., Ngo, H.H., Nghiem, L.D., Hai, F.I., Price, W.E., Wang, J., Guo, W., 2015. Evaluation of micropollutant removal and fouling reduction in a hybrid moving bed biofilm reactor-membrane bioreactor system. Bioresour. Technol. 191, 355-359.

Maeng, S.K., Choi, B.G., Lee, K.T., Song, K.G., 2013. Influences of solid retention time, nitrification and microbial activity on the attenuation of pharmaceuticals and estrogens in membrane bioreactors. Water Res. 47, 3151-3162.

Majewsky, M., Gallé, T., Yargeau, V., Fischer, K., 2011. Active heterotrophic biomass and sludge retention time (SRT) as determining factors for biodegradation kinetics of pharmaceuticals in activated sludge. Bioresour. Technol. 102, 7415-7421.

Marco-Urrea, E., Pérez-Trujillo, M., Cruz-Morató, C., Caminal, G., Vicent, T., 2010. Degradation of the drug sodium diclofenac by Trametes versicolor pellets and identification of some intermediates by NMR. J. Hazard. Mater. 176, 836-842.

Marco-Urrea, E., Pérez-Trujillo, M., Vicent, T., Caminal, G., 2009. Ability of white-rot fungi to remove selected pharmaceuticals and identification of degradation products of ibuprofen by Trametes versicolor. Chemosphere 74, 765-772.

Margot, J., Bennati-Granier, C., Maillard, J., Blánquez, P., Barry, D.A., Holliger, C., 2013a. Bacterial versus fungal laccase: potential for micropollutant degradation. AMB Express 3, 63.

Margot, J., Lochmatter, S., Barry, D.A., Holliger, C., 2016. Role of ammonia-oxidizing bacteria in micropollutant removal from wastewater with aerobic granular sludge. Water Sci. Technol. 73, 564-575.

Margot, J., Maillard, J., Rossi, L., Barry, D.A., Holliger, C., 2013b. Influence of treatment conditions on the oxidation of micropollutants by Trametes versicolor laccase. New Biotechnol. 30, 803-813.

Meerburg, F., Hennebel, T., Vanhaecke, L., Verstraete, W., Boon, N., 2012. Diclofenac and 2-anilinophenylacetate degradation by combined activity of biogenic manganese oxides and silver: DF and APA degradation by Bio-MnOx and silver. Microb. Biotechnol. 5, 388-395.

Melcer, H., Water Environment Federation (Eds.), 2003. Methods for Wastewater Characterization in Activated Sludge Modeling, Treatment Processes and Systems/Water Environment Research Foundation. Water Environment Federation: IWA Pub, Alexandria, VA: London, U.K.

Mendoza, L., Jonstrup, M., Hatti-Kaul, R., Mattiasson, B., 2011. Azo dye decolorization by a laccase/mediator system in a membrane reactor: enzyme and mediator reusability. Enzyme Microb. Technol. 49, 478-484.

Metcalfe, C.D., Koenig, B.G., Bennie, D.T., Servos, M., Ternes, T.A., Hirsch, R., 2003. Occurrence of neutral and acidic drugs in the effluents of Canadian sewage treatment plants. Environ. Toxicol. Chem. 22, 2872-2880.

Miège, C., Choubert, J.M., Ribeiro, L., Eusèbe, M., Coquery, M., 2009. Fate of pharmaceuticals and personal care products in wastewater treatment plants conception of a database and first results. Environ. Pollut. 157, 1721-1726.

Morgan-Sagastume, F., Allen, D.G., 2003. Effects of temperature transient conditions on aerobic biological treatment of wastewater. Water Res. 37, 3590-3601.

Murdoch, R.W., Hay, A.G., 2005. formation of catechols via removal of acid side chains from ibuprofen and related aromatic acids. Appl. Environ. Microbiol. 71, 
6121-6125.

Murínová, S., Dercová, K., Dudášová, H., 2014. Degradation of polychlorinated biphenyls (PCBs) by four bacterial isolates obtained from the PCB-contaminated soil and PCB-contaminated sediment. Int. Biodeterior. Biodegr. 91, 52-59.

Nanda, S., Pharm, M., 2008. Reactors and Fundamentals of Reactors Design for Chemical Reaction. Dr. Rep.. Dept Pharm. Sci. MD Univ. Rohtak Haryana.

Navaratna, D., Shu, L., Jegatheesan, V., 2016. Evaluation of herbicide (persistent pollutant) removal mechanisms through hybrid membrane bioreactors. Bioresour. Technol. 200, 795-803.

Ngo, H.-H., Guo, W., Xing, W., 2008. Evaluation of a novel sponge-submerged membrane bioreactor (SSMBR) for sustainable water reclamation. Bioresour. Technol. 99, 2429-2435.

Nguyen, L.N., Hai, F.I., Dosseto, A., Richardson, C., Price, W.E., Nghiem, L.D., 2016a. Continuous adsorption and biotransformation of micropollutants by granular activated carbon-bound laccase in a packed-bed enzyme reactor. Bioresour. Technol. 210, 108-116.

Nguyen, L.N., Hai, F.I., Kang, J., Price, W.E., Nghiem, L.D., 2013a. Removal of emerging trace organic contaminants by MBR-based hybrid treatment processes. Int. Biodeterior. Biodegr. 85, 474-482.

Nguyen, L.N., Hai, F.I., Price, W.E., Kang, J., Leusch, F.D.L., Roddick, F., van de Merwe, J.P., Magram, S.F., Nghiem, L.D., 2015. Degradation of a broad spectrum of trace organic contaminants by an enzymatic membrane reactor: complementary role of membrane retention and enzymatic degradation. Int. Biodeterior. Biodegr. 99, 115-122.

Nguyen, L.N., Hai, F.I., Price, W.E., Leusch, F.D.L., Roddick, F., Ngo, H.H., Guo, W., Magram, S.F., Nghiem, L.D., 2014a. The effects of mediator and granular activated carbon addition on degradation of trace organic contaminants by an enzymatic membrane reactor. Bioresour. Technol. 167, 169-177.

Nguyen, L.N., Hai, F.I., Yang, S., Kang, J., Leusch, F.D., Roddick, F., Price, W.E., Nghiem, L.D., 2014b. Removal of pharmaceuticals, steroid hormones, phytoestrogens, UV-filters, industrial chemicals and pesticides by Trametes versicolor: role of biosorption and biodegradation. Int. Biodeterior. Biodegr. 88, 169-175.

Nguyen, L.N., Hai, F.I., Yang, S., Kang, J., Leusch, F.D.L., Roddick, F., Price, W.E., Nghiem, L.D., 2013b. Removal of trace organic contaminants by an MBR comprising a mixed culture of bacteria and white-rot fungi. Bioresour. Technol. $148,234-241$.

Nguyen, L.N., van de Merwe, J.P., Hai, F.I., Leusch, F.D.L., Kang, J., Price, W.E Roddick, F., Magram, S.F., Nghiem, L.D., 2016b. Laccase-syringaldehyde-mediated degradation of trace organic contaminants in an enzymatic membrane reactor: removal efficiency and effluent toxicity. Bioresour. Technol. 200, 477-484.

Ordóñez, R., Hermosilla, D., Merayo, N., Gascó, A., Negro, C., Blanco, Á., 2014. Application of multi-barrier membrane filtration technologies to reclaim municipal wastewater for industrial use. Sep. Purif. Rev. 43, 263-310.

Oulton, R.L., Kohn, T., Cwiertny, D.M., 2010. Pharmaceuticals and personal care products in effluent matrices: a survey of transformation and removal during wastewater treatment and implications for wastewater management. J. Environ. Monit. 12, 1956.

Paje, M., K, U., W, M., N, T., 2002. Inhibition of lotic biofilms by diclofenac. Appl. Microbiol. Biotechnol. 59, 488-492.

Pérez, S., Eichhorn, P., Aga, D.S., 2005. Evaluating the biodegradability of sulfamethazine, sulfamethoxazole, sulfathiazole, and trimethoprim at different stages of sewage treatment. Environ. Toxicol. Chem. 24, 1361-1367.

Perilli, R., Marziano, M.L., Formisano, G., Caiazza, S., Scorcia, G., Baldassarri, L., 2000. Alteration of organized structure of biofilm formed by Staphylococcus epidermidis on soft contact lenses. J. Biomed. Mater. Res. 49, 53-57.

Petrie, B., McAdam, E.J., Lester, J.N., Cartmell, E., 2014. Assessing potential modifications to the activated sludge process to improve simultaneous removal of a diverse range of micropollutants. Water Res. 62, 180-192.

Popa Ungureanu, C., Favier, L., Bahrim, G., Amrane, A., 2014. Response surface optimization of experimental conditions for carbamazepine biodegradation by Streptomyces MIUG 4.89. New Biotechnol. 32 (3), 347-357.

Quintana, J., Weiss, S., Reemtsma, T., 2005. Pathways and metabolites of microbial degradation of selected acidic pharmaceutical and their occurrence in municipal wastewater treated by a membrane bioreactor. Water Res. 39, 2654-2664.

Quintana, J.B., Reemtsma, T., 2004. Sensitive determination of acidic drugs and triclosan in surface and wastewater by ion-pair reverse-phase liquid chromatography/tandem mass spectrometry. Rapid Commun. Mass Spectrom. 18, 765-774.

Radjenović, J., Petrović, M., Barceló, D., 2009. Fate and distribution of pharmaceuticals in wastewater and sewage sludge of the conventional activated sludge (CAS) and advanced membrane bioreactor (MBR) treatment. Water Res. 43, $831-841$.

Ren, Y.-X., Nakano, K., Nomura, M., Chiba, N., Nishimura, O., 2007. Effects of bacterial activity on estrogen removal in nitrifying activated sludge. Water Res. 41, 3089-3096.

Rentz, J.A., Alvarez, P.J.J., Schnoor, J.L., 2008. Benzo[a]pyrene degradation by Sphingomonas yanoikuyae JAR02. Environ. Pollut. 151, 669-677.

Rios, G.M., Belleville, M.P., Paolucci, D., Sanchez, J., 2004. Progress in enzymatic membrane reactors - a review. J. Membr. Sci. 242, 189-196.

Rodarte-Morales, A.I., Feijoo, G., Moreira, M.T., Lema, J.M., 2012. Operation of stirred tank reactors (STRs) and fixed-bed reactors (FBRs) with free and immobilized Phanerochaete chrysosporium for the continuous removal of pharmaceutical compounds. Biochem. Eng. J. 66, 38-45.

Rodarte-Morales, A.I., Feijoo, G., Moreira, M.T., Lema, J.M., 2011. Degradation of selected pharmaceutical and personal care products (PPCPs) by white-rot fungi. World J. Microbiol. Biotechnol. 27, 1839-1846.

Rogers, H.R., 1996. Sources, behaviour and fate of organic contaminants during sewage treatment and in sewage sludges. Sci. Total Environ. 185, 3-26.

Rosenberger, S., Krüger, U., Witzig, R., Manz, W., Szewzyk, U., Kraume, M., 2002. Performance of a bioreactor with submerged membranes for aerobic treatment of municipal waste water. Water Res. 36, 413-420.

Ruiz-Aguilar, G., 2002. Degradation by white-rot fungi of high concentrations of PCB extracted from a contaminated soil. Adv. Environ. Res. 6, 559-568.

Sipma, J., Osuna, B., Collado, N., Monclús, H., Ferrero, G., Comas, J., RodriguezRoda, I., 2010. Comparison of removal of pharmaceuticals in MBR and activated sludge systems. Desalination 250, 653-659.

Soares, A., Jonasson, K., Terrazas, E., Guieysse, B., Mattiasson, B., 2005. The ability of white-rot fungi to degrade the endocrine-disrupting compound nonylphenol. Appl. Microbiol. Biotechnol. 66, 719-725.

Sorensen, S.R., Bending, G.D., Jacobsen, C.S., Walker, A., Aamand, J., 2003. Microbial degradation of isoproturon and related phenylurea herbicides in and below agricultural fields. FEMS Microbiol. Ecol. 45, 1-11.

Stackelberg, P.E., Gibs, J., Furlong, E.T., Meyer, M.T., Zaugg, S.D., Lippincott, R.L., 2007. Efficiency of conventional drinking-water-treatment processes in removal of pharmaceuticals and other organic compounds. Sci. Total Environ. 377, $255-272$.

Stasinakis, A.S., Kotsifa, S., Gatidou, G., Mamais, D., 2009. Diuron biodegradation in activated sludge batch reactors under aerobic and anoxic conditions. Water Res. 43, 1471-1479.

Suárez, S., Carballa, M., Omil, F., Lema, J.M., 2008. How are pharmaceutical and personal care products (PPCPs) removed from urban wastewaters? Rev. Environ. Sci. Biotechnol. 7, 125-138.

Suárez, S., Lema, J.M., Omil, F., 2010. Removal of pharmaceutical and personal care products (PPCPs) under nitrifying and denitrifying conditions. Water Res. 44, $3214-3224$.

Suárez, S., Reif, R., Lema, J.M., Omil, F., 2012. Mass balance of pharmaceutical and personal care products in a pilot-scale single-sludge system: influence of T, SRT and recirculation ratio. Chemosphere 89, 164-171.

Subramanian, V., Yadav, J.S., 2009. Role of P450 monooxygenases in the degradation of the endocrine-disrupting chemical nonylphenol by the white rot fungus Phanerochaete chrysosporium. Appl. Environ. Microbiol. 75, 5570-5580.

Suda, T., Hata, T., Kawai, S., Okamura, H., Nishida, T., 2012. Treatment of tetracycline antibiotics by laccase in the presence of 1-hydroxybenzotriazole. Bioresour Technol. 103, 498-501.

Sui, Q., Cao, X., Lu, S., Zhao, W., Qiu, Z., Yu, G., 2015. Occurrence, sources and fate of pharmaceuticals and personal care products in the groundwater: a review. Emerg. Contam. 1, 14-24.

Sui, Q., Huang, J., Deng, S., Yu, G., Fan, Q., 2010. Occurrence and removal of pharmaceuticals, caffeine and DEET in wastewater treatment plants of Beijing, China. Water Res. 44, 417-426.

Suzuki, K., Hirai, H., Murata, H., Nishida, T., 2003. Removal of estrogenic activities of $17 \beta$-estradiol and ethinylestradiol by ligninolytic enzymes from white rot fungi Water Res. 37, 1972-1975.

Sylvia, D.M. (Ed.), 2005. Principles and Applications of Soil Microbiology, second ed. Pearson Prentice Hall, Upper Saddle River, NJ.

Tadkaew, N., Hai, F.I., McDonald, J.A., Khan, S.J., Nghiem, L.D., 2011. Removal of trace organics by MBR treatment: the role of molecular properties. Water Res. 45 2439-2451.

Tadkaew, N. Sivakumar, M., Khan, S.J., McDonald, J.A., Nghiem, L.D., 2010. Effect of mixed liquor $\mathrm{pH}$ on the removal of trace organic contaminants in a membrane bioreactor. Bioresour. Technol. 101, 1494-1500.

Tahri, N., Bahafid, W., Sayel, H., El Ghachtouli, N., 2013. Biodegradation: involved microorganisms and genetically engineered microorganisms. In: Chamy, $\mathrm{R}$. (Ed.), Biodegradation - Life of Science. InTech.

Tambosi, J.L., de Sena, R.F., Favier, M., Gebhardt, W., José, H.J., Schröder, H.F., Moreira, R. de F.P.M., 2010. Removal of pharmaceutical compounds in membrane bioreactors (MBR) applying submerged membranes. Desalination 261, $148-156$.

Tavares, A.P.M., Coelho, M.A.Z., Agapito, M.S.M., Coutinho, J.A.P., Xavier, A.M.R.B. 2006. Optimization and modeling of laccase production by Trametes versicolor in a bioreactor using statistical experimental design. Appl. Biochem. Biotechnol. $134,233-248$.

Wastewater engineering: treatment and reuse. In: Tchobanoglous, G., Metcalf, Eddy, Inc (Eds.), 2003. The McGraw-Hill Series in Civil and Environmental Engineering, fourth ed. McGraw-Hill, Boston, Mass.

Tixier, C., Sancelme, M., Ait-Aissa, S., Widehem, P., Bonnemoy, F., Cuer, A. Truffaut, N., Veschambre, H., 2002. Biotransformation of phenylurea herbicides by a soil bacterial strain, Arthrobacter sp. N2: structure, ecotoxicity and fate of diuron metabolite with soil fungi. Chemosphere 46, 519-526.

Tran, N.H., Urase, T., Kusakabe, O., 2010. Biodegradation characteristics of pharmaceutical substances by whole fungal culture Trametes versicolor and its laccase. J. Water Environ. Technol. 8, 125-140.

Tsutsumi, Y., Haneda, T., Nishida, T., 2001. Removal of estrogenic activities of bisphenol A and nonylphenol by oxidative enzymes from lignin-degrading basidiomycetes. Chemosphere 42, 271-276.

Turnbull, G.A., Ousley, M., Walker, A., Shaw, E., Morgan, J.A.W., 2001. Degradation of substituted phenylurea herbicides by arthrobacter globiformis strain D47 and characterization of a plasmid-associated hydrolase gene, puhA. Appl. Environ. Microbiol. 67, 2270-2275. 
Urase, T., Kagawa, C., Kikuta, T., 2005. Factors affecting removal of pharmaceutical substances and estrogens in membrane separation bioreactors. Desalination 178, 107-113.

Verlicchi, P., Al Aukidy, M., Zambello, E., 2012. Occurrence of pharmaceutical compounds in urban wastewater: removal, mass load and environmental risk after a secondary treatment-a review. Sci. Total Environ. 429, 123-155.

Vieno, N., Tuhkanen, T., Kronberg, L., 2007. Elimination of pharmaceuticals in sewage treatment plants in Finland. Water Res. 41, 1001-1012.

Vieno, N.M., Tuhkanen, T., Kronberg, L., 2005. Seasonal variation in the occurrence of pharmaceuticals in effluents from a sewage treatment plant and in the recipient water. Environ. Sci. Technol. 39, 8220-8226.

Von Gunten, U., 2003. Ozonation of drinking water: Part II. Disinfection and byproduct formation in presence of bromide, iodide or chlorine. Water Res. 37, 1469-1487.

Weiss, S., Reemtsma, T., 2008. Membrane bioreactors for municipal wastewater treatment - a viable option to reduce the amount of polar pollutants discharged into surface waters? Water Res. 42, 3837-3847.

Wells, M.J.M., 2006. Log D OW: key to understanding and regulating wastewaterderived contaminants. Environ. Chem. 3, 439.

Widehem, P., Ait-Aïssa, S., Tixier, C., Sancelme, M., Veschambre, H., Truffaut, N., 2002. Isolation, characterization and diuron transformation capacities of bacterial strain Arthrobacter sp. N2. Chemosphere 46, 527-534.

Wijekoon, K.C., Hai, F.I., Kang, J., Price, W.E., Guo, W., Ngo, H.H., Nghiem, L.D., 2013. The fate of pharmaceuticals, steroid hormones, phytoestrogens, UV-filters and pesticides during MBR treatment. Bioresour. Technol. 144, 247-254.

Wisniewski, C., 2007. Membrane bioreactor for water reuse. Desalination 203, 15-19.

Wong, D.W.S., 2009. Structure and action mechanism of ligninolytic enzymes. Appl. Biochem. Biotechnol. 157, 174-209.

Xia, S, Jia, R, Feng, F, Xie, K, Li, H., Jing, D, Xu, X, 2012, Effect of solids retention time on antibiotics removal performance and microbial communities in an $\mathrm{A} / \mathrm{O}$ -
MBR process. Bioresour. Technol. 106, 36-43.

Xue, W., Wu, C., Xiao, K., Huang, X., Zhou, H., Tsuno, H., Tanaka, H., 2010. Elimination and fate of selected micro-organic pollutants in a full-scale anaerobic/anoxic/ aerobic process combined with membrane bioreactor for municipal wastewater reclamation. Water Res. 44, 5999-6010.

Yang S., Hai, F., Nghiem, L.D., Nguyen, L.N., Roddick, F., Price, W.E., 2013a. Removal of bisphenol A and diclofenac by a novel fungal membrane bioreactor operated under non-sterile conditions. Int. Biodeterior. Biodegr. 85, 483-490.

Yang, S., Hai, F.I., Nghiem, L.D., Price, W.E., Roddick, F. Moreira, M.T. Magram, S.E. 2013b. Understanding the factors controlling the removal of trace organic contaminants by white-rot fungi and their lignin modifying enzymes: a critical review. Bioresour. Technol. 141, 97-108.

Yanze-Kontchou, C., Gschwind, N., 1994. Mineralization of the herbicide atrazine as a carbon source by a Pseudomonas strain. Appl. Environ. Microbiol. 60, 4297-4302.

Zhang, B., Yamamoto, K., Ohgaki, S., Kamiko, N., 1997. Floc size distribution and bacterial activities in membrane separation activated sludge processes for small-scale wastewater treatment/reclamation. Water Sci. Technol. 35, 37-44.

Zhang, J., Liu, X., Xu, Z., Chen, H., Yang, Y., 2008. Degradation of chlorophenols catalyzed by laccase. Int. Biodeterior. Biodegr. 61, 351-356.

Zhang, S., Yang, F., Liu, Y., Zhang, X., Yamada, Y., Furukawa, K., 2006. Performance of a metallic membrane bioreactor treating simulated distillery wastewater at temperatures of 30 to $45^{\circ} \mathrm{C}$. Desalination 194, 146-155.

Zhang, Y., Geißen, S.-U., 2012. Elimination of carbamazepine in a non-sterile fungal bioreactor. Bioresour. Technol. 112, 221-227.

Zhang, Y., Geißen, S.-U., 2010. In vitro degradation of carbamazepine and diclofenac by crude lignin peroxidase. J. Hazard. Mater. 176, 1089-1092.

Zwiener, C., Frimmel, F., 2003. Short-term tests with a pilot sewage plant and biofilm reactors for the biological degradation of the pharmaceutical compounds clofibric acid, ibuprofen, and diclofenac. Sci. Total Environ. 309, 201-211. 
Table 1 : Design parameters and main results of selected studies using classical process to remove organic micropollutants

\begin{tabular}{|c|c|}
\hline & \\
\hline Reference & Molecule $^{\mathrm{a}}$ \\
\hline & $\begin{array}{c}\text { ATZ } \\
\text { Bentazone }\end{array}$ \\
\hline & Isoproturon \\
\hline & DEA \\
\hline & Simazine \\
\hline & Terbutylazine \\
\hline & Metramitron \\
\hline & $2,4 \mathrm{D}$ \\
\hline al. 2006 & MCPA \\
\hline & MCPP \\
\hline & Icaridine \\
\hline & CBZ \\
\hline & CFA \\
\hline & DCF \\
\hline & 2,4 DBA \\
\hline & IBP \\
\hline & EDTA \\
\hline & EE2 \\
\hline & ACE \\
\hline & CFN \\
\hline & $\begin{array}{ll}\mathrm{CBZ} \\
\end{array}$ \\
\hline & CIP \\
\hline & E3 \\
\hline & E1 \\
\hline 2015 & GFZ \\
\hline & IBP \\
\hline & NPX \\
\hline & OFX \\
\hline & Pen V \\
\hline & SMX \\
\hline & TCS \\
\hline & TMP \\
\hline & \\
\hline & \\
\hline & \\
\hline & \\
\hline & DCF \\
\hline & \\
\hline & \\
\hline & \\
\hline & \\
\hline & \\
\hline & \\
\hline & IBP \\
\hline & $\mathrm{IBP}$ \\
\hline & \\
\hline & \\
\hline & \\
\hline & \\
\hline & \\
\hline & \\
\hline & \\
\hline & BZF \\
\hline & \\
\hline & \\
\hline & \\
\hline & \\
\hline & \\
\hline & \\
\hline & CBZ \\
\hline & CBL \\
\hline & \\
\hline & \\
\hline Clara et al. & \\
\hline 2005 & \\
\hline & \\
\hline & \\
\hline & IMP \\
\hline & IMIP \\
\hline & \\
\hline & \\
\hline & \\
\hline & \\
\hline & \\
\hline & \\
\hline & DZP \\
\hline & $D \angle P$ \\
\hline & \\
\hline & \\
\hline & \\
\hline & \\
\hline & \\
\hline & \\
\hline & \\
\hline & ROX \\
\hline & \\
\hline & \\
\hline & \\
\hline & \\
\hline & \\
\hline & \\
\hline & \\
\hline & $\sin x$ \\
\hline & \\
\hline & \\
\hline & \\
\hline
\end{tabular}




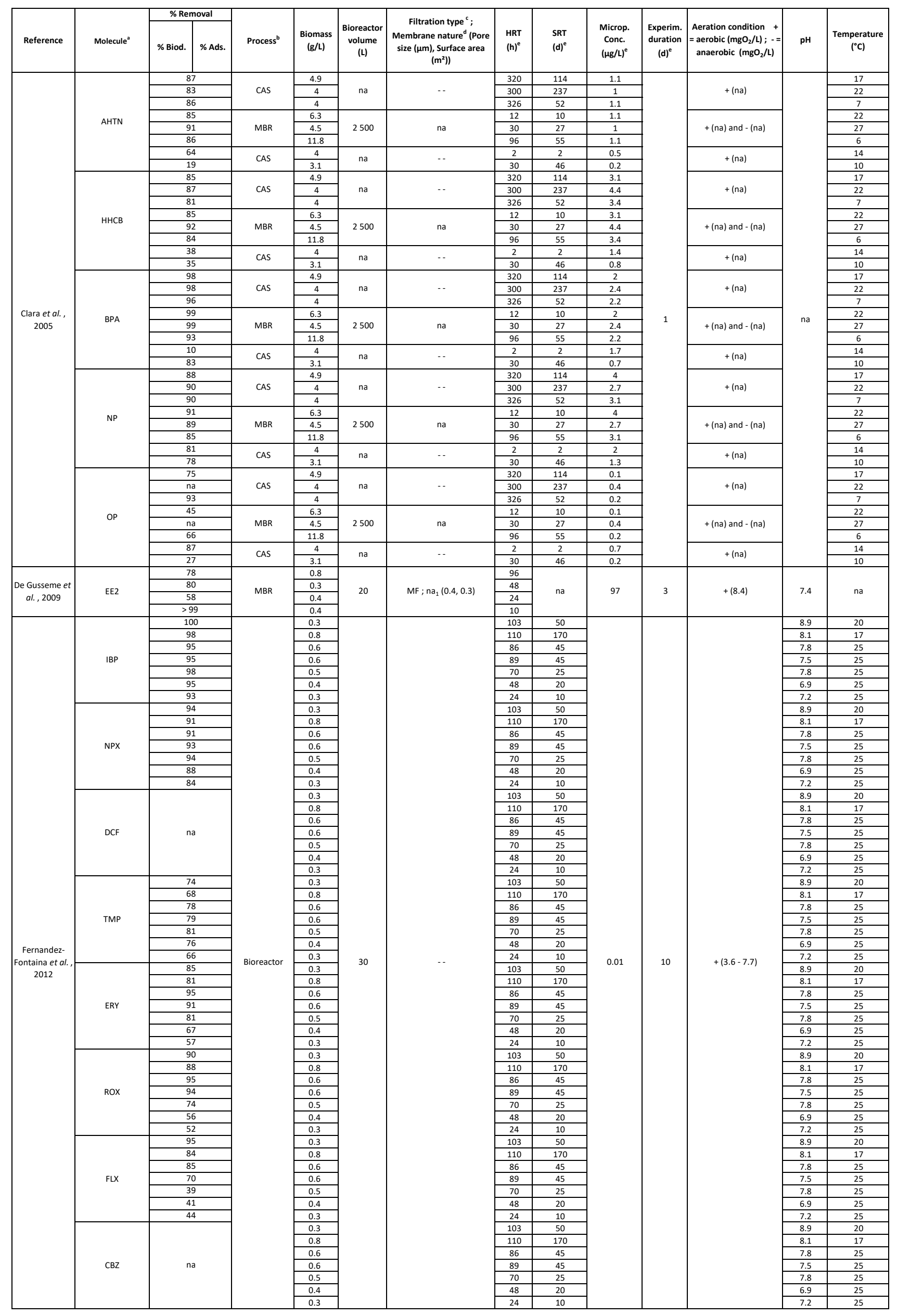




\begin{tabular}{|c|c|c|c|c|c|c|c|c|c|c|c|c|c|c|}
\hline \multirow[b]{2}{*}{ Reference } & \multirow[b]{2}{*}{ Molecule $^{\mathrm{a}}$} & $\% \operatorname{Re}$ & noval & & & & & & & & & & & \\
\hline & & \% Biod. & \% Ads. & Process $^{b}$ & $\begin{array}{c}\text { Biomass } \\
(\mathrm{g} / \mathrm{L})\end{array}$ & $\begin{array}{c}\text { Bioreactor } \\
\text { volume } \\
\text { (L) }\end{array}$ & $\begin{array}{l}\text { Membrane natured (Pore } \\
\text { size }(\mu \mathrm{mm}) \text {, Surface area } \\
\left.\left(\mathrm{m}^{2}\right)\right)\end{array}$ & $\begin{array}{l}\text { HRT } \\
(\mathrm{h})^{\mathrm{e}}\end{array}$ & $\begin{array}{l}\text { SRT } \\
\text { (d) }\end{array}$ & $\begin{array}{l}\text { Microp. } \\
\text { Conc. } \\
(\mu \mathrm{g} / L)^{\mathrm{e}}\end{array}$ & $\begin{array}{l}\text { Experim. } \\
\text { duration } \\
\text { (d) }\end{array}$ & $\mid \begin{array}{c}\text { Aeration condition }+ \\
=\text { aerobic }\left(\mathrm{mgO}_{2} / \mathrm{L}\right) ;- \\
\text { anaerobic }\left(\mathrm{mgO}_{2} / \mathrm{L}\right)\end{array}$ & $\mathrm{pH}$ & \begin{tabular}{|c} 
Temperature \\
$\left({ }^{\circ} \mathrm{C}\right)$
\end{tabular} \\
\hline & & & & & 0.3 & & & 103 & 50 & & & & 8.9 & 20 \\
\hline & & & & & 0.8 & & & 110 & 170 & & & & 8.1 & 17 \\
\hline & DZP & & $a^{a}$ & & $\frac{0.6}{0.6}$ & & & $\begin{array}{l}86 \\
89\end{array}$ & $\frac{45}{45}$ & 0.01 & & & 7.8 & $\frac{25}{25}$ \\
\hline & & & & & 0.5 & & & 70 & 25 & & & & 7.8 & 25 \\
\hline & & & & & 0.4 & & & 48 & 20 & & & & 6.9 & 25 \\
\hline & & & & & 0.3 & & & 24 & 10 & & & & 7.2 & 25 \\
\hline & & & 1 & & 0.3 & & & 103 & 50 & & & & 8.9 & 20 \\
\hline Fernandez- & & & & & 0.8 & & & 110 & 170 & & & & 8.1 & 17 \\
\hline Fontaina et al. & & & 2 & Bioreactor & 0.6 & 30 & -. & 86 & 45 & & 10 & $+(3.6-7.7)$ & 7.8 & 25 \\
\hline & HHCB & & $\frac{1}{8}$ & & 0.6 & & & 89 & 45 & & & & 7.5 & 25 \\
\hline & & & 5 & & 0.4 & & & 10 & $\frac{25}{20}$ & & & & 1.8 & 25 \\
\hline & & & & & 0.3 & & & 24 & 10 & & & & 7.2 & $\frac{25}{25}$ \\
\hline & & & & & 0.3 & & & 103 & 50 & 0.02 & & & 8.9 & 20 \\
\hline & & & & & 0.8 & & & 110 & 170 & & & & 8.1 & 17 \\
\hline & & & & & 0.6 & & & 86 & 45 & & & & 7.8 & 25 \\
\hline & AHTN & & 8 & & 0.6 & & & 89 & 45 & & & & 7.5 & 25 \\
\hline & & & & & 0.5 & & & 70 & 25 & & & & 7.8 & 25 \\
\hline & & & & & 0.4 & & & 48 & 20 & & & & 6.9 & 25 \\
\hline & & & & & 0.3 & & & 24 & 10 & & & & 7.2 & 25 \\
\hline & & & 4 & CAS & & $5.6 E 5$ & -. & 15 & 12 & & & & . & 25 \\
\hline & SPY & & a & MBR & & 18000 & $\begin{array}{l}\text { MF; ; HF (0.4 or } 0.1, \text { na) } \\
\text { and UF ; HF (0.04, na) }\end{array}$ & 13 & $16-80$ & & & & 5.8 & 14 \\
\hline & & & 2 & CAS & & $9.1 \mathrm{E} 5$ & $\ldots$ & 31 & 21 & & & & 7.5 & 12 \\
\hline & & & 07 & CAS & & 5.655 & $=\mathrm{HE}(0.4$ or 01 na) & 15 & 12 & & & & 5.8 & 14 \\
\hline & SMX & & a & MBR & & 18000 & $\begin{array}{l}\text { and UF ; HF }(0.04, \mathrm{na}) \\
\end{array}$ & 13 & $16-80$ & & & & .0. & 14 \\
\hline & & & $\frac{0}{3}$ & $\begin{array}{l}\text { CAS } \\
\text { CAS }\end{array}$ & & $\begin{array}{l}9.155 \\
5.665\end{array}$ & \begin{tabular}{|l|}
$-\cdot$ \\
$\cdots$
\end{tabular} & $\begin{array}{l}31 \\
15\end{array}$ & $\begin{array}{l}21 \\
12\end{array}$ & & & & 7.5 & 12 \\
\hline & TRI & & a & MBR & & 18000 & MF; HF (0.4 or $0.1, \mathrm{na})$ & 13 & $16-80$ & & & & 5.8 & 14 \\
\hline & & & 0 & CAS & & 9.155 & -. & 31 & 21 & & & & 7.5 & 12 \\
\hline & & & $a$ & CAS & & 5.655 & $-\cdots$ & 15 & 12 & & & & & \\
\hline $\begin{array}{l}\text { Gobelet al., } \\
2007\end{array}$ & AZI & & a & MBR & $0.1-0.2$ & 18000 & $\begin{array}{l}\text { MF; } \mathrm{HF}(0.4 \text { or } 0.1, \mathrm{na}) \\
\text { and UF }-H F(0.04, \mathrm{na})\end{array}$ & 13 & $16-80$ & na & 1 & $+(n a)$ and $-(n a)$ & 5.8 & 14 \\
\hline & & & 2 & CAS & & 9.115 & -. & 31 & 21 & & & & 7.5 & 12 \\
\hline & & & 5 & CAS & & 5.655 & & 15 & 12 & & & & & \\
\hline & ERY & & a & MBR & & 18000 & $\begin{array}{l}\text { MF; } \mathrm{HF}(0.4 \text { or } 0.1, \mathrm{na}) \\
\text { and UF } \cdot H F(0.04, \mathrm{na})\end{array}$ & 13 & $16-80$ & & & & 5.8 & 14 \\
\hline & & & 9 & CAS & & $9.1 \mathrm{E5}$ & & 31 & 21 & & & & 7.5 & 12 \\
\hline & & & 9 & CAS & & $5.6 \mathrm{E}$ & & 15 & 12 & & & & & \\
\hline & CLA & & a & MBR & & 18000 & $\begin{array}{l}\text { MF ; HF }(0.4 \text { or } 0.1, \mathrm{na}) \\
\text { and UF. } \mathrm{HF}(0.04, \mathrm{na}\end{array}$ & 13 & $16-80$ & & & & 5.8 & 14 \\
\hline & & & & CAS & & $9.1 \mathrm{E5}$ & & 31 & 21 & & & & 7.5 & 12 \\
\hline & & & 8 & CAS & & 5.655 & & 15 & 12 & & & & & \\
\hline & ROX & & a & MBR & & 18000 & $\begin{array}{l}\text { MF ; HF }(0.4 \text { or } 0.1, \text { na) } \\
\text { and UF . HF }(0.04, \text { }\end{array}$ & 13 & $16-80$ & & & & 5.8 & 14 \\
\hline & & & & CAS & & $9.1 \mathrm{E5}$ & .. & 31 & 21 & & & & 7.5 & 12 \\
\hline & ACE & & $\frac{5}{9}$ & & & & & $\frac{32}{6-10}$ & & & & & & \\
\hline & ABP & & 5 & & & & & 32 & & & & & & \\
\hline & IBP & & & & & & & $6-10$ & & & & & & \\
\hline & NPX & & 4 & & & & & 32 & & & & & & \\
\hline & & & $\frac{a}{4}$ & & & & & $\frac{6-10}{32}$ & & & & & & \\
\hline & BZF & & 8 & & & & & $6-10$ & & & & & & \\
\hline & SLA & & 4 & & & & & 32 & & & & & & \\
\hline & & & $\frac{5}{4}$ & & & & & $6-10$ & & & & & & \\
\hline & Enalapril & & 7 & & & & & $\frac{32}{6-10}$ & & & & & & \\
\hline & Pravastin & & 4 & & & & & 32 & & & & & & \\
\hline & Pravastin & & 2 & & & & & $6-10$ & & & & & & \\
\hline Grosetgl & Famotidine & & $\frac{1}{5}$ & & & & & 32 & & & & & & \\
\hline 2010 & & & $\frac{5}{8}$ & WWTP & na & na & -. & $\frac{6-10}{32}$ & na & na & 1 & $+(\mathrm{na})$ & na & na \\
\hline & Ranitidine & & 5 & & & & & $6-10$ & & & & & & \\
\hline & CIP & & 4 & & & & & 32 & & & & & & \\
\hline & & & $\frac{8}{0}$ & & & & & $6-10$ & & & & & & \\
\hline & Furosemide & & $\frac{0}{3}$ & & & & & $\frac{32}{6-10}$ & & & & & & \\
\hline & Atenolol & & 8 & & & & & 32 & & & & & & \\
\hline & Atenolor & & & & & & & $6-10$ & & & & & & \\
\hline & SMX & & 5 & & & & & 32 & & & & & & \\
\hline & & & & & & & & $6-10$ & & & & & & \\
\hline & Salbutamol & & $\frac{2}{0}$ & & & & & 32 & & & & & & \\
\hline & PP7 & & 5 & & & & & $\frac{0-10}{32}$ & & & & & & \\
\hline & PPZ & & 2 & & & & & $6-10$ & & & & & & \\
\hline & HCTZ & & 8 & & & & & 32 & & & & & & \\
\hline & SIA & & $\frac{2}{5}$ & & & & & & & & & & & 20 \\
\hline & SLA & & 5 & & & & & & & & & & & 45 \\
\hline & KPF & & & & & & & & & & & & & 20 \\
\hline & & & 2 & & & & & & & & & & & $\frac{45}{20}$ \\
\hline & FNP & & $\frac{2}{2}$ & & & & & & & & & & & $\frac{25}{45}$ \\
\hline & NPX & & 5 & & & & & & & & & & & 20 \\
\hline $\begin{array}{l}\text { Haiet al., } \\
2011\end{array}$ & & & $\frac{0}{5}$ & MBR & na & 9 & UF ; HF $(0.04,0.05)$ & 24 & 500 & 5 & 80 & $+(3)$ & 7.8 & 45 \\
\hline & MDZ & & 8 & & & & & & & & & & & $\frac{20}{45}$ \\
\hline & PRM & & 5 & & & & & & & & & & & 20 \\
\hline & & & & & & & & & & & & & & 45 \\
\hline & DCF & & 5 & & & & & & & & & & & 20 \\
\hline & & & 2 & & & & & & & & & & & 45 \\
\hline & GFZ & 1 & $\frac{00}{2}$ & & & & & & & & & & & $\frac{20}{45}$ \\
\hline
\end{tabular}




\begin{tabular}{|c|c|}
\hline & \\
\hline Reference & Molecule $^{\mathrm{a}}$ \\
\hline & CBZ \\
\hline & IBP \\
\hline & IBP \\
\hline & PCP \\
\hline & PCP \\
\hline & $E_{3}$ \\
\hline & \\
\hline & 4-BP \\
\hline & 4-BP \\
\hline & $F=$ \\
\hline & E1 \\
\hline Hai et al., & BPA \\
\hline 2011 & BPA \\
\hline & EE2 \\
\hline & EE2 \\
\hline & \\
\hline & Estradiol \\
\hline & \\
\hline & TCS \\
\hline & \\
\hline & E2 17-acetate \\
\hline & \\
\hline & 4-OP \\
\hline & \\
\hline & 4-n-NP \\
\hline & \\
\hline Jelic et al. , & CBZ \\
\hline & \\
\hline & \\
\hline & \\
\hline & \\
\hline & \\
\hline & CBZ \\
\hline & \\
\hline & \\
\hline & \\
\hline & \\
\hline & \\
\hline & \\
\hline & \\
\hline & DCF \\
\hline & \\
\hline & \\
\hline & \\
\hline & \\
\hline & \\
\hline & \\
\hline Joss et al., & IBP \\
\hline 2005 & IBP \\
\hline & \\
\hline & \\
\hline & \\
\hline & \\
\hline & \\
\hline & \\
\hline & SMX \\
\hline & SMX \\
\hline & \\
\hline & \\
\hline & \\
\hline & \\
\hline & \\
\hline & \\
\hline & NPY \\
\hline & NPX \\
\hline & \\
\hline & \\
\hline & \\
\hline & \\
\hline & CFA \\
\hline & \\
\hline & \\
\hline & DCF \\
\hline & \\
\hline & \\
\hline & KPF \\
\hline Kimura et al., & \\
\hline 2007 & \\
\hline & IBP \\
\hline & \\
\hline & \\
\hline & MFA \\
\hline & \\
\hline & \\
\hline & NPX \\
\hline & \\
\hline & IBP \\
\hline Kruglova et al., & $\mathrm{DCF}$ \\
\hline 2014 & $\mathrm{CBZ}$ \\
\hline & \\
\hline & $\mathrm{NPX}$ \\
\hline & BSP \\
\hline Oikari, 2011 & BSP \\
\hline & \\
\hline & DCF \\
\hline
\end{tabular}




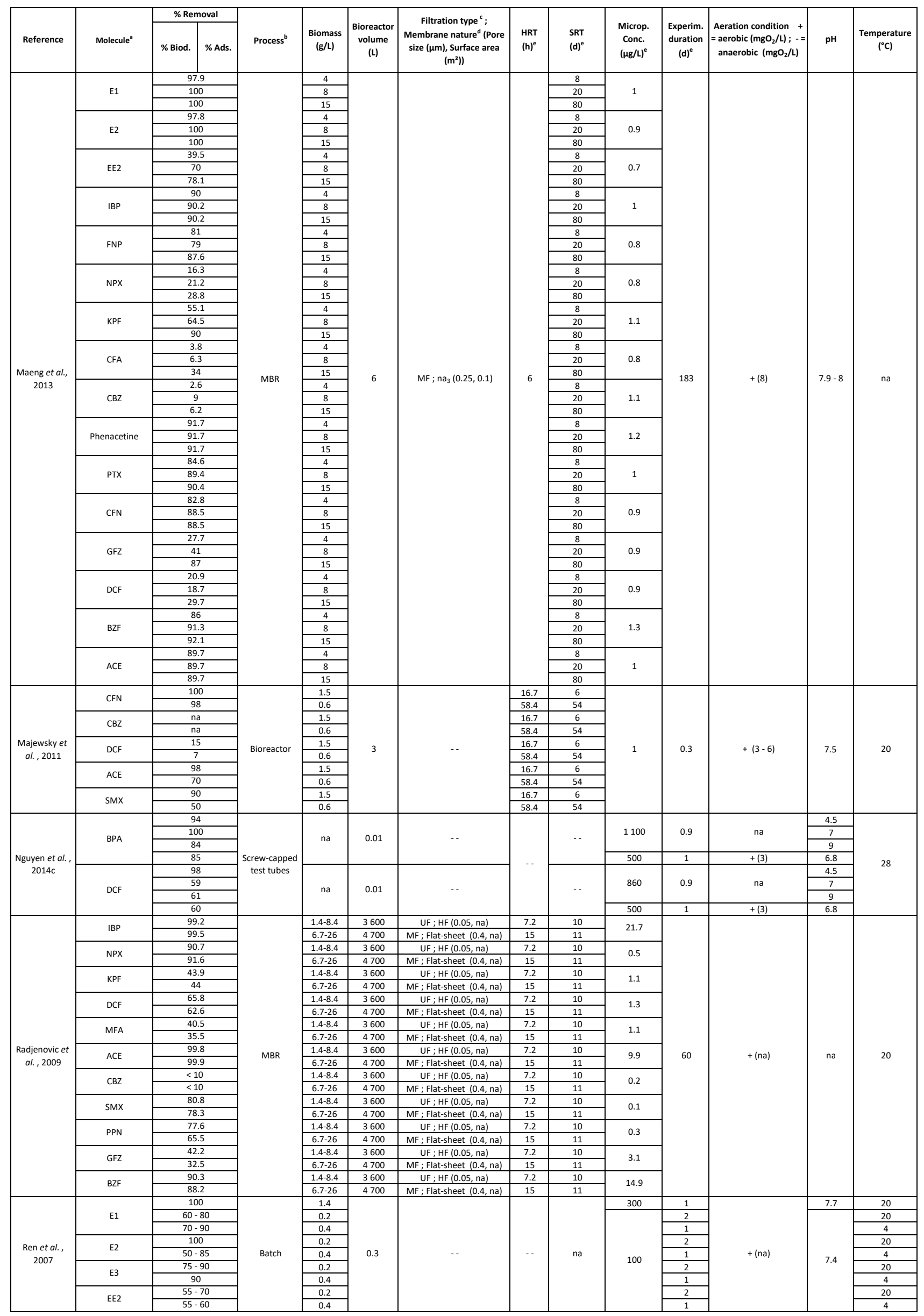




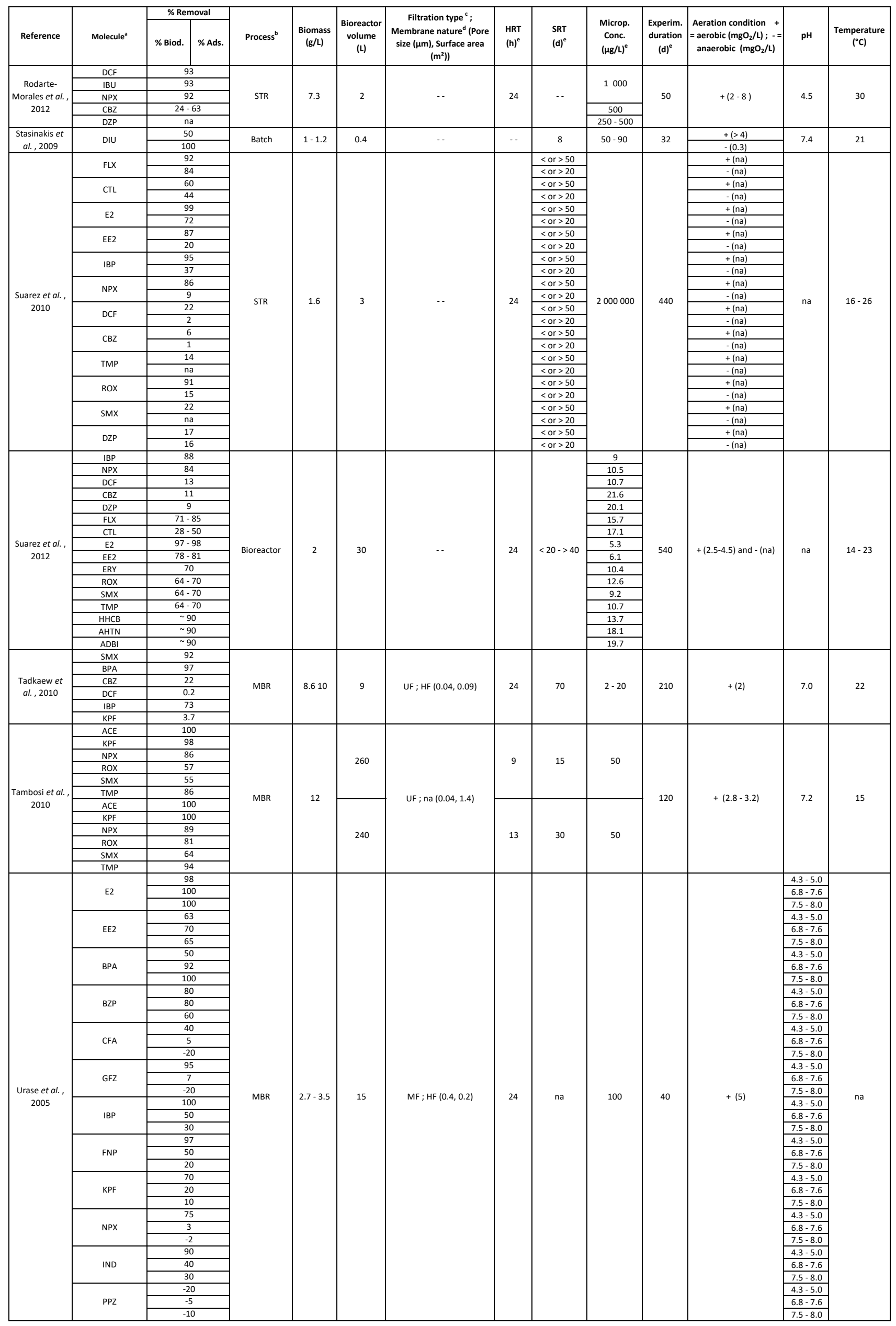




\begin{tabular}{|c|c|c|c|c|c|c|c|c|c|c|c|c|c|c|}
\hline \multirow[b]{2}{*}{ Reference } & \multirow[b]{2}{*}{ Molecule $^{\mathrm{a}}$} & \multicolumn{2}{|c|}{ \% Removal } & \multirow[b]{2}{*}{ Process $^{b}$} & \multirow[b]{2}{*}{$\begin{array}{c}\text { Biomass } \\
(\mathrm{g} / \mathrm{L})\end{array}$} & \multirow[b]{2}{*}{$\begin{array}{c}\text { Bioreactor } \\
\text { volume } \\
\text { (L) }\end{array}$} & \multirow{2}{*}{$\begin{array}{c}\text { Filtration type }{ }^{c} ; \\
\text { Membrane nature } \\
\text { size }(\mu \mathrm{m}), \text { Surface area } \\
\left.\left(\mathrm{m}^{2}\right)\right)\end{array}$} & \multirow[b]{2}{*}{$\begin{array}{l}\text { HRT } \\
(\text { h) }\end{array}$} & \multirow[b]{2}{*}{$\begin{array}{l}\text { SRT } \\
(\text { d) }\end{array}$} & \multirow[b]{2}{*}{$\begin{array}{l}\text { Microp. } \\
\text { Conc. } \\
\left(\mu \mathrm{g} / \mathrm{L}^{\mathrm{e}}\right.\end{array}$} & \multirow[b]{2}{*}{$\begin{array}{l}\text { Experim. } \\
\text { duration } \\
\text { (d) }^{e^{e}}\end{array}$} & \multirow[b]{2}{*}{$\mid \begin{array}{c}\text { Aeration condition }+ \\
=\text { aerobic }\left(\mathrm{mgO}_{2} / \mathrm{L}\right) ;-= \\
\text { anaerobic }\left(\mathrm{mgO}_{2} / \mathrm{L}\right)\end{array}$} & \multirow[b]{2}{*}{$\mathrm{pH}$} & \multirow[b]{2}{*}{$\begin{array}{c}\text { Temperature } \\
\left({ }^{\circ} \mathrm{C}\right)\end{array}$} \\
\hline & & \% Biod. & \%Ads. & & & & & & & & & & & \\
\hline \multirow{6}{*}{$\begin{array}{l}\text { Urase et al., } \\
2005\end{array}$} & \multirow{3}{*}{ DCF } & \multicolumn{2}{|c|}{95} & \multirow{6}{*}{ MBR } & & & & & & & & & $4.3-5.0$ & \\
\hline & & 1 & & & & & & & & & & & $6.8-7.6$ & \\
\hline & & 7 & & & & & & & & & & & $7.5-8.0$ & \\
\hline & & 3 & & & $2.7-3.5$ & 15 & $\mathrm{MF} ; \mathrm{HF}(0.4,0.2)$ & 24 & na & 100 & 40 & $+(5)$ & $4.3-5.0$ & na \\
\hline & CBZ & $n$ & & & & & & & & & & & $6.8-7.6$ & \\
\hline & & 5 & & & & & & & & & & & $7.5-8.0$ & \\
\hline & & 99 & & & 6.3 & & & & 60 & & & & & \\
\hline & & 99 & & & 3.4 & & & & 30 & & 180 & & & \\
\hline & $\sin x$ & 96 & & & 1.5 & & & & 10 & & 90 & & & \\
\hline & & 88 & & & 0.3 & & & & 3 & & 70 & & & \\
\hline & & 99 & & & 6.3 & & & & 60 & & & & & \\
\hline & & 99 & & $M B R$ & 3.4 & 6 & $U F \cdot H F_{2}(0.020 .1)$ & 24 & 30 & 500 & 180 & + (na) and - (na) & & \\
\hline ala et al. , 2012 & SOL & 97 & & MIBK & 1.5 & 6 & OF $; \mathrm{HF}_{2}(\mathrm{O} . \mathrm{OL}, \mathrm{O} .1)$ & 24 & 10 & 300 & 90 & + (na) ana - (na) & 1.8 & 25 \\
\hline & & 93 & & & 0.3 & & & & 3 & & 70 & & & \\
\hline & & 99 & & & 6.3 & & & & 60 & & & & & \\
\hline & & 99 & & & 3.4 & & & & 30 & & 180 & & & \\
\hline & Ampicillin & 99 & & & 1.5 & & & & 10 & & 90 & & & \\
\hline & & 94 & & & 0.3 & & & & 3 & & 70 & & & \\
\hline & 4-OP & 7 & & & & & & & & & & & & \\
\hline & 4-NP & 7 & & & & & & & & & & & & \\
\hline & BPA & $>9$ & & & & & & & & & & & & \\
\hline & E1 & $>9$ & & & & & & & & & & & & \\
\hline & E2 & $>9$ & & & & & & & & 1 & & & & \\
\hline & $17 \alpha-E 2$ & $>9$ & & & & & & & & & & & & \\
\hline & E3 & $>9$ & & & & & & & & & & & & \\
\hline & EE2 & 9 & & & & & & & & & & & & \\
\hline & ERY & $>9$ & & & & & & & & & & & & \\
\hline $\begin{array}{l}\text { Xue et al., } \\
2010\end{array}$ & TMP & $>9$ & & MBR & 1 & 10 & $\mathrm{UF} ; \mathrm{HF}_{2}(0.04,182.9)$ & 14.5 & 20 & & na & $+(4-6)$ and $-(0-0.5)$ & na & 25 \\
\hline & DCF & $<2$ & & & & & & & & & & & & \\
\hline & KPF & $>9$ & & & & & & & & & & & & \\
\hline & ME-P & $n$ & & & & & & & & & & & & \\
\hline & Sulpiride & $<2$ & & & & & & & & $1-50$ & & & & \\
\hline & DEET & $>9$ & & & & & & & & & & & & \\
\hline & $\mathrm{CBZ}$ & $<2$ & & & & & & & & & & & & \\
\hline & CFN & $>9$ & & & & & & & & & & & & \\
\hline & HHCB & 5 & & & & & & & & & & & & \\
\hline & AHTN & 5 & & & & & & & & & & & & \\
\hline & BZT & 6 & & MBR & & 21 & $M F ; n a_{1}(0.4,0.3)$ & $7-14$ & $26-102$ & 11.8 & & & & \\
\hline & BLI & 3 & & CAS & & na & -.. & 18 & 15 & 11.8 & & & & \\
\hline & 5-Tolyltriazole & 6 & & MBR & & 21 & $M F ; n a_{1}(0.4,0.3)$ & $7-14$ & $26-102$ & 1.3 & & & & \\
\hline Weiss and & 5-10iytriazole & 1 & & CAS & & na & $\ldots$ & 18 & 15 & 1.3 & & & & \\
\hline Reemtsma, & Benzothiazole-2- & 6 & & MBR & 5 & 21 & $\mathrm{MF} ; \mathrm{na}_{1}(0.4,0.3)$ & $7-14$ & $26-102$ & 3.4 & 660 & $+(n a)$ & na & na \\
\hline 2008 & sulfonate & 2 & & CAS & & na & .. & 18 & 15 & 3.4 & & & & \\
\hline & & 3 & & MBR & & 21 & $\mathrm{MF} ; \mathrm{na}_{1}(0.4,0.3)$ & $7-14$ & $26-102$ & & & & & \\
\hline & disulfonate & 1 & & CAS & & na & -. & 18 & 15 & 0.4 & & & & \\
\hline \begin{tabular}{c|} 
Zhang and \\
Geissen, 2012
\end{tabular} & CBZ & $21-68$ & $18-45$ & Bioreactor & na & 2 & -. & -. & -. & 5000 & 24 & $+(n a)$ & 7.5 & $>35$ \\
\hline
\end{tabular}

To facilitate readability of this table, all values have been rounded off to one decimal place except for values less than 0.05 which have been rounded off to two decimal place.

- defines absent in the considered item and na defines not available

a: ACE: Acetaminophen, ADBI: Celestolide, AHTN: Tonalide, ATZ: Atrazine, AZI: Azithromycin, BZF: Bezafibrate, BPA: Bisphenol A, BP: Butylphenol, BSP: Bisoprolol, BZP: Benzophenone, BZT: Benzotriazole, CBZ: Carbamazepine, CFA: Clofibric acid, CFN: Caffeine, CIP: Ciprofloxacin, CLA: Clarithromycin, CLI: Clindamycin, CP: chlorophenol, CTL: Citalopram, DBA: Dichlorobenzoic acid, DCF: Diclofenac, DEET: N,N-diethyl-m-toluamide, DIU: Diuron, DZP: Diazepam, ERY: Erythromycin, E1: Estrone, E2: 17ß-Estradiol, E3: Estriol, EE2: 17a-Ethinylestradiol, FLX: Fluoxetine, FNP: Fenoprofen, GFZ: Gemfibrozil, HCTZ: Hydrochlorothiazide, HHCB: Galaxolide, IBP: Ibuprofen, IND : Indomethacin, KPF: Ketoprofen, MDZ: Metronidazole, MFA: Mefenamic acid, NP: Nonyphenol, NPX: Naproxen, OFX: Ofloxacin, OP: Octylphenol, PCP: Pentachlorophenol, PEN: Penicillin, PPN: Propanolol, PPX: Propoxur, PRM: Primidone, PTX: Pentoxifylline, ROX: Roxithromycin, SDZ: Sulfadiazine, SLA: Salicylic acid, SMX: Sulfamethoxazole, SPY: Sulfapyridine, TCS: Triclosan, TMP: Trimethroprim

b: CAS defines Conventional Activated Sludge; MBR defiens Membrane Bioreactor; STR defines Stirred Tank Reactor; WWTP defines Wastewater Treatment Plant

c: HF defines Hollow fiber; MF defines Microfiltration; UF defines Ultrafiltration

d: Chemical nature of the used membrane: $1=$ chlorinated polyethylene, $2=$ polyvinylidene fluoride, $3=$ polyethylen

e: HRT defines Hydraulic Retention Time; SRT defines Sludge Retention Time

In order to maintain consistency, all HRT values have been converted into hours, SRT values into days, micropollutant concentrations into $\mu \mathrm{g} / \mathrm{L}$ and experimental duration into days. 
Table 2 : Biodegradation of organic micropollutants in different classical processes using several microorganism types.

\begin{tabular}{|c|c|c|c|c|c|c|c|}
\hline \multirow[b]{2}{*}{ Reference } & \multirow[b]{2}{*}{ Molecule $^{\mathrm{a}}$} & \% Removal & \multirow[b]{2}{*}{ Process $^{b}$} & \multirow{2}{*}{$\begin{array}{l}\text { Microorganisms/ } \\
\text { Enzymes }^{c}\end{array}$} & & Microp. Concentration & Experim. duration \\
\hline & & $\%$ Biod. & & & Biomass or enzyme activity & $(\mu \mathrm{g} / \mathrm{L})^{d}$ & (d) $)^{d}$ \\
\hline & & 68 & & & $2 \mathrm{U} / \mathrm{mL}$ & & \\
\hline & & 90 & & & $10 \mathrm{U} / \mathrm{mL}$ & 0.03 & \\
\hline & F1 & 100 & & & $20 \mathrm{U} / \mathrm{mL}$ & & \\
\hline & {$[1$} & 70 & & & $2 \mathrm{U} / \mathrm{mL}$ & & \\
\hline & & 90 & & & $10 \mathrm{U} / \mathrm{mL}$ & 0.1 & \\
\hline & & 100 & & & $20 \mathrm{U} / \mathrm{mL}$ & & \\
\hline & & 55 & & & $2 \mathrm{U} / \mathrm{mL}$ & & \\
\hline & & 70 & & & $10 \mathrm{U} / \mathrm{mL}$ & 0.3 & \\
\hline & & 100 & & & $20 \mathrm{U} / \mathrm{mL}$ & & \\
\hline & E2 & 65 & & & $2 \mathrm{U} / \mathrm{mL}$ & & \\
\hline & & 90 & & & $10 \mathrm{U} / \mathrm{mL}$ & 0.1 & \\
\hline Auriol et al., & & 100 & & & $20 \mathrm{U} / \mathrm{mL}$ & & \\
\hline 2007 & & 60 & Batch & LAC from T. versicolor & $2 \mathrm{U} / \mathrm{mL}$ & & 0.04 \\
\hline & & 89 & & & $10 \mathrm{U} / \mathrm{mL}$ & 0.01 & \\
\hline & & 100 & & & $20 \mathrm{U} / \mathrm{mL}$ & & \\
\hline & E3 & 50 & & & $2 \mathrm{U} / \mathrm{mL}$ & & \\
\hline & & 92 & & & $10 \mathrm{U} / \mathrm{mL}$ & 0.1 & \\
\hline & & 100 & & & $20 \mathrm{U} / \mathrm{mL}$ & & \\
\hline & & 70 & & & $2 \mathrm{U} / \mathrm{mL}$ & & \\
\hline & & 88 & & & $10 \mathrm{U} / \mathrm{mL}$ & 0.01 & \\
\hline & & 100 & & & $20 \mathrm{U} / \mathrm{mL}$ & & \\
\hline & EE2 & 82 & & & $2 \mathrm{U} / \mathrm{mL}$ & & \\
\hline & & 98 & & & $10 \mathrm{U} / \mathrm{mL}$ & 0.1 & \\
\hline & & 100 & & & $20 \mathrm{U} / \mathrm{mL}$ & & \\
\hline & & 43.8 & & T. versicolor & & & \\
\hline & & 10.1 & & D. squalens & & & \\
\hline & Metalaxyl & 3.9 & & P. velutina & & & \\
\hline & & 10.1 & & P. ostreatus & & & \\
\hline & & 63.3 & & T. versicolor & & & \\
\hline & Terbuthylazine & 52 & & D. squalens & & & \\
\hline & lerbuthylazıne & 53.9 & & P. velutina & & & \\
\hline Bending et al., & & 31 & Batch & P. ostreatus & $m$ & 10000 & 42 \\
\hline 2002 & & 86.2 & Batch & T. versicolor & na & 10000 & 42 \\
\hline & AT7 & 25.6 & & D. squalens & & & \\
\hline & AIL & 20.3 & & P. velutina & & & \\
\hline & & 15.5 & & P. ostreatus & & & \\
\hline & & 99.4 & & T. versicolor & & & \\
\hline & & 21.4 & & D. squalens & & & \\
\hline & DIU & 5.6 & & P. velutina & & & \\
\hline & & 12.4 & & P. ostreatus & & & \\
\hline & KPF & 62 & & & & 0.5 & \\
\hline & BZF & 91 & & & & 2.6 & \\
\hline Benito Quintana & NPX & 71 & MBR & Activated sludge & $20-30 \mathrm{~g} / \mathrm{L}$ & 1 & $8.8-10$ \\
\hline & IBP & 97 & & & & 5.7 & \\
\hline & DCF & 23 & & & & 2.8 & \\
\hline & ATZ & 9 & & & & & \\
\hline & Bentazone & 16 & & & & 25000 & \\
\hline & Isoproturon & 25 & & & & & \\
\hline & MCPP & 50 & & & & & \\
\hline & Icaridine & 93 & & & & & \\
\hline Bernhard et al., & CBZ & 13 & MBR & Activated sludge & na & & 510 \\
\hline 2006 & CFA & 54 & & & & & \\
\hline & DCF & 58 & & & & na & \\
\hline & 2,4-DBA & 83 & & & & & \\
\hline & IBP & 99 & & & & & \\
\hline & EDTA & 0 & & & & & \\
\hline & & 70 & & F. oxysporum & & & \\
\hline & & 35 & & G. galactomyces & & & \\
\hline & DEHP & 20 & & T. harzianum & & 250000 & \\
\hline & & 100 & & F. solani & & & \\
\hline & & 50 & & F. oxysporum & & & \\
\hline & $\mathrm{Fl}$ & $<5$ & & G. galactomyces & & 250 & \\
\hline & & $<5$ & & T. harzianum & & & \\
\hline Bouchiat et al., & & 10 & Ratch & F. solani & $10^{4} \mathrm{snores} / \mathrm{ml}$ & & 10 \\
\hline 2016 & & 28 & Batch & F. oxysporum & $10^{-1}$ spores $/ \mathrm{mL}$ & & 10 \\
\hline & & 0 & & G. galactomyces & & & \\
\hline & AMPA & 70 & & T.harzianum & & 2.5 & \\
\hline & & 30 & & F. solani & & & \\
\hline & & & & F. oxysporum & & & \\
\hline & E1 & 0 & & G. galactomyces & & 0.01 & \\
\hline & & & & T. harzianum & & 0.01 & \\
\hline & & & & F. solani & & & \\
\hline & & 70 & & T. versicolor & & & \\
\hline & & 28 & & B. adusta & $2-3 \mathrm{mg}$ & & \\
\hline & & 40 & & P. cinnabarinus & & & \\
\hline $\begin{array}{c}\text { Cajthaml et al ., } \\
2009\end{array}$ & 4-NP & 40 & Batch & P. chrysosporium & & 2500 & 14 \\
\hline & & 20 & & P. magnoliae & & & \\
\hline & & 60 & & P. ostreatus & $4-5 \mathrm{mg}$ & & \\
\hline & & 30 & & D. squalens & & & \\
\hline
\end{tabular}




\begin{tabular}{|c|c|c|c|c|c|c|c|c|}
\hline \multirow[b]{2}{*}{ Reference } & \multirow[b]{2}{*}{ Molecule $^{\mathrm{a}}$} & \multicolumn{2}{|c|}{ \% Removal } & \multirow[b]{2}{*}{ Process $^{b}$} & \multirow{2}{*}{$\begin{array}{c}\text { Microorganisms/ } \\
\text { Enzymes }^{c}\end{array}$} & \multirow[b]{2}{*}{ Biomass or enzyme activity } & \multirow{2}{*}{$\begin{array}{l}\text { Microp. Concentration } \\
(\mu \mathrm{g} / \mathrm{L})^{\mathrm{d}}\end{array}$} & \\
\hline & & $\%$ Biod. & $\%$ Ads. & & & & & (d) ${ }^{d}$ \\
\hline & & & & & T. versicolor & & & \\
\hline & & & & & B. adusta & $2-3 \mathrm{mg}$ & & \\
\hline & NP & & & & P. cinnabarinus & & 3000 & \\
\hline & $\mathrm{NP}$ & & & & P. chrysosporium & & 3000 & \\
\hline & & & & & P. magnoliae & & & \\
\hline & & & & & P. ostreatus & $4-5 \mathrm{mg}$ & & \\
\hline & & & & & D. squalens & & & \\
\hline & & & & & T. versicolor & & & \\
\hline & & & & & B. adusta & $2-3 \mathrm{mg}$ & & \\
\hline & & & & & P. cinnabarinus & & & \\
\hline & BPA & & & & P. chrysosporium & & 10000 & \\
\hline & & & & & P. magnoliae & & & \\
\hline & & & & & P. ostreatus & $4-5 \mathrm{mg}$ & & \\
\hline Cajthaml et al ., & & & & Batch & D. squalens & & & 14 \\
\hline 2009 & & & & Dactur & T. versicolor & & & 14 \\
\hline & & & & & B. adusta & $2-3 \mathrm{mg}$ & & \\
\hline & & & & & P. cinnabarinus & & & \\
\hline & EE2 & & & & P. chrysosporium & & 10000 & \\
\hline & & & & & P. magnoliae & & & \\
\hline & & & & & P. ostreatus & $4-5 \mathrm{mg}$ & & \\
\hline & & & & & D. squalens & & & \\
\hline & & & & & T. versicolor & & & \\
\hline & & & & & B. adusta & $2-3 \mathrm{mg}$ & & \\
\hline & & & & & P. cinnabarinus & & & \\
\hline & TCS & & & & P. chrysosporium & & 2500 & \\
\hline & & & & & P. magnoliae & & & \\
\hline & & & & & P. ostreatus & $4-5 \mathrm{mg}$ & & \\
\hline & & & & & D. squalens & & & \\
\hline \begin{tabular}{|c|} 
Castillo et al. , \\
2006 \\
\end{tabular} & DIU & & & Batch & S. albidoflavus & $10^{6}$ cells $/ \mathrm{mL}$ & 4000 & 5 \\
\hline $\begin{array}{c}\text { Coelho-Moreira } \\
\text { et al. , } 2013\end{array}$ & DIU & & & Batch & P. chrysosporium & na & 7000 & 10 \\
\hline & & & & & & $2.5 \mathrm{~g} \mathrm{dw} / \mathrm{L}$ & 35.6 & \\
\hline & NPX & & & & & $1.5 \mathrm{~g} \mathrm{dw} / \mathrm{L}$ & na & \\
\hline & IBP & & & & & $2.5 \mathrm{~g} \mathrm{dw} / \mathrm{L}$ & 12.6 & \\
\hline & IBP & & & & & $1.5 \mathrm{~g} \mathrm{dw} / \mathrm{L}$ & 2.2 & \\
\hline & ACE & & & & & $2.5 \mathrm{~g} \mathrm{dw} / \mathrm{L}$ & 3.8 & \\
\hline & ACE & & & & & $1.5 \mathrm{~g} \mathrm{dw} / \mathrm{L}$ & 1.6 & \\
\hline & & & & & & $2.5 \mathrm{~g} \mathrm{dw} / \mathrm{L}$ & 0.9 & \\
\hline & SLA & & & & & $1.5 \mathrm{~g} \mathrm{dw} / \mathrm{L}$ & na & \\
\hline & & & & & & $2.5 \mathrm{~g} \mathrm{dw} / \mathrm{L}$ & 0.5 & \\
\hline & KPF & & & & & $1.5 \mathrm{~g} \mathrm{dw} / \mathrm{L}$ & 0.1 & \\
\hline & Codeine & & & & & $2.5 \mathrm{~g} \mathrm{dw} / \mathrm{L}$ & 0.02 & \\
\hline & Codeine & & & & & $1.5 \mathrm{~g} \mathrm{dw} / \mathrm{L}$ & na & \\
\hline & ERY & & & & & $2.5 \mathrm{~g} \mathrm{dw} / \mathrm{L}$ & 0.3 & \\
\hline & $E R Y$ & & & & & $1.5 \mathrm{~g} \mathrm{dw} / \mathrm{L}$ & na & \\
\hline & MDZ & & & & & $2.5 \mathrm{~g} \mathrm{dw} / \mathrm{L}$ & 0.05 & \\
\hline & MDZ & & & & & $1.5 \mathrm{~g} \mathrm{dw} / \mathrm{L}$ & na & \\
\hline Cruz-Morato et & CIP & & & Batch & & $2.5 \mathrm{~g} \mathrm{dw} / \mathrm{L}$ & na & 7 \\
\hline al. , 2013 & CIP & & & Batch & T. versicolor & $1.5 \mathrm{~g} \mathrm{dw} / \mathrm{L}$ & 84.7 & \\
\hline & & & & & & $2.5 \mathrm{~g} \mathrm{dw} / \mathrm{L}$ & na & \\
\hline & AZI & & & & & $1.5 \mathrm{~g} \mathrm{dw} / \mathrm{L}$ & 4.3 & \\
\hline & Cefalexine & & & & & $2.5 \mathrm{~g} \mathrm{dw} / \mathrm{L}$ & na & \\
\hline & & & & & & $1.5 \mathrm{~g} \mathrm{dw} / \mathrm{L}$ & 0.6 & \\
\hline & PPN & & & & & $2.5 \mathrm{~g} \mathrm{dw} / \mathrm{L}$ & na & \\
\hline & PPN & & & & & $1.5 \mathrm{~g} \mathrm{dw} / \mathrm{L}$ & 0.1 & \\
\hline & CB7 & & & & & $2.5 \mathrm{~g} \mathrm{dw} / \mathrm{L}$ & 0.7 & \\
\hline & CBZ & & & & & $1.5 \mathrm{~g} \mathrm{dw} / \mathrm{L}$ & 0 & \\
\hline & & & & & & $2.5 \mathrm{~g} \mathrm{dw} / \mathrm{L}$ & 1 & \\
\hline & Acridone & & & & & $1.5 \mathrm{~g} \mathrm{dw} / \mathrm{L}$ & 0 & \\
\hline & & & & & & $2.5 \mathrm{~g} \mathrm{dw} / \mathrm{L}$ & 19.8 & \\
\hline & 10,11-ерохуCBZ & & & & & $1.5 \mathrm{~g} \mathrm{dw} / \mathrm{L}$ & 75.5 & \\
\hline & 2-HydroxyCBZ & & & & & $2.5 \mathrm{~g} \mathrm{dw} / \mathrm{L}$ & 0.5 & \\
\hline & & & & & & $1.5 \mathrm{~g} \mathrm{dw} / \mathrm{L}$ & 163.8 & \\
\hline & CTI & & & & & $2.5 \mathrm{~g} \mathrm{dw} / \mathrm{L}$ & 0.1 & \\
\hline & CTL & & & & & $1.5 \mathrm{~g} \mathrm{dw} / \mathrm{L}$ & 0.04 & \\
\hline & $A C F$ & 83.4 & 1.8 & Batch & & $1.5 \mathrm{~g} \mathrm{dw} / \mathrm{L}-2.5 \mathrm{~g} \mathrm{dw} / \mathrm{L}$ & 200 & 0.3 \\
\hline & ACE & & & MBR & & $1.5 \mathrm{~g} \mathrm{dw} / \mathrm{L}-2.5 \mathrm{~g} \mathrm{dw} / \mathrm{L}$ & 5 & 115 \\
\hline & & 96.8 & 1.2 & Batch & & $1.5 \mathrm{~g} \mathrm{dw} / \mathrm{L}-2.5 \mathrm{~g} \mathrm{dw} / \mathrm{L}$ & 200 & 0.3 \\
\hline & E2 & & 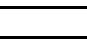 & MBR & & $1.5 \mathrm{~g} \mathrm{dw} / \mathrm{L}-2.5 \mathrm{~g} \mathrm{dw} / \mathrm{L}$ & 5 & 115 \\
\hline Fanetal 2014 & & 39.8 & 7 & Batch & & $1.5 \mathrm{~g} \mathrm{dw} / \mathrm{L}-2.5 \mathrm{~g} \mathrm{dw} / \mathrm{L}$ & 200 & 0.3 \\
\hline Fan et al. , 2014 & NPX & & & MBR & Activated sludge & $1.5 \mathrm{~g} \mathrm{dw} / \mathrm{L}-2.5 \mathrm{~g} \mathrm{dw} / \mathrm{L}$ & 5 & 115 \\
\hline & DCE-Na & 4.8 & 14.9 & Batch & & $1.5 \mathrm{~g} \mathrm{dw} / \mathrm{L}-2.5 \mathrm{~g} \mathrm{dw} / \mathrm{L}$ & 200 & 0.3 \\
\hline & DCF-Na & & & MBR & & $1.5 \mathrm{~g} \mathrm{dw} / \mathrm{L}-2.5 \mathrm{~g} \mathrm{dw} / \mathrm{L}$ & 5 & 115 \\
\hline & $C B 7$ & 1.1 & 7.8 & Batch & & $1.5 \mathrm{~g} \mathrm{dw} / \mathrm{L}-2.5 \mathrm{~g} \mathrm{dw} / \mathrm{L}$ & 200 & 0.3 \\
\hline & CBL & & & MBR & & $1.5 \mathrm{~g} \mathrm{dw} / \mathrm{L}-2.5 \mathrm{~g} \mathrm{dw} / \mathrm{L}$ & 5 & 115 \\
\hline
\end{tabular}




\begin{tabular}{|c|c|c|c|c|c|c|c|c|}
\hline \multirow[b]{2}{*}{ Reference } & \multirow[b]{2}{*}{ Molecule $^{a}$} & \multicolumn{2}{|c|}{ \% Removal } & \multirow[b]{2}{*}{ Process $^{b}$} & \multirow{2}{*}{$\begin{array}{l}\text { Microorganisms/ } \\
\text { Enzymes }^{c}\end{array}$} & \multirow[b]{2}{*}{ Biomass or enzyme activity } & \multirow{2}{*}{$\begin{array}{l}\text { Microp. Concentration } \\
\qquad(\mu \mathrm{g} / \mathrm{L})^{d}\end{array}$} & \multirow{2}{*}{$\begin{array}{l}\text { Experim. duration } \\
\text { (d) }{ }^{\text {d }}\end{array}$} \\
\hline & & $\%$ Biod & $\%$ Ads. & & & & & \\
\hline & Tamoxifen & 5 & 94 & & & & 10000 & \\
\hline Climent et al. , & Ifosfamide & 0 & 0 & Batch & T. versicolor & $0.6 \mathrm{~g} \mathrm{dw} / \mathrm{L}$ & 10000 & 9 \\
\hline & CTX & 0 & $<10$ & & & & 300 & \\
\hline & & & & & P. ostreatus F6 & & & \\
\hline Golan-Rozen et & & & & & P. ostreatus NOO1 & & 10000 & 17 \\
\hline al. , 2011 & CBZ & & & Batch & & na & & \\
\hline & & & & & P. ostreatus PC9 & & 1 & 8 \\
\hline & & & & & Sphingomonas sp. & & & \\
\hline & & & & & Mycobacterium sp. & & & \\
\hline & Phe & & & & $\begin{array}{l}\text { Sphingomonas sp. and } \\
\text { Mycobacterium sp. }\end{array}$ & & & \\
\hline & & & & & Sphingomonas sp. & & & \\
\hline & & & & & Mycobacterium sp. & & & \\
\hline Guo et al. , 2010 & $\mathrm{FI}$ & & & Batch & $\begin{array}{l}\text { Sphingomonas sp. and } \\
\text { Mycobacterium sp. }\end{array}$ & na & 50000 & 14 \\
\hline & & & & & Sphingomonas sp. & & & \\
\hline & & & & & Mycobacterium sp. & & & \\
\hline & Pyrene & & & & $\begin{array}{l}\text { Sphingomonas sp. and } \\
\text { Mycobacterium sp. }\end{array}$ & & & \\
\hline Hataetal 2010 & DCF & & & Ratch & $P$ sordida $Y K-624$ & $n$ & 30000 & 6 \\
\hline Hata et al. , 2010 & MFA & & & Batch & P. sordida YK-624 & na & 24000 & 6 \\
\hline & & & & & $\mathrm{MnP}$ & & & \\
\hline Hirai et al. , 2004 & Methoxychlor & & & Batch & LiP & 10 nkat & na & 1 \\
\hline & & & & & LAC & & & \\
\hline & & & & & & & 9000 & 2 \\
\hline Jelic et al. , 2012 & CBZ & 44 & 17 & Batch & T. versicolor & $9.6 \mathrm{~g} / \mathrm{L}$ & 50 & 7 \\
\hline & & & & & LAC from T. versicolor & & & \\
\hline Kim and Nicell, & & & & & LAC with SA & & & \\
\hline 2006 & TCS & & & Batch & LAC with ABTS & $3000 \mathrm{U} / \mathrm{L}$ & 5800 & 10 \\
\hline & & & & & LAC with HBT & & & \\
\hline & Atenolol & & & & & & 2.3 & \\
\hline & AZI & & & & & & 0.1 & \\
\hline & BZT & & & & & & 23.6 & \\
\hline & BZF & & & & & & 0.1 & \\
\hline & CBZ & & & & & & 0.2 & \\
\hline & Cilastatin & & & & & & 1 & \\
\hline & CIP & & & & & & 32 & \\
\hline & CLA & & & & & & 2.6 & \\
\hline & $\mathrm{CLI}$ & & & & & & 1 & \\
\hline & CFA & & & & & & $<0.1$ & \\
\hline & DEX & & & & & & 0.1 & \\
\hline & Diatrizoate & & & & & & 348.7 & \\
\hline & DZP & & & & & & 0.1 & \\
\hline & DCF & & & & & & 0.8 & \\
\hline & ERY & & & & & & 0.2 & \\
\hline & Fluconazole & & & & & & 3.4 & \\
\hline & $\mathrm{FLX}$ & & & & & & $<0.03$ & \\
\hline & Furosemide & & & & & & 2 & \\
\hline & Iohexol & & & & & & $<12$ & \\
\hline Kovalova et al. , & Iomeprol & & & MBR & Activated sludge & $2 \mathrm{~g} / \mathrm{L}$ & 439 & 1 \\
\hline & lopamidol & & & & & & 2599 & \\
\hline & IPM & & & & & & 170.6 & \\
\hline & MFA & & & & & & 6.1 & \\
\hline & METOP & & & & & & 1.3 & \\
\hline & MDZ & & & & & & 3.4 & \\
\hline & NPX & & & & & & $<5.6$ & \\
\hline & Norfloxacin & & & & & & 5.9 & \\
\hline & Oxazepam & & & & & & 1.1 & \\
\hline & ACE & & & & & & 107 & \\
\hline & Phenazone & & & & & & 0.2 & \\
\hline & PRM & & & & & & 0.4 & \\
\hline & PPN & & & & & & 0.1 & \\
\hline & ROX & & & & & & 0.02 & \\
\hline & Sotalol & & & & & & 0.7 & \\
\hline & SDZ & & & & & & 1.9 & \\
\hline & SMX & & & & & & 3.5 & \\
\hline & TMP & & & & & & 0.9 & \\
\hline & Valsartan & & & & & & 3 & \\
\hline & Venlafaxine & & & & & & 0.8 & \\
\hline Li et al. , 2013 & CBZ & & & Batch & Pseudomonas sp. CBZ-4 & $13 \% \mathrm{v} / \mathrm{v}$ & $10000-160000$ & 6 \\
\hline & & & & Batch & & 1g wood chips & 20000 & 7 \\
\hline & NPX & & & Reactor & & na & 1000 & 2.7 \\
\hline Li et al. , 2015 & & & & Batch & P. chrysosporium & 1g wood chips & 20000 & 7 \\
\hline & CBZ & & & Reactor & & na & 1000 & 2.7 \\
\hline
\end{tabular}




\begin{tabular}{|c|c|c|c|c|c|c|c|c|}
\hline \multirow{2}{*}{ Reference } & \multirow{2}{*}{ Molecule $^{a}$} & \multicolumn{2}{|c|}{ \% Removal } & \multirow{2}{*}{ Process $^{b}$} & \multirow{2}{*}{$\begin{array}{l}\text { Microorganisms/ } \\
\text { Enzymes }^{c}\end{array}$} & & Microp. Concentration & Experim. duration \\
\hline & & \% Biod. & $\%$ Ads. & & & Biomass or enzyme activity & $(\mu \mathrm{g} / \mathrm{L})^{\mathrm{d}}$ & $(d)^{d}$ \\
\hline & DCF & 100 & & & & & & \\
\hline & NPX & 60 & & & LAC from $M$ & & & \\
\hline Lloret et al., & E1 & 100 & & Batch & thermophila with & $2000 \mathrm{U} / \mathrm{L}$ & 5000 & 1 \\
\hline 2010 & E2 & 100 & & & synthetic or natural & $20000 / \mathrm{L}$ & & \\
\hline & EE2 & 100 & & & & & & \\
\hline & & 94.1 & & Fed-Batch & & & 5000 & 0.3 \\
\hline Lloret et al., & E1 & 95.6 & & EMR & LAC from $M$. & & 4000 & 0.4 \\
\hline 2012 & & 95.5 & & Fed-Batch & thermophila & $5000 / \mathrm{L}$ & 5000 & 0.3 \\
\hline & E2 & $>98$ & & EMR & & & 4000 & 0.4 \\
\hline & FPP & 25 & & & & & & \\
\hline & CBZ & 10 & & & & & & \\
\hline & MDZ & 16 & & & & & & \\
\hline & DCF & 40 & & & & & & \\
\hline & 4-BP & 56 & & & & & & \\
\hline & EE2 & 58 & & & & & & \\
\hline & KPF & 50 & & & & & & \\
\hline & GFZ & 80 & & & & & & \\
\hline & PCP & 82 & & & & & & \\
\hline & $4-O P$ & 84 & & & & & & \\
\hline Luo et al. , 2015 & PRM & 58 & & MBR & Activated sludge & $2.3 \mathrm{~g} / \mathrm{L}$ & 100000 & 16 \\
\hline & NPX & 78 & & & & & & \\
\hline & BPA & 50 & & & & & & \\
\hline & ACE & 90 & & & & & & \\
\hline & TCS & 90 & & & & & & \\
\hline & SLA & 88 & & & & & & \\
\hline & E3 & 62 & & & & & & \\
\hline & E1 & 78 & & & & & & \\
\hline & 4-NP & 92 & & & & & & \\
\hline & E2 & 94 & & & & & & \\
\hline & IBP & 96 & & & & & & \\
\hline & & 57 & & & T. versicolor & $2 \mathrm{mg} / \mathrm{L}$ & & \\
\hline & $C R 7$ & $<10$ & & & I. lacteus & $4 \mathrm{mg} / \mathrm{L}$ & & \\
\hline & CBL & 46 & & & G. lucidum & $3 \mathrm{mg} / \mathrm{L}$ & & \\
\hline & & $\sim 40$ & & & P. chrysosporium & $7 \mathrm{mg} / \mathrm{L}$ & & \\
\hline & & 97 & & & T. versicolor & $2 \mathrm{mg} / \mathrm{L}$ & & \\
\hline Marco-Urrea et & CEA & 0 & & Batch & I. lacteus & $4 \mathrm{mg} / \mathrm{L}$ & 10000 & 7 \\
\hline al. , 2009 & CFA & $\sim 25$ & & Batcn & G. lucidum & $3 \mathrm{mg} / \mathrm{L}$ & $\sim 10000$ & 7 \\
\hline & & $\sim 30$ & & & P. chrysosporium & $7 \mathrm{mg} / \mathrm{L}$ & & \\
\hline & & 100 & & & T. versicolor & $2 \mathrm{mg} / \mathrm{L}$ & & \\
\hline & IBP & 100 & & & I. lacteus & $4 \mathrm{mg} / \mathrm{L}$ & & \\
\hline & IBP & 100 & & & G. Iucidum & $3 \mathrm{mg} / \mathrm{L}$ & & \\
\hline & & 70 & & & P. chrysosporium & $7 \mathrm{mg} / \mathrm{L}$ & & \\
\hline $\begin{array}{l}\text { Marco-Urrea et } \\
\text { al. , 2010 }\end{array}$ & DCF & 53 & 47 & Batch & T. versicolor & $20 \mathrm{~g}$ wet pellets & 10000 & 7 \\
\hline & & 57 & & & T. versicolor & & & \\
\hline & $C B 7$ & 0 & & & I. lacteus & & & \\
\hline & CDL & 46 & & & G. lucidum & & & \\
\hline & & 0 & & & P. chrysosporium & & & \\
\hline & & $\sim 100$ & & & T. versicolor & & & \\
\hline Marco-Urrea et & IRP & $\sim 100$ & & Ratch & I. lacteus & $10 \% \times v$ & 10000 & 7 \\
\hline al. , 2012 & IBP & $\sim 100$ & & Batch & G. lucidum & $10 \% \mathrm{v} / \mathrm{v}$ & 10000 & 7 \\
\hline & & 65 & & & P. chrysosporium & & & \\
\hline & & 97 & & & T. versicolor & & & \\
\hline & CEA & 20 & & & I. lacteus & & & \\
\hline & CFA & 40 & & & G. lucidum & & & \\
\hline & & 0 & & & P. chrysosporium & & & \\
\hline & RPA & 98 & & & & $730 \mathrm{U} / \mathrm{L}$ & 20000 & 0.4 \\
\hline & DPA & $>90$ & & & & $500 \mathrm{U} / \mathrm{L}$ & 1 & 0.8 \\
\hline & $D C F$ & 20 & & & & $730 \mathrm{U} / \mathrm{L}$ & 20000 & 0.4 \\
\hline & Ucr & $>90$ & & & & $500 \mathrm{U} / \mathrm{L}$ & 1 & 0.8 \\
\hline Margot et al. , & MEA & 80 & & Batch & Ac from $T$ yersicolor & $730 \mathrm{U} / \mathrm{L}$ & 20000 & 0.4 \\
\hline 2013 & TVIFA & $>90$ & & Datcin & LAC IIIII I. VETSICOIOI & $500 \mathrm{U} / \mathrm{L}$ & 1 & 0.8 \\
\hline & E1 & & & & & & & \\
\hline & E2 & $>90$ & & & & $500 \mu / 1$ & 1 & 08 \\
\hline & EE2 & & & & & $3000 / \mathrm{L}$ & & \\
\hline & E3 & & & & & & & \\
\hline & BPA & 100 & & & LAC from T. versicolor & & & 2 \\
\hline & BPA & 97 & & & LAC from $S$ cyaneus & & & \\
\hline Margot et al., & DCF & 100 & & Batch & LAC from $T$. versicolor & $210-220$ U/L & 20000 & \\
\hline 2013 & DCF & 60 & & Batch & LAC from $S$ cyaneus & $210-2200 / \mathrm{L}$ & 20000 & 12 \\
\hline & MFA & 98 & & & LAC from T. versicolor & & & 12 \\
\hline & MIFA & 50 & & & LAC from $S$ cyaneus & & & \\
\hline $\begin{array}{l}\text { Murdoch and } \\
\text { Hay, } 2005\end{array}$ & IBP & 100 & & Batch & $\begin{array}{c}\text { Sphingomonas sp. Strain } \\
I B U-2\end{array}$ & na & 500000 & 80 \\
\hline & & 6 & & Batch & LAC from T. versicolor & $35 \mu \mathrm{M} / \mathrm{min}$ & 100 & 1 \\
\hline & PPX & 0 & & Batch & $\mathrm{LAC}+\mathrm{SA}$ & $35 \mu \mathrm{M} / \mathrm{min}$ & 100 & 1 \\
\hline Nguyen etal. & & 22 & & MBR & Act. sludge/ T. versicolor & $3 \mathrm{~g} / \mathrm{L}$ & 5 & 2 \\
\hline $2013 b$ & & 4 & & Batch & LAC from T. versicolor & $35 \mathrm{MM} / \mathrm{min}$ & 100 & 1 \\
\hline & CBZ & 0 & & Batcn & $\mathrm{LAC}+\mathrm{SA}$ & $35 \mu \mathrm{lv} / \mathrm{min}$ & 100 & 1 \\
\hline & & 23 & & MBR & Act. sludge/ T. versicolor & $3 \mathrm{~g} / \mathrm{L}$ & 5 & 2 \\
\hline
\end{tabular}




\begin{tabular}{|c|c|c|c|c|c|c|c|}
\hline \multirow{2}{*}{ Reference } & \multirow{2}{*}{ Molecule $^{\mathrm{a}}$} & \% Removal & \multirow{2}{*}{ Process $^{b}$} & \multirow{2}{*}{$\begin{array}{l}\text { Microorganisms/ } \\
\text { Enzymes }^{c}\end{array}$} & \multirow{2}{*}{ Biomass or enzyme activity } & \multirow{2}{*}{$\begin{array}{c}\text { Microp. Concentration } \\
(\mu \mathrm{g} / \mathrm{L})^{d}\end{array}$} & \multirow{2}{*}{$\begin{array}{l}\text { Experim. duration } \\
\text { (d) }^{\text {d }}\end{array}$} \\
\hline & & \% Biod. & & & & & \\
\hline & \multirow{3}{*}{ IBP } & 2 & \multirow{2}{*}{ Batch } & LAC from T. versicolor & \multirow{2}{*}{$35 \mu \mathrm{M} / \mathrm{min}$} & \multirow{2}{*}{100} & \multirow{2}{*}{1} \\
\hline & & 0 & & $\mathrm{LAC}+\mathrm{SA}$ & & & \\
\hline & & 98 & MBR & Act. sludge/ T. versicolor & $3 \mathrm{~g} / \mathrm{L}$ & 5 & 2 \\
\hline & & 0 & & LAC from $T$. versicolor & & & \\
\hline & BZP & 0 & Batch & $L A C+S A$ & $35 \mu \mathrm{M} / \mathrm{mIn}$ & 100 & 1 \\
\hline & & 85 & MBR & Act. sludge/ T. versicolor & $3 \mathrm{~g} / \mathrm{L}$ & 5 & 2 \\
\hline & & 0 & Batch & LAC from T. versicolor & $35 \mu \mathrm{M} / \mathrm{min}$ & 100 & 1 \\
\hline & FMN & 0 & Datin & $\mathrm{LAC}+\mathrm{SA}$ & 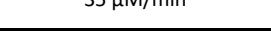 & & \\
\hline & & 97 & MBR & Act. sludge/ T. versicolor & $3 \mathrm{~g} / \mathrm{L}$ & 5 & 2 \\
\hline & & 8 & Batch & LAC from $T$. versicolor & $35 \mu \mathrm{M} / \mathrm{min}$ & 100 & 1 \\
\hline & CFA & 1 & & $\mathrm{LAC}+\mathrm{SA}$ & & & \\
\hline & & 65 & MBR & Act. sludge/ T. versicolor & $3 \mathrm{~g} / \mathrm{L}$ & 5 & 2 \\
\hline & & 9 & Batch & LAC from T. versicolor & $35 \mu \mathrm{M} / \mathrm{min}$ & 100 & 1 \\
\hline & FPP & 1 & Datcil & $\mathrm{LAC}+\mathrm{SA}$ & & & \\
\hline & & 57 & MBR & Act. sludge/ T. versicolor & $3 \mathrm{~g} / \mathrm{L}$ & 5 & 2 \\
\hline & & 0 & Batch & LAC from $T$. versicolor & $35 \mu \mathrm{M} / \mathrm{min}$ & 100 & 1 \\
\hline & KPF & 7 & then & $\mathrm{LAC}+\mathrm{SA}$ & & & \\
\hline & & 94 & MBR & Act. sludge/ T. versicolor & $3 \mathrm{~g} / \mathrm{L}$ & 5 & 2 \\
\hline & & 17 & Batch & LAC from $T$. versicolor & $35 \mu \mathrm{M} / \mathrm{min}$ & 100 & 1 \\
\hline & MDZ & 11 & 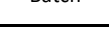 & $\mathrm{LAC}+\mathrm{SA}$ & & & \\
\hline & & 40 & MBR & Act. sludge/ T. versicolor & $3 \mathrm{~g} / \mathrm{L}$ & 5 & 2 \\
\hline & & 19 & Batch & LAC from T. versicolor & $35 \mu \mathrm{M} / \mathrm{min}$ & 100 & 1 \\
\hline & OCT & 13 & Datcil & $\mathrm{LAC}+\mathrm{SA}$ & & 100 & \\
\hline & & 93 & MBR & Act. sludge/ $T$. versicolor & $3 \mathrm{~g} / \mathrm{L}$ & 5 & 2 \\
\hline & & 68 & Batch & LAC from T. versicolor & $35 \mathrm{uM} / \mathrm{min}$ & 100 & 1 \\
\hline & BPA & 67 & DdtCII & $\mathrm{LAC}+\mathrm{SA}$ & 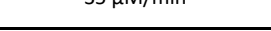 & 100 & 1 \\
\hline & & 75 & MBR & Act. sludge/ T. versicolor & $3 \mathrm{~g} / \mathrm{L}$ & 5 & 2 \\
\hline & & 71 & Batch & LAC from T. versicolor & $35 \mu \mathrm{M} / \mathrm{min}$ & 100 & 1 \\
\hline & TCS & 82 & Datcil & $\mathrm{LAC}+\mathrm{SA}$ & & & \\
\hline Nguyen et al., & & 97 & MBR & Act. sludge/ T. versicolor & $3 \mathrm{~g} / \mathrm{L}$ & 5 & 2 \\
\hline & & 85 & Batch & LAC from T. versicolor & $35 \mu \mathrm{M} / \mathrm{min}$ & 100 & 1 \\
\hline & EE2 & 85 & (1) & $\mathrm{LAC}+\mathrm{SA}$ & & & \\
\hline & & 92 & MBR & Act. sludge/ T. versicolor & $3 \mathrm{~g} / \mathrm{L}$ & 5 & 2 \\
\hline & & 88 & Batch & LAC from T. versicolor & $35 \mu \mathrm{M} / \mathrm{min}$ & 100 & 1 \\
\hline & E2-17 acetate & 87 & & $\mathrm{LAC}+\mathrm{SA}$ & & & \\
\hline & & 98 & MBR & Act. sludge/ T. versicolor & $3 \mathrm{~g} / \mathrm{L}$ & 5 & 2 \\
\hline & & 85 & Batch & LAC from T. versicolor & $35 \mu \mathrm{M} / \mathrm{min}$ & 100 & 1 \\
\hline & E1 & 88 & & $\mathrm{LAC}+\mathrm{SA}$ & & & \\
\hline & & 94 & MBR & Act. sludge/ T. versicolor & $3 \mathrm{~g} / \mathrm{L}$ & 5 & 2 \\
\hline & & 87 & Batch & LAC from $T$. versicolor & $35 \mu \mathrm{M} / \mathrm{min}$ & 100 & 1 \\
\hline & E2 & 88 & DdtcII & $\mathrm{LAC}+\mathrm{SA}$ & & & \\
\hline & & 99 & MBR & Act. sludge/ T. versicolor & $3 \mathrm{~g} / \mathrm{L}$ & 5 & 2 \\
\hline & & 85 & Batch & LAC from T. versicolor & $35 \mu \mathrm{M} / \mathrm{min}$ & 100 & 1 \\
\hline & E3 & 88 & & $\mathrm{LAC}+\mathrm{SA}$ & & & \\
\hline & & 95 & MBR & Act. sludge/ T. versicolor & $3 \mathrm{~g} / \mathrm{L}$ & 5 & 2 \\
\hline & & 89 & Batch & LAC from T. versicolor & $35 \mu \mathrm{M} / \mathrm{min}$ & 100 & 1 \\
\hline & 4-BP & 90 & & $\mathrm{LAC}+\mathrm{SA}$ & & & \\
\hline & & 98 & MBR & Act. sludge/ T. versicolor & $3 \mathrm{~g} / \mathrm{L}$ & 5 & 2 \\
\hline & & 92 & Batch & LAC from T. versicolor & $35 \mathrm{uM} / \mathrm{min}$ & 100 & 1 \\
\hline & $4-O P$ & 95 & & $\mathrm{LAC}+\mathrm{SA}$ & & & \\
\hline & & 98 & MBR & Act. sludge/ T. versicolor & $3 \mathrm{~g} / \mathrm{L}$ & 5 & 2 \\
\hline & & 1 & Batch & LAC from T. versicolor & $35 \mu \mathrm{M} / \mathrm{min}$ & 100 & 1 \\
\hline & GFZ & 26 & & $L A C+S A$ & & & \\
\hline & & 99 & MBR & Act. sludge/ T. versicolor & $3 \mathrm{~g} / \mathrm{L}$ & 5 & 2 \\
\hline & & 0 & Batch & LAC from T. versicolor & $35 \mu \mathrm{M} / \mathrm{min}$ & 100 & 1 \\
\hline & Amitriptyline & 28 & Datcin & $\mathrm{LAC}+\mathrm{SA}$ & & & \\
\hline & & 87 & MBR & Act. sludge/ T. versicolor & $3 \mathrm{~g} / \mathrm{L}$ & 5 & 2 \\
\hline & & 6 & Batch & LAC from T. versicolor & $35 \mu \mathrm{M} / \mathrm{min}$ & 100 & 1 \\
\hline & Ametryn & 30 & & $\mathrm{LAC}+\mathrm{SA}$ & & & \\
\hline & & 31 & MBR & Act. sludge/ T. versicolor & $3 \mathrm{~g} / \mathrm{L}$ & 5 & 2 \\
\hline & & 0 & Rotch & LAC from $T$. versicolor & $25 \mathrm{H} / \mathrm{min}$ & 100 & 1 \\
\hline & PRM & 40 & Batch & $\mathrm{LAC}+\mathrm{SA}$ & $35 \mu \mathrm{MI} / \mathrm{min}$ & 100 & 1 \\
\hline & & 95 & MBR & Act. sludge/ T. versicolor & $3 \mathrm{~g} / \mathrm{L}$ & 5 & 2 \\
\hline
\end{tabular}




\begin{tabular}{|c|c|c|c|c|c|c|c|}
\hline \multirow{2}{*}{ Reference } & \multirow{2}{*}{ Molecule $^{a}$} & \% Removal & \multirow{2}{*}{ Process $^{b}$} & \multirow{2}{*}{$\begin{array}{c}\text { Microorganisms/ } \\
\text { Enzymes }^{c}\end{array}$} & \multirow{2}{*}{ Biomass or enzyme activity } & \multirow{2}{*}{$\begin{array}{l}\text { Microp. Concentration } \\
(\mu \mathrm{g} / \mathrm{L})^{\mathrm{d}}\end{array}$} & \multirow{2}{*}{$\begin{array}{l}\text { Experim. duration } \\
\text { (d) }{ }^{\text {d }}\end{array}$} \\
\hline & & \% Biod. & & & & & \\
\hline \multirow{21}{*}{$\begin{array}{l}\text { Nguyen et al., } \\
2013 b\end{array}$} & \multirow{3}{*}{ SLA } & 0 & \multirow{2}{*}{ Batch } & LAC from $T$. versicolor & $35 \mathrm{uM} / \mathrm{min}$ & 100 & 1 \\
\hline & & 75 & & $\mathrm{LAC}+\mathrm{SA}$ & 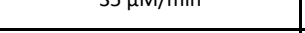 & 100 & 1 \\
\hline & & 92 & MBR & Act. sludge/ T. versicolor & $3 \mathrm{~g} / \mathrm{L}$ & 5 & 2 \\
\hline & & 30 & Batch & LAC from $T$. versicolor & $35 \mu \mathrm{M} / \min$ & 100 & 1 \\
\hline & PCP & 90 & 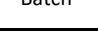 & $\mathrm{LAC}+\mathrm{SA}$ & (3) & 100 & 1 \\
\hline & & 92 & MBR & Act. sludge/ T. versicolor & $3 \mathrm{~g} / \mathrm{L}$ & 5 & 2 \\
\hline & & 0 & Batch & LAC from $T$. versicolor & $35 \mathrm{uM} / \mathrm{min}$ & 100 & 1 \\
\hline & ENL & 96 & Datcil & $L A C+S A$ & 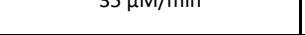 & 100 & 1 \\
\hline & & 97 & MBR & Act. sludge/ T. versicolor & $3 \mathrm{~g} / \mathrm{L}$ & 5 & 2 \\
\hline & & 2 & Ratch & LAC from $T$. versicolor & $25,4 \mathrm{M} / \mathrm{min}$ & 100 & 1 \\
\hline & ATZ & 95 & Batcrn & $\mathrm{LAC}+\mathrm{SA}$ & 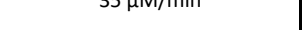 & 100 & 1 \\
\hline & & 13 & MBR & Act. sludge/ T. versicolor & $3 \mathrm{~g} / \mathrm{L}$ & 5 & 2 \\
\hline & & 5 & Batch & LAC from T. versicolor & $35 \mu \mathrm{M} / \mathrm{min}$ & 100 & 1 \\
\hline & OBZ & 95 & Datcin & $\mathrm{LAC}+\mathrm{SA}$ & (S) & 100 & 1 \\
\hline & & 98 & MBR & Act. sludge/ T. versicolor & $3 \mathrm{~g} / \mathrm{L}$ & 5 & 2 \\
\hline & & 72 & Batch & LAC from $T$. versicolor & $35 \mathrm{uM} / \mathrm{min}$ & 100 & 1 \\
\hline & DCF & 95 & ( & $\mathrm{LAC}+\mathrm{SA}$ & (S) & 100 & 1 \\
\hline & & 50 & MBR & Act. sludge/ T. versicolor & $3 \mathrm{~g} / \mathrm{L}$ & 5 & 2 \\
\hline & & 20 & & LAC from $T$. versicolor & & & \\
\hline & NPX & 98 & Batch & $\mathrm{LAC}+\mathrm{SA}$ & $35 \mu \mathrm{M} / \mathrm{min}$ & 100 & 1 \\
\hline & & 99 & MBR & Act. sludge/ T. versicolor & $3 \mathrm{~g} / \mathrm{L}$ & 5 & 2 \\
\hline & DCF & 21 & & LAC & & 4900 & \\
\hline & Dur & 64 & & $\mathrm{LAC}+\mathrm{SA}$ & & 4900 & \\
\hline & CBZ & 10 & & LAC & & 5600 & \\
\hline Nguyen et al. , & CoL & 16 & Batch & $\mathrm{LAC}+\mathrm{SA}$ & na & 3000 & 1 \\
\hline $2014 a$ & ATZ & 14 & Batcn & LAC & na & 4300 & 1 \\
\hline & AIL & 31 & & $\mathrm{LAC}+\mathrm{SA}$ & & 4300 & \\
\hline & SMX & 9 & & LAC & & 4700 & \\
\hline & Sivix & 17 & & $\mathrm{LAC}+\mathrm{SA}$ & & 4700 & \\
\hline Nguyen et al. , & DCF & $11-98$ & Batch & IAC from A oruzae & $904 \mathrm{M} / \mathrm{min}$ & 1100 & 1 \\
\hline $2014 c$ & BPA & $43-100$ & Datcin & LAC ITOM A. Oryzae & 90 माvi/min & 860 & 1 \\
\hline $\begin{array}{l}\text { Popa Ungureanu } \\
\text { et al. , } 2014\end{array}$ & CBZ & 30 & Batch & Streptomyces MIUG 4,89 & $7 \% \mathrm{v} / \mathrm{v}$ & 200 & 7 \\
\hline $\begin{array}{c}\text { Rentz et al. , } \\
2008\end{array}$ & $\mathrm{BaP}$ & 100 & Batch & $\begin{array}{c}\text { Sphingomonas } \\
\text { yanoikuyae JAR02 }\end{array}$ & na & 1.3 & 1 \\
\hline & SMX & 32 & & P. chrysosporium & & & \\
\hline & & 10 & & B. adusta & & & \\
\hline & CTI & $<10$ & & P. chrysosporium & & & \\
\hline & CIL & $<10$ & & B. adusta & & & \\
\hline & $F L X$ & $23-46$ & & P. chrysosporium & & & \\
\hline & & & & B. adusta & & & \\
\hline & DCF & 70 & & P. chrysosporium & & & \\
\hline & & 55 & & B. adusta & & & 4 \\
\hline & IBP & 95 & & P. chrysosporium & & & \\
\hline & & 75 & & B. adusta & & & \\
\hline Rodarte Morales & NPX & 100 & Batch & P. chrysosporium & $6 \mathrm{~mm}$ of arar with active fungucl & 1000 & \\
\hline et al., 2011 & TNRA & 30 & Batcn & B. adusta & $6 \mathrm{~mm}$ of agar with active fungus & 1000 & \\
\hline & CBZ & 0 & & P. chrysosporium & & & \\
\hline & & $<10$ & & B. adusta & & & \\
\hline & DZP & $<10$ & & P. chrysosporium & & & \\
\hline & & $<10$ & & B. adusta & & & \\
\hline & $A D B$ & 100 & & P. chrysosporium & & & \\
\hline & ADBI & 100 & & B. adusta & & & \\
\hline & $\mathrm{HHCB}$ & 100 & & P. chrysosporium & & & 14 \\
\hline & HHCB & 100 & & B. adusta & & & 14 \\
\hline & AHTN & 100 & & P. chrysosporium & & & \\
\hline & AHIN & 100 & & B. adusta & & & \\
\hline & DCF & 94 & & & & 1000 & \\
\hline Rodarte-Moralest & IBP & 100 & & & & 1000 & \\
\hline notal 5015 & NPX & 94 & CAS & P. chrysosporium & $7.3 \mathrm{~g} / \mathrm{L}$ & 1000 & 50 \\
\hline & $\mathrm{CBZ}$ & $24-63$ & & & & 500 & \\
\hline & DZP & I & & & & $250-500$ & \\
\hline & & $30-50$ & & P. chrysosporium & & & \\
\hline & & $32-70$ & & P. ostreatus & & & \\
\hline 2005. & NP & 96 & Batch & T. versicolor & $15-20$ g.dw. of soil & 100000 & 25 \\
\hline & & 96 & & Bjerkandera sp. BOL13 & & & \\
\hline $\begin{array}{c}\text { Sørensen et al. , } \\
2013\end{array}$ & DIU & 100 & Batch & Sphingomonas sp. SRS2 & $10^{7}$ cells $/ \mathrm{mL}$ & 10000 & 10 \\
\hline \begin{tabular}{|c|} 
Subramanian \\
and Yadav et al. \\
2009
\end{tabular} & NP & 100 & Batch & P. chrysosporium & na & 100000 & 3 \\
\hline
\end{tabular}




\begin{tabular}{|c|c|c|c|c|c|c|c|c|}
\hline \multirow{2}{*}{ Reference } & \multirow{2}{*}{ Molecule $^{\mathrm{a}}$} & \multicolumn{2}{|c|}{ \% Removal } & \multirow{2}{*}{ Process $^{b}$} & \multirow{2}{*}{$\begin{array}{c}\text { Microorganisms/ } \\
\text { Enzymes }^{c}\end{array}$} & \multirow{2}{*}{ Biomass or enzyme activity } & Microp. Concentration & Experim. duration \\
\hline & & \% Biod. & \% Ads. & & & & $(\mu \mathrm{g} / L)^{d}$ & $(d)^{d}$ \\
\hline & $F_{2}$ & & & & LAC-HBT & & & \\
\hline Suzuki et al. , & E2 & & & Batch & $\mathrm{MnP}$ & 10 nkat/ml & 3000 & 0.3 \\
\hline 2003 & EF2 & & & Batch & Lacacse-HBT & $10 \mathrm{nkat} / \mathrm{mL}$ & 3000 & 0.3 \\
\hline & EE2 & & & & $\mathrm{MnP}$ & & & \\
\hline & CFA & & & & Crude LAC & $1500 \mathrm{U} / \mathrm{L}+\mathrm{MnP} 30 \mathrm{U} / \mathrm{L}$ & & \\
\hline & $C A$ & & & & T. versicolor & na & & \\
\hline & GE7 & & & & Crude LAC & $1500 \mathrm{U} / \mathrm{L}+\mathrm{MnP} 30 \mathrm{U} / \mathrm{L}$ & & \\
\hline & GFL & & & & T. versicolor & na & & \\
\hline & & & & & Crude LAC & $1500 \mathrm{U} / \mathrm{L}+\mathrm{MnP} 30 \mathrm{U} / \mathrm{L}$ & & \\
\hline & IBP & & & & T. versicolor & na & & \\
\hline & ENP & & & & Crude LAC & $1500 \mathrm{U} / \mathrm{L}+\mathrm{MnP} 30 \mathrm{U} / \mathrm{L}$ & & \\
\hline & FNP & & & & T. versicolor & na & & \\
\hline & $K P F$ & & & & Crude LAC & $1500 \mathrm{U} / \mathrm{L}+\mathrm{MnP} 30 \mathrm{U} / \mathrm{L}$ & & \\
\hline & $\mathrm{KPF}$ & & & & T. versicolor & na & & \\
\hline Tran et al. , 2010 & NPX & & & Batch & Crude LAC & $1500 \mathrm{U} / \mathrm{L}+\mathrm{MnP} 30 \mathrm{U} / \mathrm{L}$ & 10 & 7 \\
\hline & NPX & & & & T. versicolor & na & & \\
\hline & DCF & & & & Crude LAC & $1500 \mathrm{U} / \mathrm{L}+\mathrm{MnP} 30 \mathrm{U} / \mathrm{L}$ & & \\
\hline & DCF & & & & T. versicolor & na & & \\
\hline & IND & & & & Crude LAC & $1500 \mathrm{U} / \mathrm{L}+\mathrm{MnP} 30 \mathrm{U} / \mathrm{L}$ & & \\
\hline & IND & & & & T. versicolor & na & & \\
\hline & PP7 & & & & Crude LAC & $1500 \mathrm{U} / \mathrm{L}+\mathrm{MnP} 30 \mathrm{U} / \mathrm{L}$ & & \\
\hline & PPL & & & & T. versicolor & na & & \\
\hline & דחת & & & & Crude LAC & $1500 \mathrm{U} / \mathrm{L}+\mathrm{MnP} 30 \mathrm{U} / \mathrm{L}$ & & \\
\hline & CDL & & & & T. versicolor & na & & \\
\hline \begin{tabular}{|c|} 
Turnbull et al., \\
2001 \\
\end{tabular} & DIU & & & Batch & Arthrobacter D47 & $10^{6}$ cells $/ \mathrm{mL}$ & 20000 & 5 \\
\hline \begin{tabular}{|c|}
$\begin{array}{c}\text { Widehem et al. } \\
2002\end{array}$ \\
\end{tabular} & DIU & & & Batch & Arthrobacter sp. N2 & $10^{6}$ cells $/ \mathrm{mL}$ & 40000 & 2.1 \\
\hline & SLA & 90 & 6 & & & & & \\
\hline & KPF & 90 & 4 & & & & & \\
\hline & NPX & 77 & 3 & & & & & \\
\hline & MDZ & 70 & 22 & & & & & \\
\hline & IBP & 99 & 1 & & & & & \\
\hline & PRM & 96 & 3 & & & & & \\
\hline & $\mathrm{DCF}$ & 20 & 5 & & & & & \\
\hline & GFZ & 92 & 5 & & & & & \\
\hline & $\mathrm{CBZ}$ & 25 & 20 & & & & & \\
\hline & Amitriptyline & 78 & 18 & & & & & \\
\hline & TCS & 45 & 50 & & & & & \\
\hline & E3 & 85 & 5 & & & & & \\
\hline & E1 & 97 & 0 & & & & & \\
\hline & EE2 & 87 & 10 & & & & & \\
\hline Wijekoon et al., & E2 & 99 & 0 & MBR & $\begin{array}{l}\text { Acclimatized activated } \\
\text { sludge }\end{array}$ & $5 \mathrm{~g} / \mathrm{L}$ & 5 & 1.1 \\
\hline & E2-17-acetate & 97 & 3 & & & & & \\
\hline & CFA & 82 & 1 & & & & & \\
\hline & FPP & 85 & 2 & & & & & \\
\hline & PPX & 49 & 1 & & & & & \\
\hline & PCP & 84 & 6 & & & & & \\
\hline & ATZ & 32 & 1 & & & & & \\
\hline & Ametryn & 92 & 1 & & & & & \\
\hline & 4-BP & 92 & 5 & & & & & \\
\hline & 4-OP & 97 & 2 & & & & & \\
\hline & FMN & 92 & 3 & & & & & \\
\hline & ENL & 93 & 2 & & & & & \\
\hline & BZP & 99 & 1 & & & & & \\
\hline & OBZ & 98 & 1 & & & & & \\
\hline & OCT & 70 & 25 & & & & & \\
\hline & DCF & & & Batch & & $0.5 \mathrm{~g}$ & 690 & 7 \\
\hline Yang etal 2013 & DCF & & & MBR & T versicolor & $3 \mathrm{~g} / \mathrm{L}$ & $30-1500$ & 1 \\
\hline Yang et al. , 2013 & BPA & & & Batch & T. versicolor & $0.5 \mathrm{~g}$ & 745 & 7 \\
\hline & BPA & & & MBR & & $3 \mathrm{~g} / \mathrm{L}$ & na & 1 \\
\hline $\begin{array}{c}\text { Yanze-Kontchou } \\
\text { and Gschwind, } \\
1994\end{array}$ & ATZ & & & Batch & $\begin{array}{c}\text { Pseudomonas DSM 93- } \\
99\end{array}$ & na & 30000 & 50 \\
\hline & & & & & & $20 \mathrm{mg} / \mathrm{L}$ & & \\
\hline & & & & & & $40 \mathrm{mg} / \mathrm{L}$ & & \\
\hline & 2,4-DCP & & & & & $60 \mathrm{mg} / \mathrm{L}$ & & \\
\hline & & & & & & $80 \mathrm{mg} / \mathrm{L}$ & & \\
\hline & & & & & & $120 \mathrm{mg} / \mathrm{L}$ & & \\
\hline & & & & & & $20 \mathrm{mg} / \mathrm{L}$ & & \\
\hline & & & & & & $40 \mathrm{mg} / \mathrm{L}$ & & \\
\hline Zhang et al., & 4-CP & & & & LAC from Coriolus & $60 \mathrm{mg} / \mathrm{L}$ & & \\
\hline 2008 & & & & Batch & versicolor & $80 \mathrm{mg} / \mathrm{L}$ & 10000 & 7 \\
\hline & & & & & & $120 \mathrm{mg} / \mathrm{L}$ & & \\
\hline & & & & & & $20 \mathrm{mg} / \mathrm{L}$ & & \\
\hline & & & & & & $40 \mathrm{mg} / \mathrm{L}$ & & \\
\hline & $2-C P$ & & & & & $60 \mathrm{mg} / \mathrm{L}$ & & \\
\hline & & & & & & $80 \mathrm{mg} / \mathrm{L}$ & & \\
\hline & & & & & & $120 \mathrm{mg} / \mathrm{L}$ & & \\
\hline
\end{tabular}




\begin{tabular}{|c|c|c|c|c|c|c|c|c|}
\hline \multirow{2}{*}{ Reference } & \multirow{2}{*}{ Molecule $^{a}$} & \multicolumn{2}{|c|}{ \% Removal } & \multirow{2}{*}{ Process $^{b}$} & \multirow{2}{*}{$\begin{array}{c}\text { Microorganisms/ } \\
\text { Enzymes }^{c}\end{array}$} & \multirow{2}{*}{ Biomass or enzyme activity } & \multirow{2}{*}{$\begin{array}{c}\text { Microp. Concentration } \\
(\mu \mathrm{g} / \mathrm{L})^{\mathrm{d}}\end{array}$} & \multirow{2}{*}{$\begin{array}{c}\text { Experim. duration } \\
\text { (d) }{ }^{\text {d }}\end{array}$} \\
\hline & & \% Biod. & \% Ads. & & & & & \\
\hline \multirow{2}{*}{$\begin{array}{c}\text { Zhang and } \\
\text { Geissen, } 2010\end{array}$} & CBZ & \multicolumn{2}{|c|}{$<10$} & Batch & LiP from $P$. & na & 5000 & 0.1 \\
\hline & DCF & \multicolumn{2}{|c|}{100} & & & & & \\
\hline $\begin{array}{c}\text { Zhang and } \\
\text { Geissen, } 2012\end{array}$ & CBZ & $21-68$ & $18-45$ & Batch & P. chrysosporium & na & 5000 & 24 \\
\hline
\end{tabular}

To facilitate readability of this table, all values have been rounded off to one decimal place except for values less than 0.05 which have been rounded off to two decimal place. na defines not available To facilitate readability of this table, all values have been rounded off to one decimal place except for values less than 0.05 which have been rounded off to two decimal place. na defines not available

a: ACE: Acetaminophen, ADBI: Celestolide, AHTN: Tonalide, AMPA: Aminomethylphosphoric acid, ATZ: Atrazine, AZI: Azithromycin, BaP: Benzo(a)pyrene, BZF: Bezafibrate, BPA: Bisphenol A, BP: Butylphenol, BZP: Benzophenone, BZT: Benzotriazole, CBZ: Carbamazepine, CFA: Clofibric acid, CFN: Caffeine, CIP: Ciprofloxacin, CLA: Clarithromycin, CLI: Clindamycin, CP: chlorophenol, CTL: Citalopram, DBA: Dichlorobenzoic acid, DCF: Diclofenac, DCP: Dichlorophenol, DEET: N,N-diethyl-m-toluamide, DEHP: di(2-ethylhexyl)phthalate, DEX: Dexamethasone, DIU: Diuron, DZP: Diazepam, ENL: Enterolactone, ERY: Erythromycin, E1: Estrone, E2: 17ß-Estradiol, E3: Estriol, EE2: 17 $\alpha$-Ethinylestradiol, FI: Fluoranthene, FLX: Fluoxetine, FMN: Formononetin, FNP: Fenoprofen, FPP: Fenoprop, GFZ: Gemfibrozil, HHCB: Galaxolide, IBP: Ibuprofen, IND : Indomethacin, KPF: Ketoprofen, MDZ: Metronidazole, METOP: Metoprolol, MFA: Mefenamic acid, NP: Nonyphenol, NPX: Naproxen, OBZ: Oxybenzone, OCT: Octocrylene, OP: Octylphenol, PCP: Pentachlorophenol, PCT: Paracetamol, Phe: Phenanthrene, PPN: Propanolol, PPX: Propoxur, PPZ: Propyphenazone, PRM: Primidone, ROX: Roxithromycin, SDZ: Sulfadiazine, SLA: Salicylic acid, SMX: Sulfamethoxazole, TCS: Triclosan, TMP: Trimethroprim b: CAS defines Conventional Activated Sludge; MBR defines Membrane Bioreactor

c: ABTS defines 2,2'-azino-bis-(3-ethylbenzothiazoline)-6-sulfonate; HBT defines 1-hydroxybenzotriazole; LAC defines Laccase; LiP defines Lignin Peroxidase; MnP defines Manganese Peroxidase; SA defines syringaldehyde

A. oryzae: Aspergillus oryzae, B. adusta : Bjerkandera adusta, D. squalens : Dichotomitus squalens, F. oxysporum : Fusarium oxysporum, F. solani: Fusarium solani, G. galactomyces : Geotrichum galactomyces, G. lucidum : Ganoderma lucidum, I. lacteus : Irpex lacteus, M. thermophila : Myceliophthora thermophila, P. chrysosporium : Phanerochaete chrysosporium, P. magnoliae : Phanerochaete magnoliae, P. sordida : Phanerochaete sordida, P. velutina : Phanerochaete velutina, P. cinnabarinus : Pycnoporus cinnabarinus, P. ostreatus : Pleurotus ostreatus, T. harzianum : Trichoderma harzianum, T. versicolor : Trametes versicolor, S. albidoflavus: Streptomyces albidoflavus, S. yanoikuya: Sphingomonas yanoikuya $\mathrm{d}$ : In order to maintain consistency, all micropollutant concentrations have been converted into $\mu \mathrm{g} / \mathrm{L}$ and experimental duration into days. 
Table 3 : Percentage of biodegradation of selected micropollutants using hybrid processes depending on operating conditions

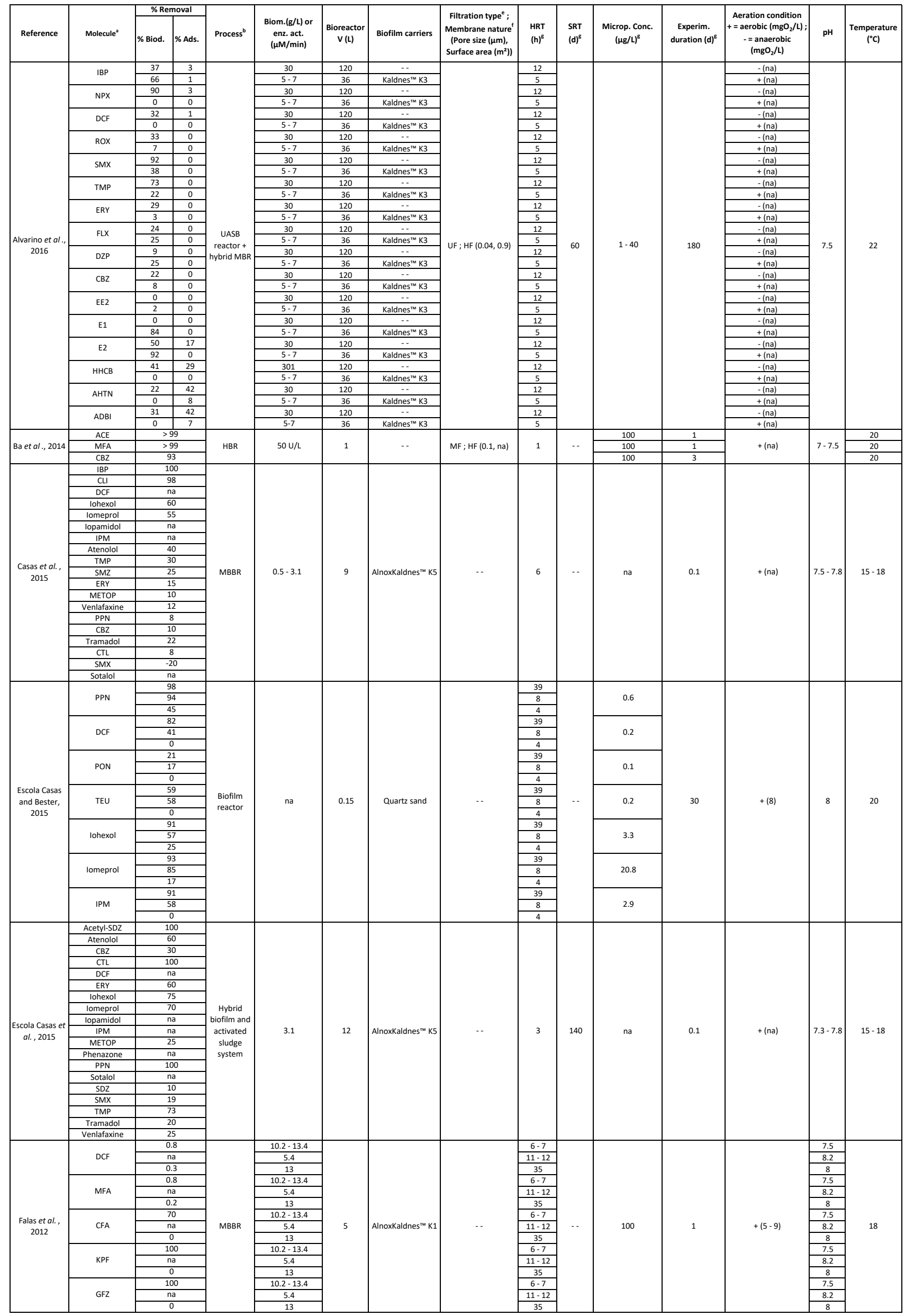




\begin{tabular}{|c|c|c|c|c|c|c|c|c|c|c|c|c|c|c|c|}
\hline \multirow[b]{2}{*}{ Reference } & \multirow[b]{2}{*}{ Molecule $^{a}$} & \% Ren & moval & & & & & & & & & & & & \\
\hline & & $\%$ Biod. & $\%$ Ads. & Process $^{b}$ & $\begin{array}{l}\text { Biom.(g/L) or } \\
\text { enz. act. } \\
(\mu \mathrm{M} / \mathrm{min})\end{array}$ & $\begin{array}{c}\text { Bioreactor } \\
\text { V(L) }\end{array}$ & Biofilm carriers & $\begin{array}{l}\text { Filtration type } ; \\
\text { Membrane nature } \\
(\text { Pore size }(\mu \mathrm{m}), \\
\left.\text { Surface area }\left(\mathrm{m}^{2}\right)\right)\end{array}$ & $\begin{array}{l}\text { HRT } \\
(\text { (h) }\end{array}$ & $\begin{array}{l}\text { SRT } \\
\text { (d) }\end{array}$ & $\begin{array}{l}\text { Microp. Conc. } \\
\left(\mu \mathrm{g} / \mathrm{L}^{\mathrm{s}}\right.\end{array}$ & $\begin{array}{l}\text { Experim. } \\
\text { duration }(d)^{8}\end{array}$ & $\begin{array}{l}\text { Aeration conditton } \\
+=\text { aerobic (mgo/ } / L) ; \\
-=\text { anaerobic } \\
\quad\left(\mathrm{mgO}_{2} / \mathrm{LI}\right)\end{array}$ & $\mathrm{pH}$ & $\begin{array}{l}\text { Temperature } \\
\text { ('C) }\end{array}$ \\
\hline & NPX & $\frac{100}{\mathrm{na}}$ & & & $\frac{10.2-13.4}{5.4}$ & & & & \begin{tabular}{|l|}
$6-7$ \\
$11-12$
\end{tabular} & & & & & $\begin{array}{l}7.5 \\
8.2\end{array}$ & \\
\hline Falas et al., & & 0 & & MBBR & 13 & 5 & Alnoxkaldnes"' K1 & .. & 35 & .. & 100 & 1 & $+(5-9)$ & 8 & 18 \\
\hline & IBP & $\frac{100}{n a}$ & & & & & & & & & & & & $\frac{7.5}{8.2}$ & \\
\hline & DCF & $\begin{array}{ll}0 \\
26\end{array}$ & $\frac{1}{20}$ & & 13 & & & & 35 & & & & & 8 & \\
\hline & CBZ & $\begin{array}{l}0 \\
5 \varepsilon\end{array}$ & $\begin{array}{l}0 \\
58\end{array}$ & & & & & & & & & & & & \\
\hline & Valsartan & $\mathrm{na}_{\mathrm{a}}$ & na & & & & & & & & & & & & \\
\hline & BZF & & na & & & & & & & & & & & & \\
\hline Falas et $\alpha$ l., & $\begin{array}{l}\text { Atenolol } \\
\text { METOP }\end{array}$ & & 25 & Hybrid & & & & & & & & & & & \\
\hline 2013 & TMP & & $\frac{1}{2}$ & biofilm & na & 30 & AlnoxKaldnes ${ }^{m m}$ K1 & -. & 12 & $3-4$ & 1 & 1 & $+(3.5)$ and $-(0.5)$ & 7.8 & 16 \\
\hline & CLA & 0 & 0 & & & & & & & & & & & & \\
\hline & $\begin{array}{l}\mathrm{HCTZ} \\
\mathrm{KPPF}\end{array}$ & $\frac{1}{n^{n}}$ & $\frac{1}{n a}$ & & & & & & & & & & & & \\
\hline & BPF & & na & & & & & & & & & & & & \\
\hline & $\begin{array}{l}\text { DLP } \\
\text { PRM }\end{array}$ & & na & & & & & & & & & & & & \\
\hline & Phenazone & & na & & & & & & & & & & & & \\
\hline Joss et al, & E1 & & 90 & 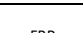 & & 11900 & 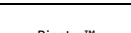 & 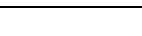 & 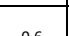 & & 0.007 & 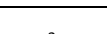 & 2 & & 45 \\
\hline 2004 & $\begin{array}{ll}\mathrm{E} 2 \\
\mathrm{EE2}\end{array}$ & & $\frac{95}{69}$ & $\mathrm{FBR}$ & na & 190000 & Biostyr"wa & $\cdots$ & 0.6 & $\cdot \cdot$ & $\begin{array}{l}0.005 \\
0.007\end{array}$ & 2 & $+(2-3)$ & na & $15-16$ \\
\hline & $\begin{array}{ll}A C E \\
C B Z\end{array}$ & & 1.4 & & & & & & & & & & & & \\
\hline & DCF & & 5.7 & & & & & & & & & & & & \\
\hline & $\frac{G F Z}{1 B P}$ & & 2.47 & & & & & & & & & & & & \\
\hline & KPF & & 8.2 & & & & & & & & & & & & \\
\hline & MDZ & & 4.8 & & & & & & & & & & & & \\
\hline & $\begin{array}{l}\text { NPX } \\
\text { PRM }\end{array}$ & & 1.1 & & & & & & & & & & & & \\
\hline & SLA & & 1.1 & & & & & & & & & & & & \\
\hline Luo et al., & TCS & & 1.7 & MBBR & na & 40 & Sponge cubes & $\ldots$ & 24 & - & - & +1 & $+(5-6)-2>$ & 7 & 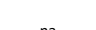 \\
\hline 2014 & E1 & & 9.6 & MBBR & na & 40 & Sponge cubes & $\cdots$ & 24 & - & 5 & 1 & $+(5-6)$ & 1 & na \\
\hline & $\begin{array}{l}\text { E2 } \\
E 2 \text { 1-2-actate }\end{array}$ & & 6.2 & & & & & & & & & & & & \\
\hline & EE2 & & 5.2 & & & & & & & & & & & & \\
\hline & $\mathrm{E} 3$ & & 2.5 & & & & & & & & & & & & \\
\hline & 4-BP & & 4.9 & & & & & & & & & & & & \\
\hline & BPA & & 7.8 & & & & & & & & & & & & \\
\hline & $\mathrm{NP}$ & & 5.7 & & & & & & & & & & & & \\
\hline & FPP & & 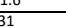 & & & & & & & & & & & & \\
\hline & PCP & & 8.9 & & & & & & & & & & & & \\
\hline & $\frac{\text { SLA }}{\text { MDZ }}$ & $\frac{94}{30}$ & \begin{tabular}{|l|}
2 \\
\end{tabular} & & & & & & & & & & & & \\
\hline & $\begin{array}{l}\mathrm{MDL} 2 \\
\text { FPP }\end{array}$ & $\frac{30}{8}$ & 8 & & & & & & & & & & & & \\
\hline & $\begin{array}{l}\text { KPF } \\
\text { ACE }\end{array}$ & $\frac{60}{70}$ & \begin{tabular}{|l}
20 \\
10
\end{tabular} & & & & & & & & & & & & \\
\hline & NPX & 77 & 5 & & & & & & & & & & & & \\
\hline & PRM & 68 & 10 & & & & & & & & & & & & \\
\hline & IBP & 85 & 3 & & & & & & & & & & & & \\
\hline & $\begin{array}{ll}\mathrm{CCB} \\
\mathrm{CBZ}\end{array}$ & $\frac{25}{15}$ & \begin{tabular}{|l|}
20 \\
15
\end{tabular} & & & & & & & & & & & & \\
\hline Luo et al., & GFZ & 60 & 10 & MBBR-MBR & 2.3 & 40 & Sponge cubes & $\mathrm{MF}^{\prime} \mathrm{HF}_{3}(0.2,0.2)$ & 6 & Infinite & 5 & 90 & $+(n a)$ & 7 & $\mathrm{na}$ \\
\hline 2015 & $\begin{array}{ll}E 3 \\
\text { PCP }\end{array}$ & 93 & $\begin{array}{ll}1 \\
25 \\
\end{array}$ & & & (70 & (5) & 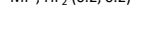 & & & & & & & nad \\
\hline & $4-B P$ & 60 & 25 & & & & & & & & & & & & \\
\hline & $\begin{array}{ll}\text { E1 } \\
\text { BPA }\end{array}$ & 90 & 3 & & & & & & & & & & & & \\
\hline & $\frac{\mathrm{BPA}}{\mathrm{EE} 2}$ & $\frac{85}{70}$ & \begin{tabular}{|l|} 
\\
\end{tabular} & & & & & & & & & & & & \\
\hline & $\mathrm{E} 2$ & 95 & 1 & & & & & & & & & & & & \\
\hline & E2 17-acetate & 92 & 2 & & & & & & & & & & & & \\
\hline & 4.OP & 50 & 15 & & & & & & & & & & & & \\
\hline & TCS & 75 & $\frac{10}{2}$ & & & & & & & & & & & & \\
\hline & DCF & 55 & 55 & & & & & & & & 500 & & & & \\
\hline & $C B Z$ & & 25 & & & & & & & & 2500 & & & & \\
\hline Nguyen et al., & CBL & & 30 & EMR & $70-100$ & 1.5 & & $\mathrm{UF} ; \mathrm{HF}(\mathrm{na}, 0.2)$ & 8 & & $\frac{250}{500}$ & 66 & $+(3)$ & 6.8 & 28 \\
\hline 2014a & ATZ & & 25 & & & & & & & & $\frac{500}{250}$ & & & & \\
\hline & SMX & & $\frac{15}{25}$ & & & & & & & & 500 & & & & \\
\hline Nguyen et $a$ l. & BPA & & 85 & EMB & $70-100$ & 1.5 & .. & UE.HE $(\mathrm{na} 0.2)$ & 8 & .. & 570 & 66 & $+(3)$ & 68 & $n_{0}$ \\
\hline $2014 c$ & DCF & & $\frac{60}{88}$ & & & & $\cdots$ & $\mathrm{OF} ; \mathrm{HF}(\mathrm{na}, 0.2)$ & & $\cdots$ & 480 & 66 & $+(3)$ & 6.8 & na \\
\hline & $\begin{array}{l}\text { OBB } \\
\text { TCS }\end{array}$ & & 88 & & & & & & & & & & & & \\
\hline & $\begin{array}{l}\text { E2 17-acetate } \\
\text { 4-OP }\end{array}$ & $\begin{array}{l}95 \\
95\end{array}$ & 99 & & & & & & & & & & & & \\
\hline & $\mathrm{E} 3$ & & 90 & & & & & & & & & & & & \\
\hline & $\begin{array}{ll}E 22 \\
62\end{array}$ & & 77 & & & & & & & & & & & & \\
\hline & $\frac{\mathrm{E} 2}{4-\mathrm{BP}}$ & & 70 & & & & & & & & & & & & \\
\hline & E1 & & 55 & & & & & & & & & & & & \\
\hline & $\begin{array}{l}\text { BPA } \\
\text { SIA }\end{array}$ & & $\frac{44}{40}$ & & & & & & & & & & & & \\
\hline & FMN & & 50 & & & & & & & & & & & & \\
\hline & $\begin{array}{ll}P C P \\
F C H\end{array}$ & & 49 & & & & & & & & & & & & \\
\hline Nguyen et $a$ l. & $\begin{array}{l}\text { ENL } \\
\text { OCT }\end{array}$ & & 200 & & 170 & & & & & & & & & & \\
\hline 2015 & Amitriptyline & & 98 & EMR & 170 - 190 & 1.5 & & UF; $\mathrm{HF}(\mathrm{na}, 0.2)$ & 8 & -. & 5 & 3 & $+(3)$ & 6.8 & 28 \\
\hline & BZP & $\frac{65}{46}$ & $\frac{65}{40}$ & & & & & & & & & & & & \\
\hline & $\frac{\mathrm{DCF}}{\mathrm{IBP}}$ & $\frac{44}{4 !}$ & 41 & & & & & & & & & & & & \\
\hline & Ametryn & & 35 & & & & & & & & & & & & \\
\hline & $\frac{1 \mathrm{NX}}{\text { PRM }}$ & & $\frac{20}{5}$ & & & & & & & & & & & & \\
\hline & KPF & & 18 & & & & & & & & & & & & \\
\hline & GFZ & & 20 & & & & & & & & & & & & \\
\hline & $\begin{array}{l}M D Z \\
\text { FPP }\end{array}$ & $\frac{5}{7}$ & $\frac{5}{7}$ & & & & & & & & & & & & \\
\hline & CFA & $\frac{1}{16}$ & $\frac{7}{10}$ & & & & & & & & & & & & \\
\hline & $\frac{P P X}{P P X}$ & 6 & 6 & & & & & & & & & & & & \\
\hline & $\begin{array}{ll}\mathrm{CBZ} \\
\mathrm{ATZ}\end{array}$ & $\frac{0}{0}$ & $\frac{0}{0}$ & & & & & & & & & & & & \\
\hline
\end{tabular}




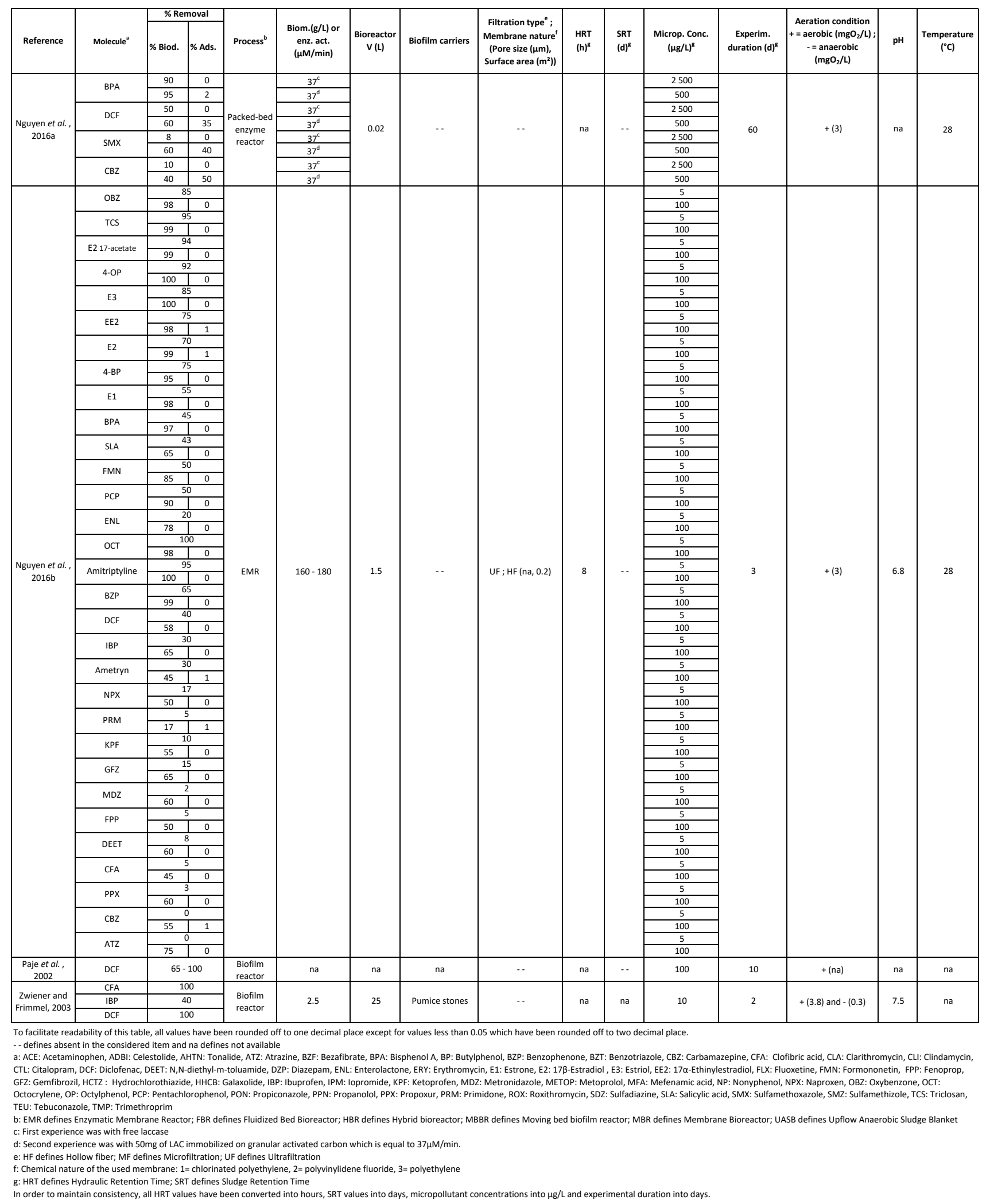


Table 4 : Biodegradation of organic micropollutants in different hybrid processes using several microorganism types or enzymes

\begin{tabular}{|c|c|c|c|c|c|c|c|}
\hline \multirow{2}{*}{ Reference } & \multirow{2}{*}{ Molecule $^{\mathrm{a}}$} & \% Removal & \multirow{2}{*}{ Process $^{b}$} & \multirow{2}{*}{$\begin{array}{l}\text { Microorg./ } \\
\text { Enzymes }^{c}\end{array}$} & \multirow{2}{*}{$\begin{array}{c}\text { Biom. }(\mathrm{g} / \mathrm{L}) \text { or enz. } \\
\text { act. }(\mu \mathrm{M} / \mathrm{min} \text { or } \\
\mathrm{U} / \mathrm{L})\end{array}$} & \multirow{2}{*}{$\begin{array}{l}\text { Microp. Conc. } \\
\qquad(\mu \mathrm{g} / \mathrm{L})^{\mathrm{f}}\end{array}$} & \multirow{2}{*}{$\begin{array}{c}\text { Experim. } \\
\text { duration }(d)^{f}\end{array}$} \\
\hline & & \% Biod. \% Ads. & & & & & \\
\hline \multirow{3}{*}{$\begin{array}{c}\text { Ba et al. , } \\
2014\end{array}$} & ACE & $>99$ & \multirow{3}{*}{ HBR } & \multirow{3}{*}{$\begin{array}{l}\text { LAC from } T \text {. } \\
\text { versicolor }\end{array}$} & \multirow{3}{*}{$50 \mathrm{U} / \mathrm{L}$} & 100 & 1 \\
\hline & MFA & \multirow{2}{*}{$\begin{array}{c}>99 \\
93\end{array}$} & & & & 100 & 1 \\
\hline & CBZ & & & & & 100 & 3 \\
\hline \multirow{19}{*}{$\begin{array}{c}\text { Casas et al. , } \\
2015\end{array}$} & IBP & 100 & \multirow{19}{*}{ MBBR } & \multirow{19}{*}{$\begin{array}{l}\text { Activated } \\
\text { sludge }\end{array}$} & \multirow{19}{*}{$0.5-3.1$} & \multirow{19}{*}{ na } & \multirow{19}{*}{0.1} \\
\hline & $\mathrm{CLI}$ & 98 & & & & & \\
\hline & DCF & na & & & & & \\
\hline & lohexol & 60 & & & & & \\
\hline & lomeprol & 55 & & & & & \\
\hline & Iopamidol & na & & & & & \\
\hline & IPM & na & & & & & \\
\hline & Atenolol & 40 & & & & & \\
\hline & TMP & 30 & & & & & \\
\hline & SMZ & 25 & & & & & \\
\hline & ERY & 15 & & & & & \\
\hline & METOP & 10 & & & & & \\
\hline & Venlafaxine & 12 & & & & & \\
\hline & PPN & 8 & & & & & \\
\hline & CBZ & 10 & & & & & \\
\hline & Tramadol & 22 & & & & & \\
\hline & CTL & 8 & & & & & \\
\hline & SMX & -20 & & & & & \\
\hline & Sotalol & na & & & & & \\
\hline & PPN & $45-98$ & & & & 0.1 & \\
\hline & DCF & $0-82$ & & & & 0.2 & \\
\hline Escola Casas & PON & $0-21$ & & & & 0.1 & \\
\hline and Bester, & TEU & $0-59$ & Biofilm & Activated & na & 0.2 & 30 \\
\hline 2015 & Iohexol & $25-91$ & & & & 3.3 & \\
\hline & lomeprol & $17-93$ & & & & 20.8 & \\
\hline & IPM & $0-91$ & & & & 2.9 & \\
\hline & Acetyl-SDZ & 100 & & & & & \\
\hline & Atenolol & 60 & & & & & \\
\hline & CBZ & 30 & & & & & \\
\hline & $\overline{C T L}$ & 100 & & & & & \\
\hline & DCF & na & & & & & \\
\hline & ERY & 60 & & & & & \\
\hline & lohexol & 75 & Hybrid & & & & \\
\hline & lomeprol & 70 & biofilm and & & & & \\
\hline Escola Casas & Iopamidol & na & activated & Activated & & & \\
\hline et 2015 & IPM & na & sludge & sludge & 3.2 & na & 0.1 \\
\hline & METOP & 25 & sludge & & & & \\
\hline & Phenanzone & na & system & & & & \\
\hline & PPN & 100 & (Hybas ${ }^{\mathrm{TM}}$ ) & & & & \\
\hline & Sotalol & na & & & & & \\
\hline & SDZ & 10 & & & & & \\
\hline & SMX & 19 & & & & & \\
\hline & TMP & 73 & & & & & \\
\hline & Tramadol & 20 & & & & & \\
\hline & Venlafaxine & 25 & & & & & \\
\hline
\end{tabular}




\begin{tabular}{|c|c|c|c|c|c|c|c|c|}
\hline \multirow[b]{2}{*}{ Reference } & \multirow[b]{2}{*}{ Molecule $^{a}$} & \multicolumn{2}{|c|}{ \% Removal } & \multirow[b]{2}{*}{ Process $^{b}$} & \multirow{2}{*}{$\begin{array}{c}\text { Microorg./ } \\
\text { Enzymes }^{c}\end{array}$} & \multirow{2}{*}{$\begin{array}{l}\text { Biom. }(\mathrm{g} / \mathrm{L}) \text { or enz. } \\
\text { act. }(\mu \mathrm{M} / \mathrm{min} \text { or } \\
\mathrm{U} / \mathrm{L})\end{array}$} & \multirow{2}{*}{$\begin{array}{l}\text { Microp. Conc. } \\
\qquad(\mu \mathrm{g} / \mathrm{L})^{f}\end{array}$} & \multirow{2}{*}{$\begin{array}{c}\text { Experim. } \\
\text { duration }(d)^{f}\end{array}$} \\
\hline & & $\%$ Biod. & \% Ads. & & & & & \\
\hline \multirow{22}{*}{$\begin{array}{l}\text { Luo et al., } \\
2014\end{array}$} & ACE & 71 & .4 & \multirow{22}{*}{ MBBR } & \multirow{22}{*}{$\begin{array}{l}\text { Activated } \\
\text { sludge }\end{array}$} & \multirow{22}{*}{ na } & \multirow{22}{*}{5} & \multirow{22}{*}{1} \\
\hline & CBZ & 25 & .9 & & & & & \\
\hline & DCF & 45 & .7 & & & & & \\
\hline & GFZ & 62 & .4 & & & & & \\
\hline & IBP & 93 & 37 & & & & & \\
\hline & KPF & 58 & .2 & & & & & \\
\hline & MDZ & 54 & 8 & & & & & \\
\hline & $\mathrm{NPX}$ & 81 & .1 & & & & & \\
\hline & PRM & 83 & .5 & & & & & \\
\hline & SLA & 91 & .1 & & & & & \\
\hline & TCS & 91 & .7 & & & & & \\
\hline & E1 & \multicolumn{2}{|c|}{89.6} & & & & & \\
\hline & E2 & \multicolumn{2}{|c|}{96.2} & & & & & \\
\hline & E2 17-acetate & \multicolumn{2}{|c|}{96.8} & & & & & \\
\hline & EE2 & \multicolumn{2}{|c|}{85.2} & & & & & \\
\hline & E3 & 92 & .5 & & & & & \\
\hline & 4-BP & 74 & .9 & & & & & \\
\hline & BPA & 77 & .8 & & & & & \\
\hline & $\mathrm{NP}$ & 95 & .7 & & & & & \\
\hline & $4-O P$ & 91 & .6 & & & & & \\
\hline & FPP & 3 & 1 & & & & & \\
\hline & PCP & 78 & .9 & & & & & \\
\hline & SLA & 94 & 2 & & & & & \\
\hline & MDZ & 30 & 7 & & & & & \\
\hline & FPP & 8 & 8 & & & & & \\
\hline & KPF & 60 & 20 & & & & & \\
\hline & $\mathrm{ACE}$ & 70 & 10 & & & & & \\
\hline & NPX & 77 & 5 & & & & & \\
\hline & $\begin{array}{l}\text { PRM } \\
\end{array}$ & 68 & 10 & & & & & \\
\hline & $\mathrm{IBP}$ & 85 & 3 & & & & & \\
\hline & DCF & 25 & 20 & & & & & \\
\hline & $\mathrm{CBZ}$ & 15 & 15 & & & & & \\
\hline Luo et al., & GFZ & 60 & 10 & hybrid & Activated & & & \\
\hline 2015 & E3 & 93 & 1 & MBBR-MBR & sludge & 2.3 & 5 & 90 \\
\hline & PCP & 45 & 25 & & & & & \\
\hline & 4-BP & 60 & 12 & & & & & \\
\hline & E1 & 90 & 3 & & & & & \\
\hline & BPA & 85 & 4 & & & & & \\
\hline & EE2 & 70 & 6 & & & & & \\
\hline & E2 & 95 & 1 & & & & & \\
\hline & E2 17-acetate & 92 & 2 & & & & & \\
\hline & 4-OP & 50 & 15 & & & & & \\
\hline & TCS & 75 & 10 & & & & & \\
\hline & 4-NP & 95 & 2 & & & & & \\
\hline & & 5 & 5 & & LAC & & & \\
\hline & DCF & 7 & 5 & & $L A C+S A$ & & & \\
\hline & & 2 & 5 & & LAC & & & \\
\hline & CBL & 2 & 5 & & $L A C+S A$ & & & \\
\hline al. , 2014a & & 2 & 5 & EMR & LAC & $70-100$ & 500 & 66 \\
\hline & AIL & 3 & 3 & & $L A C+S A$ & & & \\
\hline & $\sin$ & 1 & 5 & & LAC & & & \\
\hline & SIVIX & 3 & 5 & & $L A C+S A$ & & & \\
\hline
\end{tabular}




\begin{tabular}{|c|c|c|c|c|c|c|c|c|}
\hline \multirow[b]{2}{*}{ Reference } & \multirow[b]{2}{*}{ Molecule $^{a}$} & \multicolumn{2}{|c|}{ \% Removal } & \multirow{2}{*}{ Process $^{b}$} & \multirow{2}{*}{$\begin{array}{l}\text { Microorg./ } \\
\text { Enzymes }^{c}\end{array}$} & \multirow{2}{*}{$\begin{array}{l}\text { Biom. }(\mathrm{g} / \mathrm{L}) \text { or enz. } \\
\text { act. }(\mu \mathrm{M} / \mathrm{min} \text { or } \\
\mathrm{U} / \mathrm{L})\end{array}$} & \multirow{2}{*}{$\begin{array}{l}\text { Microp. Conc. } \\
\qquad(\mu \mathrm{g} / \mathrm{L})^{\mathrm{f}}\end{array}$} & \multirow{2}{*}{$\begin{array}{c}\text { Experim. } \\
\text { duration }(d)^{f}\end{array}$} \\
\hline & & \% Biod. & \% Ads. & & & & & \\
\hline \multirow{4}{*}{$\begin{array}{l}\text { Nguyen et } \\
\text { al. , 2014c }\end{array}$} & \multirow{2}{*}{ BPA } & \multicolumn{2}{|c|}{85} & \multirow{4}{*}{ EMR } & LAC & \multirow{4}{*}{$70-100$} & 570 & \multirow{4}{*}{66} \\
\hline & & 9 & & & $\mathrm{LAC}+\mathrm{SA}$ & & & \\
\hline & \multirow{2}{*}{ DCF } & \multicolumn{2}{|c|}{60} & & LAC & & 480 & \\
\hline & & \multicolumn{2}{|c|}{80} & & $\mathrm{LAC}+\mathrm{SA}$ & & 480 & \\
\hline & RPA & 90 & 0 & & & $37^{c}$ & 2500 & \\
\hline & $D F A$ & 95 & 2 & & & $37^{d}$ & 500 & \\
\hline & RCE & 50 & 0 & & & $37^{c}$ & 2500 & \\
\hline Nguyen et & DCt & 60 & 35 & $\begin{array}{l}\text { Packed-bed } \\
\text { enzyme }\end{array}$ & LAC from & $37^{d}$ & 500 & 60 \\
\hline al. , 2016a & & 8 & 0 & reactor & A. oryzae & $37^{c}$ & 2500 & \\
\hline & SIVIX & 60 & 40 & & & $37^{d}$ & 500 & \\
\hline & & 10 & 0 & & & $37^{c}$ & 2500 & \\
\hline & CBL & 40 & 50 & & & $37^{d}$ & 500 & \\
\hline & OBZ & 8 & & & LAC & & 5 & \\
\hline & UBL & 98 & 0 & & $\mathrm{LAC}+\mathrm{SA}$ & & 100 & \\
\hline & TCS & 9 & & & LAC & & 5 & \\
\hline & ICS & 99 & 0 & & $\mathrm{LAC}+\mathrm{SA}$ & & 100 & \\
\hline & E2 17-acetate & 9 & & & LAC & & 5 & \\
\hline & EL 1/-acetate & 99 & 0 & & $\mathrm{LAC}+\mathrm{SA}$ & & 100 & \\
\hline & 4-OP & 9 & & & LAC & & 5 & \\
\hline & 4-UP & 100 & 0 & & $\mathrm{LAC}+\mathrm{SA}$ & & 100 & \\
\hline & F2 & 8 & & & LAC & & 5 & \\
\hline & E3 & 100 & 0 & & $\mathrm{LAC}+\mathrm{SA}$ & & 100 & \\
\hline & FF? & 7 & & & LAC & & 5 & \\
\hline & EE2 & 98 & 1 & & $\mathrm{LAC}+\mathrm{SA}$ & & 100 & \\
\hline & F2 & 7 & & & LAC & & 5 & \\
\hline & EL & 99 & 1 & & $\mathrm{LAC}+\mathrm{SA}$ & & 100 & \\
\hline & $4-B P$ & 7 & & & LAC & & 5 & \\
\hline & & 95 & 0 & & $\mathrm{LAC}+\mathrm{SA}$ & & 100 & \\
\hline & F1 & 5 & & & LAC & & 5 & \\
\hline & EI & 98 & 0 & & $\mathrm{LAC}+\mathrm{SA}$ & & 100 & \\
\hline & RPA & 4 & & & LAC & & 5 & \\
\hline & BPA & 97 & 0 & & $\mathrm{LAC}+\mathrm{SA}$ & & 100 & \\
\hline Nguyen et & SIA & $\overline{4}$ & & FMR & LAC & & 5 & 3 \\
\hline al. , 2016b & SLA & 65 & 0 & EIVIR & $\mathrm{LAC}+\mathrm{SA}$ & $160-180$ & 100 & 3 \\
\hline & FMN & $\underline{5}$ & & & LAC & & 5 & \\
\hline & FIVIN & 85 & 0 & & $\mathrm{LAC}+\mathrm{SA}$ & & 100 & \\
\hline & PCP & $\underline{5}$ & & & LAC & & 5 & \\
\hline & $P C P$ & 90 & 0 & & $\mathrm{LAC}+\mathrm{SA}$ & & 100 & \\
\hline & FNI & 2 & & & LAC & & 5 & \\
\hline & EIVL & 78 & 0 & & $\mathrm{LAC}+\mathrm{SA}$ & & 100 & \\
\hline & OCT & 10 & & & LAC & & 5 & \\
\hline & $0<1$ & 98 & 0 & & $\mathrm{LAC}+\mathrm{SA}$ & & 100 & \\
\hline & Amitrintyline & 9 & & & LAC & & 5 & \\
\hline & Amitriptyıne & 100 & 0 & & $\mathrm{LAC}+\mathrm{SA}$ & & 100 & \\
\hline & BZP & $\underline{6}$ & & & LAC & & 5 & \\
\hline & BLP & 99 & 0 & & $\mathrm{LAC}+\mathrm{SA}$ & & 100 & \\
\hline & $\mathrm{DCF}$ & 4 & & & LAC & & 5 & \\
\hline & DCr & 58 & 0 & & $\mathrm{LAC}+\mathrm{SA}$ & & 100 & \\
\hline & IRP & 3 & & & LAC & & 5 & \\
\hline & IBP & 65 & 0 & & $\mathrm{LAC}+\mathrm{SA}$ & & 100 & \\
\hline & Ametryn & $\overline{2}$ & & & LAC & & 5 & \\
\hline & & 45 & 1 & & $\mathrm{LAC}+\mathrm{SA}$ & & 100 & \\
\hline & NPX & 1 & & & LAC & & 5 & \\
\hline & INPX & 50 & 0 & & $\mathrm{LAC}+\mathrm{SA}$ & & 100 & \\
\hline
\end{tabular}




\begin{tabular}{|c|c|c|c|c|c|c|c|c|}
\hline \multirow[b]{2}{*}{ Reference } & \multirow[b]{2}{*}{ Molecule $^{\mathrm{a}}$} & \multicolumn{2}{|c|}{ \% Removal } & \multirow[b]{2}{*}{ Process $^{b}$} & \multirow{2}{*}{$\begin{array}{l}\text { Microorg./ } \\
\text { Enzymes }^{c}\end{array}$} & \multirow{2}{*}{$\begin{array}{c}\text { Biom. }(\mathrm{g} / \mathrm{L}) \text { or enz. } \\
\text { act. }(\mu \mathrm{M} / \mathrm{min} \text { or } \\
\mathrm{U} / \mathrm{L})\end{array}$} & \multirow{2}{*}{$\begin{array}{l}\text { Microp. Conc. } \\
\qquad(\mu \mathrm{g} / \mathrm{L})^{\mathrm{f}}\end{array}$} & \multirow{2}{*}{$\begin{array}{c}\text { Experim. } \\
\text { duration }(d)^{f}\end{array}$} \\
\hline & & $\%$ Biod. & $\%$ Ads. & & & & & \\
\hline \multirow{20}{*}{$\begin{array}{l}\text { Nguyen et } \\
\text { al., 2016b }\end{array}$} & \multirow{2}{*}{ PRM } & \multicolumn{2}{|c|}{5} & \multirow{20}{*}{ EMR } & LAC & \multirow{20}{*}{$160-180$} & 5 & \multirow{20}{*}{3} \\
\hline & & 17 & 1 & & $\mathrm{LAC}+\mathrm{SA}$ & & 100 & \\
\hline & \multirow{2}{*}{ KPF } & \multicolumn{2}{|c|}{10} & & LAC & & 5 & \\
\hline & & 55 & 0 & & $\mathrm{LAC}+\mathrm{SA}$ & & 100 & \\
\hline & \multirow{2}{*}{ GFZ } & \multicolumn{2}{|c|}{15} & & LAC & & 5 & \\
\hline & & 65 & 0 & & $L A C+S A$ & & 100 & \\
\hline & \multirow{2}{*}{ MDZ } & \multicolumn{2}{|c|}{2} & & LAC & & 5 & \\
\hline & & 60 & 0 & & $\mathrm{LAC}+\mathrm{SA}$ & & 100 & \\
\hline & \multirow{2}{*}{ FPP } & \multicolumn{2}{|c|}{$\frac{1}{5}$} & & LAC & & 5 & \\
\hline & & 50 & 0 & & $\mathrm{LAC}+\mathrm{SA}$ & & 100 & \\
\hline & \multirow{2}{*}{ DEET } & \multicolumn{2}{|c|}{8} & & LAC & & 5 & \\
\hline & & 60 & 0 & & $L A C+S A$ & & 100 & \\
\hline & \multirow{2}{*}{ CFA } & \multicolumn{2}{|c|}{5} & & LAC & & 5 & \\
\hline & & 45 & 0 & & $\mathrm{LAC}+\mathrm{SA}$ & & 100 & \\
\hline & \multirow{2}{*}{ PPX } & \multicolumn{2}{|c|}{3} & & LAC & & 5 & \\
\hline & & 60 & 0 & & $L A C+S A$ & & 100 & \\
\hline & \multirow{2}{*}{ CBZ } & \multicolumn{2}{|c|}{0} & & LAC & & 5 & \\
\hline & & 55 & 1 & & $L A C+S A$ & & 100 & \\
\hline & \multirow{2}{*}{ ATZ } & \multicolumn{2}{|c|}{0} & & LAC & & 5 & \\
\hline & & 75 & 0 & & $L A C+S A$ & & 100 & \\
\hline & CFA & $<5 \% / 7$ & $70-74 \%$ & & & & & \\
\hline Frimmel, & IBP & $35 \% / 7$ & $9-83 \%$ & Biofilm & $\begin{array}{l}\text { Activated } \\
\text { sludge }\end{array}$ & 2.5 & 10 & 2 \\
\hline & DCF & $<5 \% / \epsilon$ & $52-66 \%$ & & & & & \\
\hline
\end{tabular}

To facilitate readability of this table, all values have been rounded off to one decimal place except for values less than 0.05 which have been rounded off to two decimal place.

na defines not available

a: ACE: Acetaminophen, ATZ: Atrazine, BPA: Bisphenol A, BP: Butylphenol, BZP: Benzophenone, CBZ:

Carbamazepine, CFA: Clofibric acid, CLI: Clindamycin, CTL: Citalopram, DCF: Diclofenac, DEET: N,N-diethyl-mtoluamide, ENL: Enterolactone, ERY: Erythromycin, E1: Estrone, E2: 17 -Estradiol , E3: Estriol, EE2: 17 $\alpha$ -

Ethinylestradiol, FMN: Formononetin, FPP: Fenoprop, GFZ: Gemfibrozil, IBP: Ibuprofen, IPM: lopromide, KPF:

Ketoprofen, MDZ: Metronidazole, METOP: Metoprolol, MFA: Mefenamic acid, NP: Nonyphenol, NPX: Naproxen, OBZ: Oxybenzone, OCT: Octocrylene, OP: Octylphenol, PCP: Pentachlorophenol, PON: Propiconazole, PPN:

Propanolol, PPX: Propoxur, PRM: Primidone, SDZ: Sulfadiazine, SLA: Salicylic acid, SMX: Sulfamethoxazole, SMZ:

Sulfamethizole, TCS: Triclosan, TEU: Tebuconazole, TMP: Trimethroprim

b: EMR: Enzymatic Membrane Reactor, MBBR: Moving bed biofilm reactor, MBR: Membrane Bioreactor c: LAC defines Laccase; SA defines syringaldehyde

A. oryzae: Aspergillus oryzae, T. versicolor: Trametes versicolor

d: First experience was with free laccase

e: Second experience was with 50mg of LAC immobilized on granular activated carbon which is equal to $37 \mu \mathrm{M} / \mathrm{min}$.

$\mathrm{f}$ : In order to maintain consistency, all micropollutant concentrations have been converted into $\mu \mathrm{g} / \mathrm{L}$ and experimental duration into days. 